\title{
BODY | MOVEMENT | ARCHITECTURE
}

Dinushi Kumarawansa 
All unattributed figures are authors own

All images of people not blurred are from the following sources:

Immediate Entourage, http://www.immediateentourage.com/category/free-cutout-photos/.

Skalgubbar, http://skalgubbar.se/categories.

A 120 point thesis submitted to the Victoria University of Wellington in partial fulfilment of the requirements of the degree of Master of Architecture (Professional) By Dinushi Kumarawansa

Victoria Universtiy of Wellington, 2015

School of Architecture 


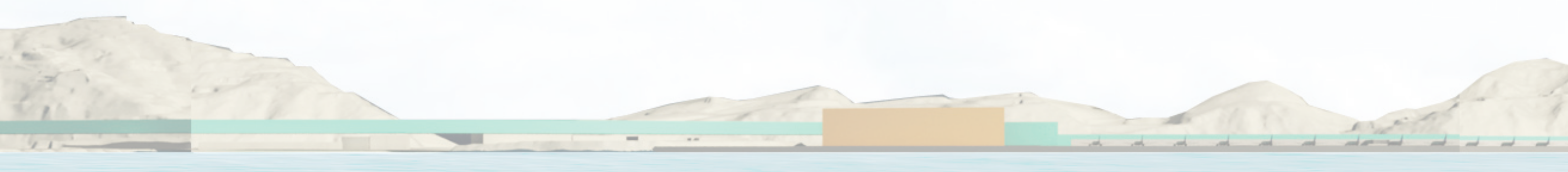




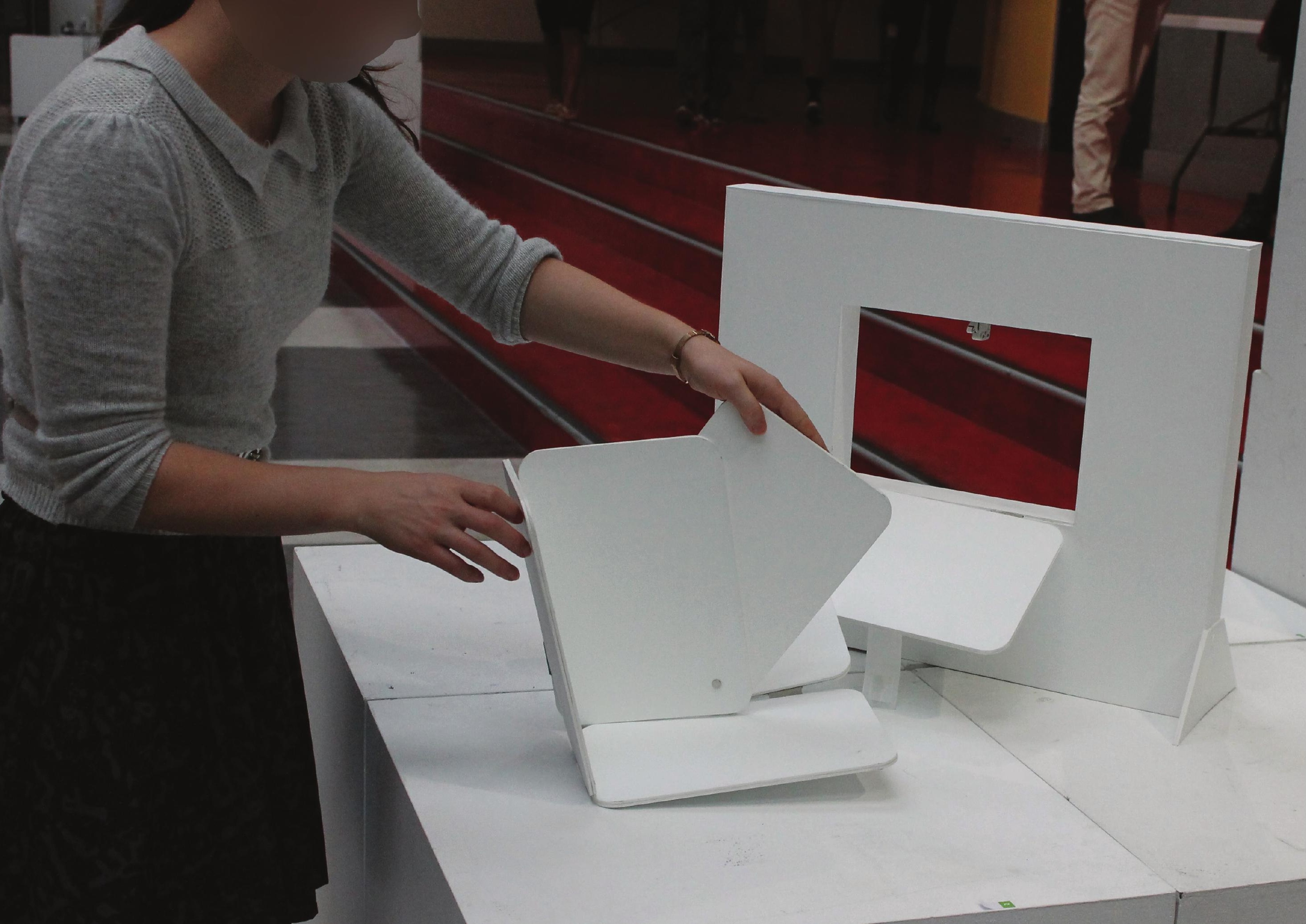




\section{A B S T R A C T}

Architecture historically has been considered a permanent and solid structure incapable of responding and adapting to the constant changing needs of the user. ${ }^{1}$ This thesis questions the static nature of architecture and instead seeks to create a flexible and dynamic architecture which engages the body with the built environment. The thesis focuses on the direct relationship between the body's movement and architecture to address the thesis proposition how can movement be used to engage the body with architecture. Two strategies of using movement; the physical and the contained have been focused on to explore the research proposition. This inquiry into how movement engages the body with architecture was investigated using a design through research methodology. ${ }^{2}$ An iterative design process including model making, photography and sketches was used to create a portfolio of work that tested architecture and movement. The results of this inquiry into movement in architecture were three architectural outcomes at three scales.
Firstly the design of a mobile installation tested the user's personal engagement with architecture at a micro scale. Secondly a medium scale house was designed to test how movement could be used to create different experiences in one space. Finally the findings of these two outcomes were incorporated into the design of a macro scale transport hub that used movement to create spatial experiences and engagement for the user. This thesis concludes that movement in architecture enables users to become more aware of the architecture they are inhabiting and offers them more choice of how to engage with the architecture.
1 William Zuk, and Roger H. Clark, Kinetic Architecture (New York: Van Nostrand Reinhold, 1970), 3 RMIT Publishing, 2003), 17 


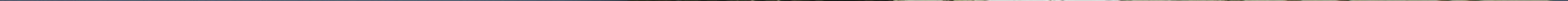




\section{ACKNOWLEDGEMENTS}

Firstly I would like to thank my supervisors Simon Twose and Jan Smitheram. Your constant support and feedback has been invaluable.

To my family I want to say the biggest thank you for all the words of encouragement, support and care packages throughout the past five years. I could not have realised this dream of finishing architecture school without you all.

To my friends at university, thank you so much for making the past five years enjoyable. I will miss being able to see you every day. To all my other friends thank you for all the support and encouraging messages that you have sent my way.
And finally I want to say a huge thank you to Madhushan. You have been my rock through this whole Masters. Thank you for putting up with me during all my times of stress and for your never ending support. 


$$
\text { सत्येत्र }
$$

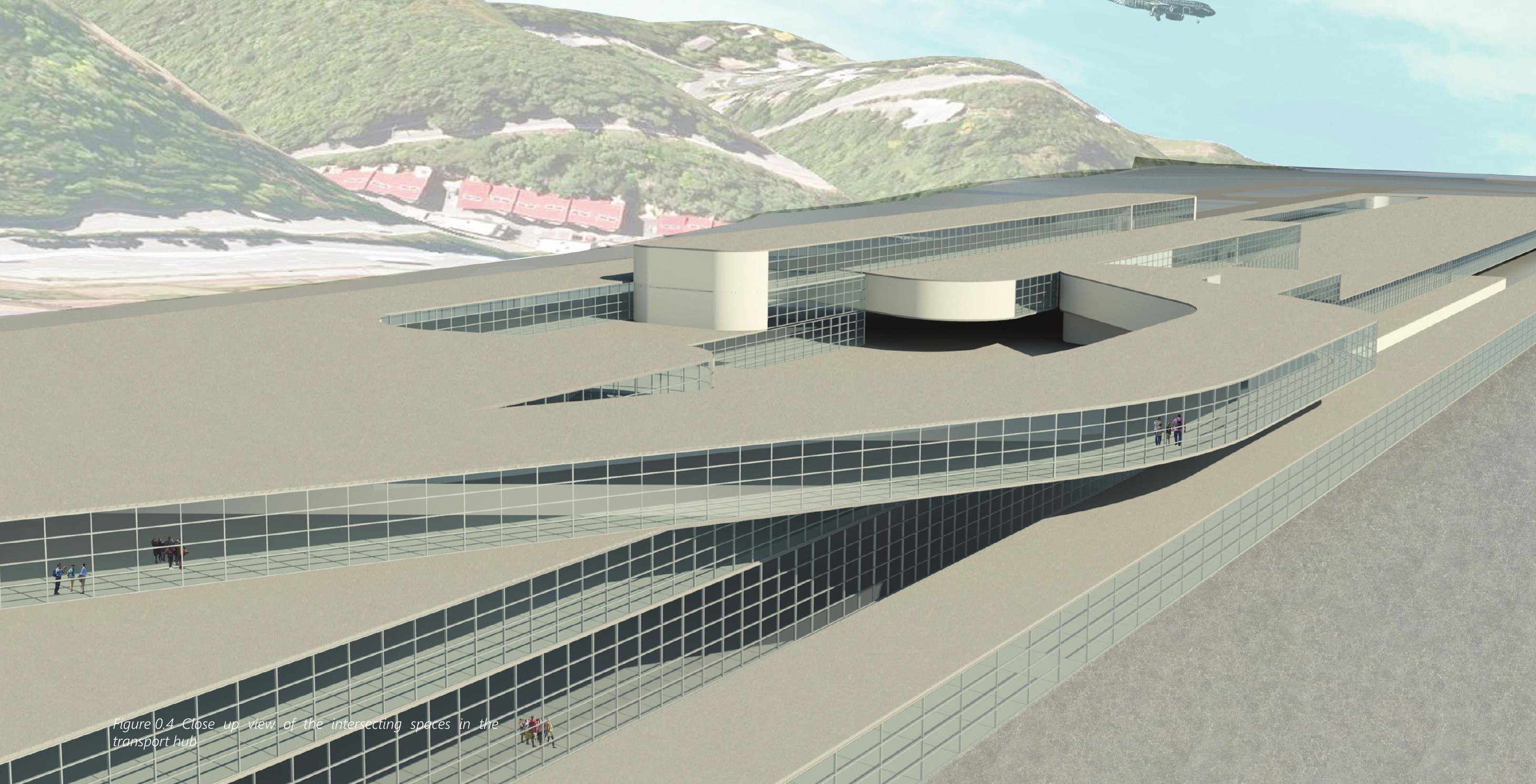




\section{CONTENTS}

\begin{tabular}{lr}
\hline 1 Introduction & 1 \\
\hline 2 Theoretical Context & 7 \\
\hline Case Studies & 19 \\
\hline Design Solutions & 41 \\
Installation & 47 \\
Mobile House & 67 \\
Transport Hub & 91 \\
Design Discussion & 148 \\
& \\
Conclusion & 151 \\
& 155 \\
List of Figures & 159 \\
Bibliography &
\end{tabular}





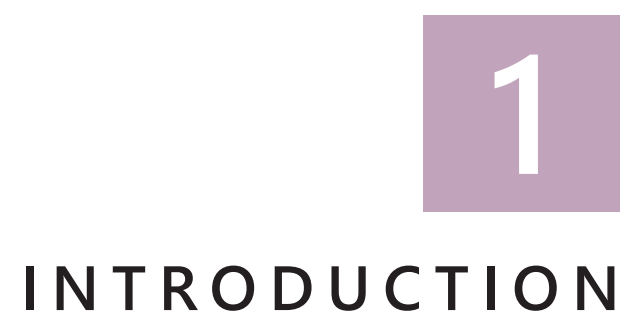




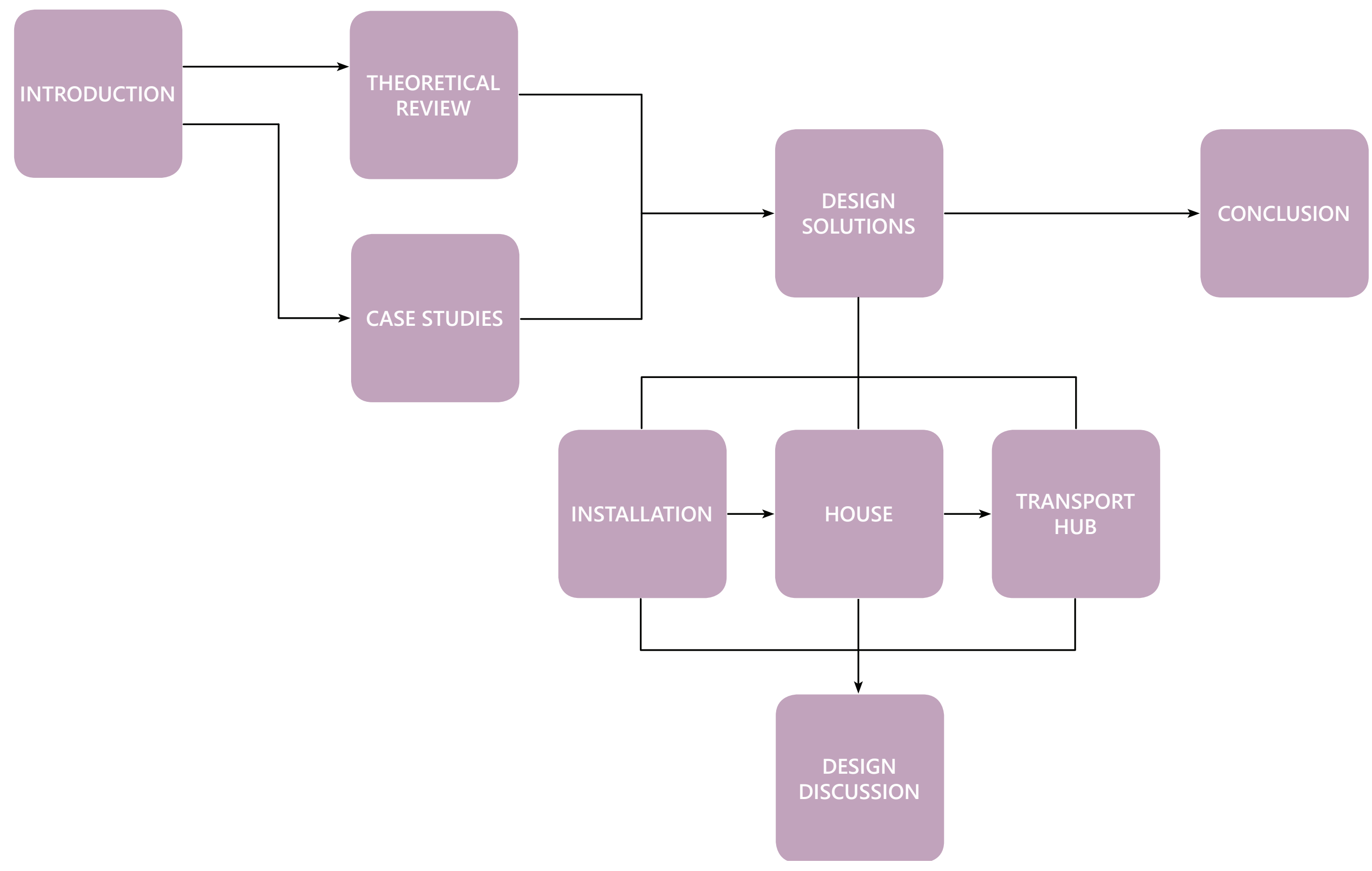


3 Zuk and Clark, Kinetic Architecture, 4.

4 lbid.

5 Downton, Design Research, 17.

6 Albert C Smith, Architectural Model as Machine (Oxford: Architectural Press, 2004), 2-3.
"Architecture has traditionally been perceived as enduring, permanent structures"3 incapable of responding and adapting to the constant changing needs of the user. This thesis questions the static nature of architecture and instead seeks to create a flexible and dynamic architecture which engages the body with the built environment. ${ }^{4}$ Specifically this thesis tests the proposition how can movement be used to engage the body with architecture. The thesis primarily focuses on the physical movement of the body and how movement can be traced along a building. It does not explore responsive kinetic architecture or mechanical forms of movement. This thesis instead aims to provide strategies for using movement as an architectural driver to design responsive architecture that creates experiences and engages the body with space.

The research in this thesis follows a design through research methodology where design ideas are tested to create a body of knowledge based on previous designs that are then used to reflect on and aid future designs. ${ }^{5}$ Both analogue and digital methods will be used to create a portfolio of work containing sketches, physical and digital models to test how the body can be engaged with architecture through movement. Physical models will be used as the main method of design testing during the design investigation stages as they provide a tangible understanding of how interaction between the user and the architecture can occur. ${ }^{6}$ A critical reflection enables an analysis of the effectiveness of each design test in conveying movement and engaging the body and architecture.

The architectural outcomes of this thesis are an installation and two buildings which test the relationship between the body, architecture and movement at three scales. The first outcome is a small scale installation designed to provide a direct relationship between the body and architecture through physical movement. The second 


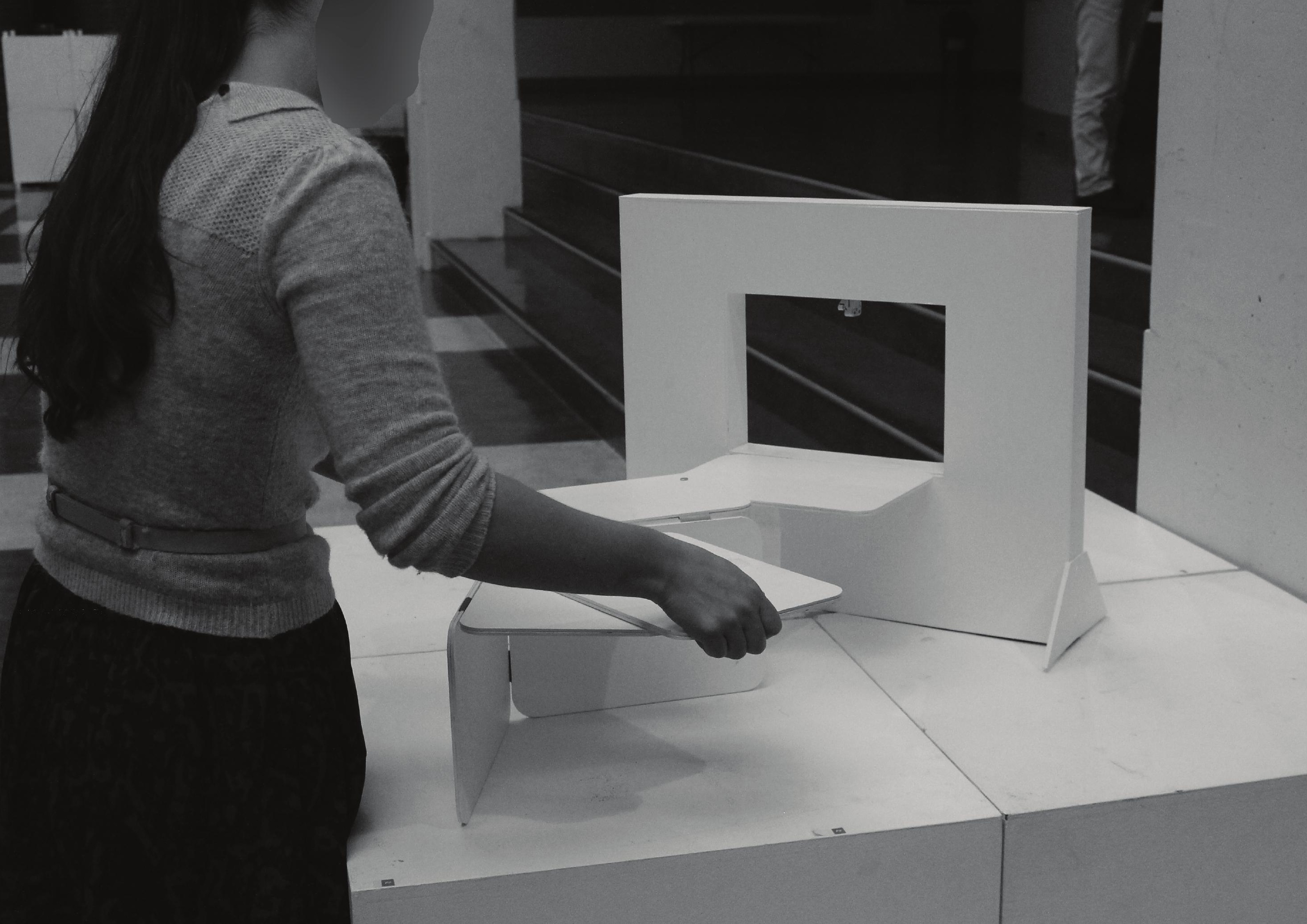


outcome is a medium scale house which tests the relationship between the body and architecture through both physical and non-physical concepts of movement. The final outcome is a large scale transport hub which tests the use of contained movement to engage the body with architecture without the architecture physically moving. The site for the speculative transport hub was chosen for its location which provokes both pedestrian and vehicular movement. It provides a testing ground for addressing the thesis proposition. The three design outcomes and strategies enabled the thesis proposition to be tested at different scales.

This thesis has been divided into five chapters. Following on from this Introduction, chapter two, Theoretical Context provides a background to how movement has influenced architecture and where it sits within architecture today. Different strategies of creating movement in architecture are analysed. With a focus on Michael Schumacher's book Move and Adam Hardy's article "The expression of Movement in Architecture" physical and contained movement strategies are investigated. Chapter three, Case Studies analyse architectural precedents which highlight movement in their designs. The precedents are examined against the works of Schumacher and Hardy. Strategies developed from this analysis are used in chapter four, Design Solutions which is divided into four parts, Installation, House, Transport Hub and Design Discussion. This chapter showcases design tests exploring the body's engagement with architecture through movement. The chapter ends with a critical reflection of the architectural outcomes to determine their strengths and limitations in engaging the body with architecture through movement. Finally Chapter five, Conclusion reflects on the overall thesis and provides a foundation for further design. 



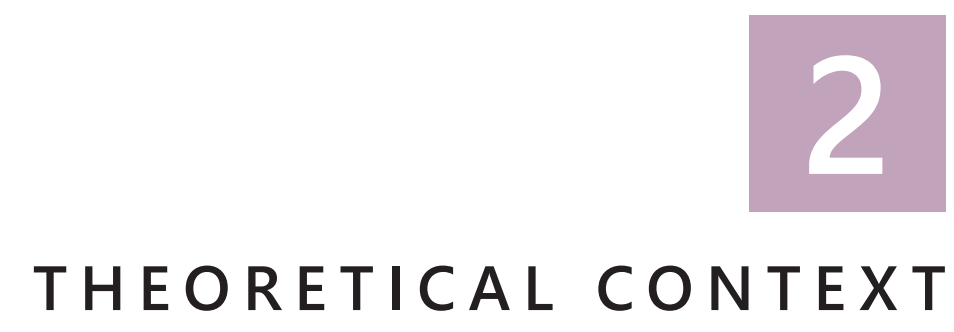


This chapter provides a background into the discussion of movement in architecture. After a general introduction to questions facing architects around movement, the first section will cover a brief history of movement in architectural discourse. The historical background will follow the timeline and arguments presented in Kari Jormakka's book Flying Dutchmen: Motion in Architecture. This historical background informs the next section Types of Movement which introduces and analyses two main approaches to creating movement in architecture (physical and contained) and how these can create engagement between the body and architecture.

The relationship between movement and architecture has been an ongoing discussion in architectural history. This discussion about movement has ranged from the functional concept of circulation to psychological concepts which question how our bodily movements through space create experiences. ${ }^{7}$ For Stickells, this connection between our bodily movement and architecture is a result of the contemporary city we live in. ${ }^{8}$ The cities we live in today can be viewed as complex networks of flows which allow us to travel and be in constant motion. However, Zuk and Clark argue that architecture today remains static and permanent in its current state, ${ }^{9}$ and this needs to be challenged if architecture is to engage with the contemporary city. Rowan in a similar manner argues that we need to move away from a static architecture towards "a fluid, vibrating, changeable backdrop for the varied and constantly changing modes of life". ${ }^{10}$ What is clear is this desire to connect the changing environment with architecture is not just a contemporary desire but also a historical one.

\section{MOVEMENT IN ARCHITECTURE}

At the end of the 19th century, the concept of circulation was a key component of architecture. When writing about circulation, architects would often relate it back to the body. As Cesar Daly 


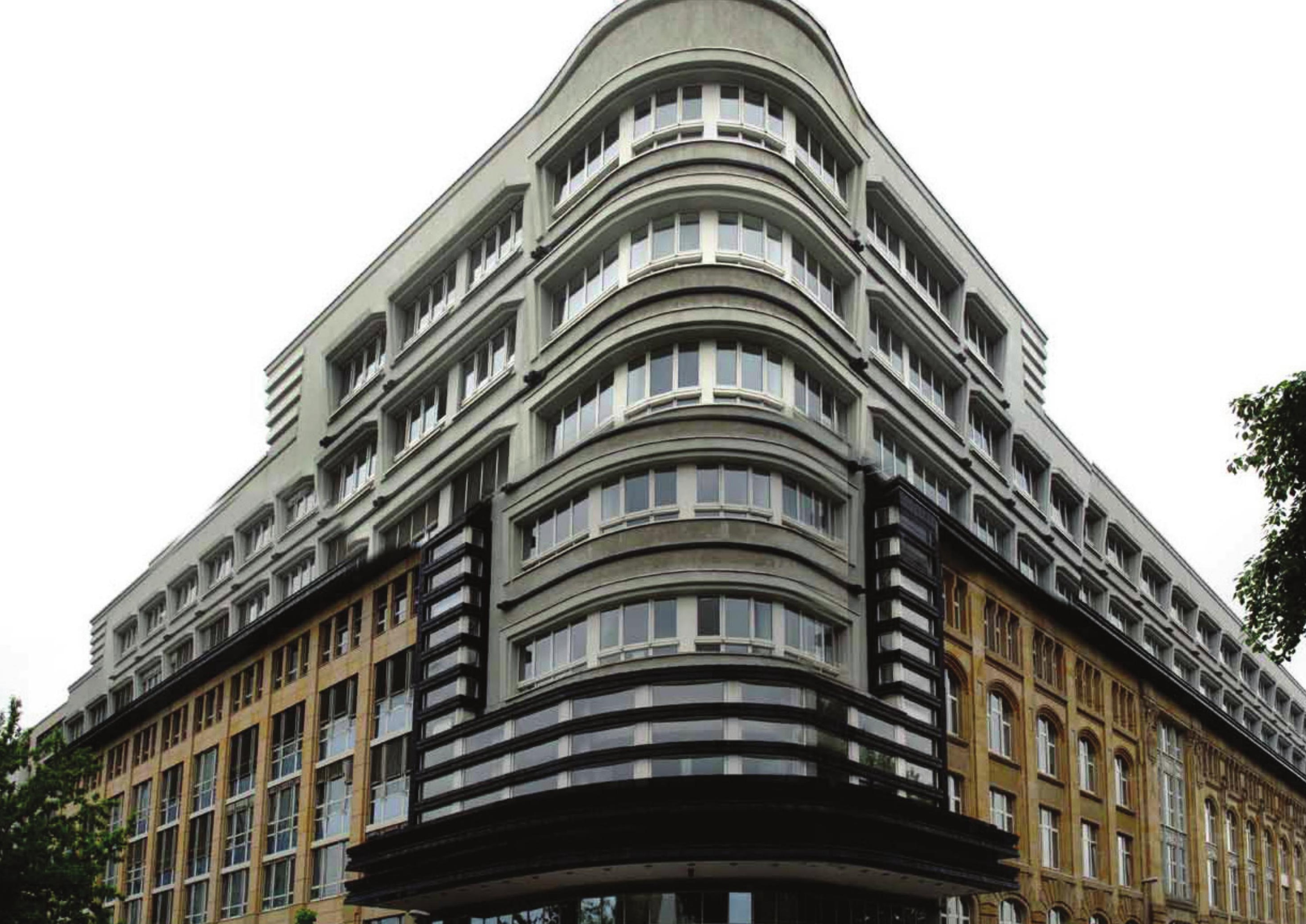


11 Cesar Daly qtd. in Forty, Words and Building 89.

12 Forty, Words and Building, 89.

13 Viollet-le-Duc atd. in Forty, Words and Building, 90.

14 Forty, Words and Building, 92.

15 Heinrich Wolfflin, "Prolegomena to a Psychology of Architecture" in Empathy, Form and Space, ed. Robert Vischer, Harry Francis Mallgrave and Eleftherios Ikonomou. (Chicage: Getty Center for the History of Art and the Humanities, 1994), 150

16 Forty, Words and Building, 95.

17 Paul Frankl qtd. in Stickells, "Architecture of Movement", 44

18 Kari Jormakka, Flving Dutchmen: Motion in Architecture (Basel: Birkhauser, 2002), 10 writes "[t]his building . . . is almost a living body with its own nervous and cardiovascular systems".11 However this reference to the body was not to explain its ability to create human movement but instead to describe the mechanical systems within the building. ${ }^{12}$ While circulation was being used as a metaphor for an independent system like the body, other architects were starting to describe it as a more functional concept. Viollet-le-Duc describes circulation as the flow within a building that is not tied down to its physical entity. ${ }^{13}$ This description of circulation resonated more with architects who began to question not only the physical movement/flow through the building but also the perceived bodily movement. ${ }^{14}$ Both concepts of circulation, whether it be metaphorical or functional were concerned with its effect on the perception of space.

Heinrich Wolfflin in his thesis Prolegomena to a Psychology of Architecture explains that "the emotional tone of a form is explained by the kinaesthetic response of the eye when its focus follows the lines".15 In order to experience the form, the user must be able to read the different elements in the form and how they are acting to create the architecture. Forty when analysing the work of Wolfflin states that for Wolfflin, the emphasis was on the way architecture communicates experiences to the user rather than how forces are transferred through the building. ${ }^{16}$ Paul Frankl (Wolfllin's successor) followed on with these notions of projected bodily movement but also included architectural space and form. For both Wolfllin and Frankl, movement was "critical to the experience of architecture, particularly the notion that bodily movement was vital to the understanding of the form and composition of a building".17 This influence of psychology was also manifested in the early 20th century. Modernist architects used strategies such as "inclined planes, horizontal emphases, acceleration of façade rhythm"18 and aerodynamic curves to express movement in architecture of the body and of 

its surrounding movement. This continuation of creating movement in architecture from the late 19th century highlights the role projected movement has played in allowing the body to engage with the architecture it is experiencing.

An example of expressing movement in Modernist architecture is Le Corbusier's promenade architecturale. Corbusier argues that user's experiences of architecture are based on their ability to traverse through the space. ${ }^{19}$ The promenade architecturale focused on the use of ramps as a circulatory element that would guide people through architecture. The promenade became a vital spatial link through the building that "smoothly revealed its spatial structuring and permitted constantly changing, unexpected but carefully composed perspectives".20 By moving along the promenade, users are able to experience the different spaces and engage with the architecture.
Along with this metaphorical representation of movement in architecture, for Kari Jormakka there has been an increasing push towards creating architecture that physically moves. By using physical movement, architects are able to connect architecture into its surroundings. ${ }^{21}$ Adriaan Geuze discusses strategies to connect users with the built environment and allow them to have a role in the creation of the form through spaces that can be continuously configured in different ways. As Geuze explains, "speed and time have replaced the traditional idea of space. Movement connects the fragments in space in constantly changing configurations"22 to enable users to change their spaces to fit into their ever changing lifestyles and surroundings. ${ }^{23}$

In contrast to moving architecture, Jormakka uses the works of architects such as Rem Koolhass, Ben van Berkel and Caroline Bos to argue that buildings do not have to move to represent movement as they already contain plenty of 


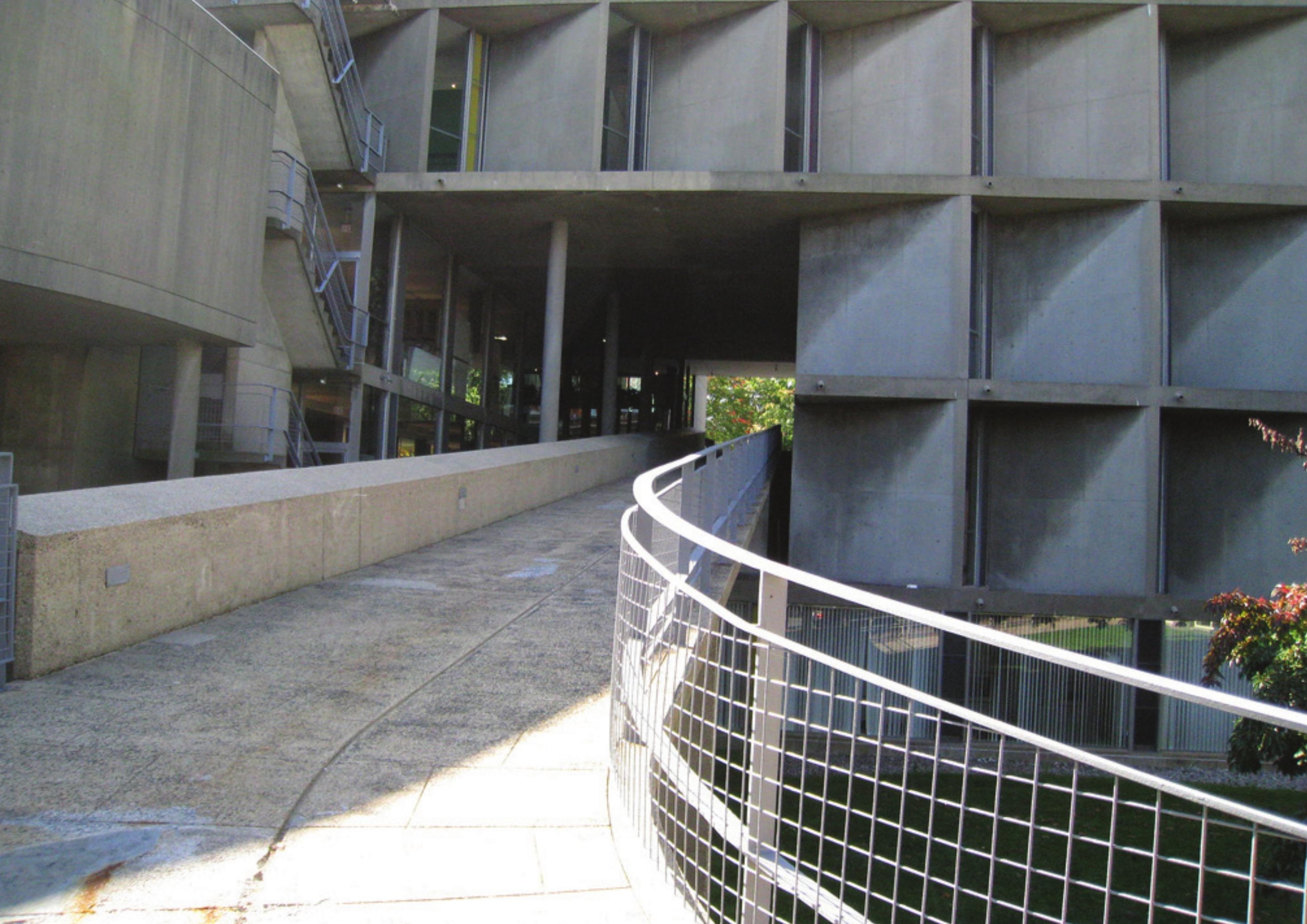


movement mechanisms such as stairs, doors and windows. ${ }^{24}$ These mechanisms could be used to engage the body with architecture as they allow links from one space to another to be made. For example, for lain Borden "[t]he visibility and detail of the stairway both promotes movement and gives expression to the possibility of that movement" ${ }^{\prime 25}$ which allows users to imagine their body along the stairway.

From the late 19th century a common concern for the perception of movement in architecture by the user and their body has been addressed by architects through the creation of an architecture of movement. The next section deals with how this can be broken into types of movement.

\section{TYPES OF MOVEMENT}

Jormakka states that movement can be created in architecture through framing movement in the design, physically moving elements, highlighting circulation paths, digital methods of movement, kinetic components and contained movement. ${ }^{26}$ However this thesis focuses on only two of these approaches; the physical and the contained.

The first of these approaches is physical movement where the architecture is able to move. William Zuk and Roger Clark argue for a kinetic architecture, where the architecture itself moves and evolves, as this will create a "more personal architecture [as] there will be a direct correlation between the human and the way he lives and the physical form-response". ${ }^{27}$ Zuk and Clark state that allowing users to manipulate and change the form of the building will create a variety of spatial experiences for them. ${ }^{28}$ The resulting moving architectural form would not necessarily be the end result but instead a form that could evolve and adapt with time. Michael Schumacher in his book Move also argues for an architecture that is flexible and responsive to the user. He suggests the use of movable walls to allow spaces to become flexible and multi-functional, as "variability can 


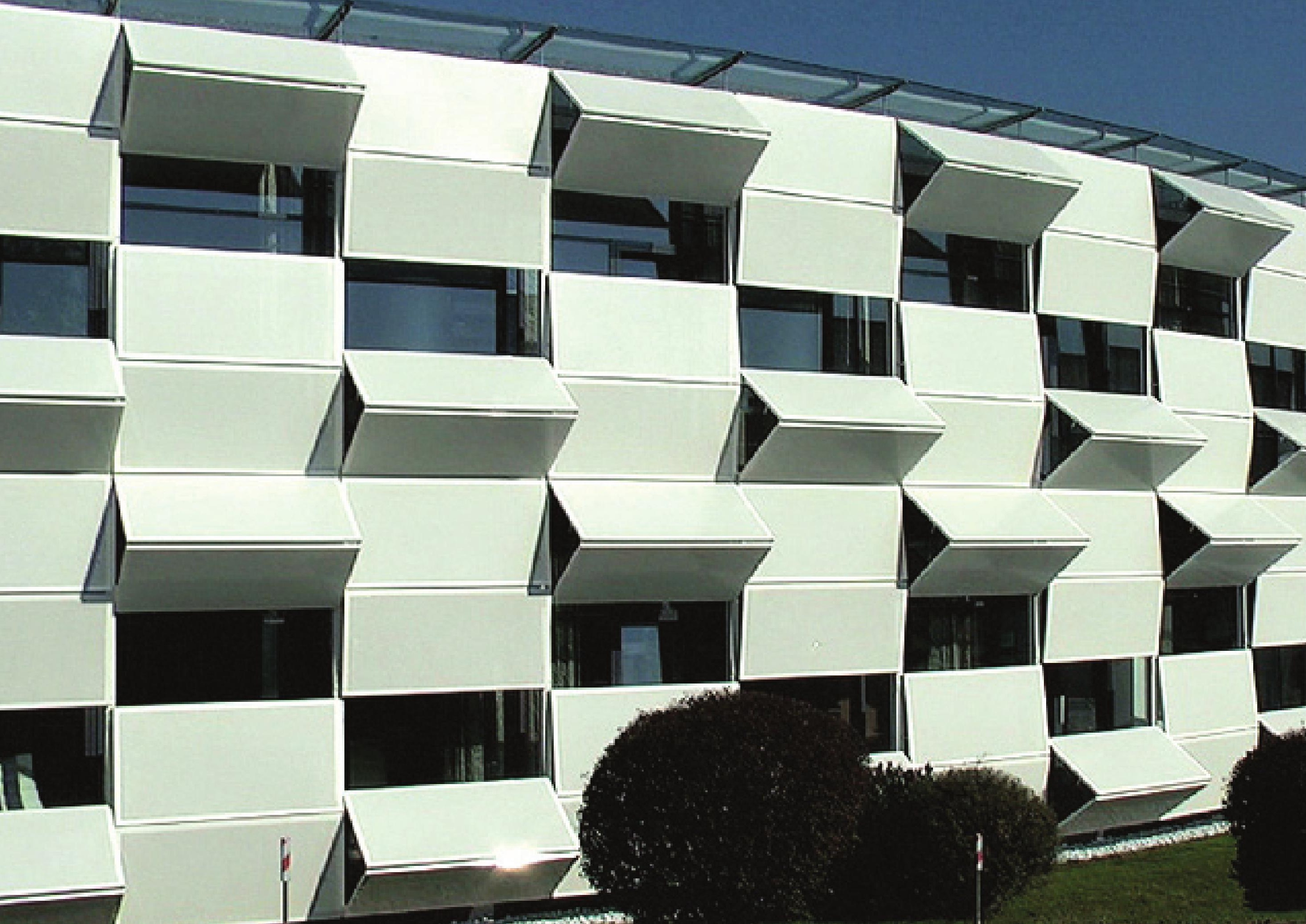


become an experience in itself. Even the aesthetic moment of change can be made into an enriching experience". ${ }^{29}$ He argues further that the ability to be able to manipulate spaces and witness these changes enables the user to become aware of themselves in the space. ${ }^{30}$ In summary the physical movement in architecture gives control to the user, allowing them to create the spatial qualities they need in a space.

The second approach is the concept of contained movement. Contained movement has been described in Adam Hardy's article "The expression of Movement in Architecture" as movement that is "seen in the architecture: it is not the architecture that is thought of as moving, but the eye and mind, or the imagined body, or forces". ${ }^{31}$ In order to understand the building, the user must be able to understand their body moving through the space. Contained movement is perceived when the user's eyes run up the stairs, along a path or around the shifting configurations of form. ${ }^{32}$
This concept of contained movement, relates back to the perception of bodily movement that was influenced by psychology in the late 19th century. The user's ability to perceive their body moving through the space creates the illusion of movement in the building.

In conclusion, movement has played a key role in the history of architecture and how it engages the user with architecture. The two types of movement discussed present strategies to engage the body and architecture. Physical movement hands control over to the user and allows them to manipulate the form to create a varying spatial experience. Contained movement allows users to perceive their body's moving through the space to create the illusion of movement in the building. The following chapter analyses case studies to further explore how architects design for contained and physical movement. 



\section{3 \\ CASE STUDIES}




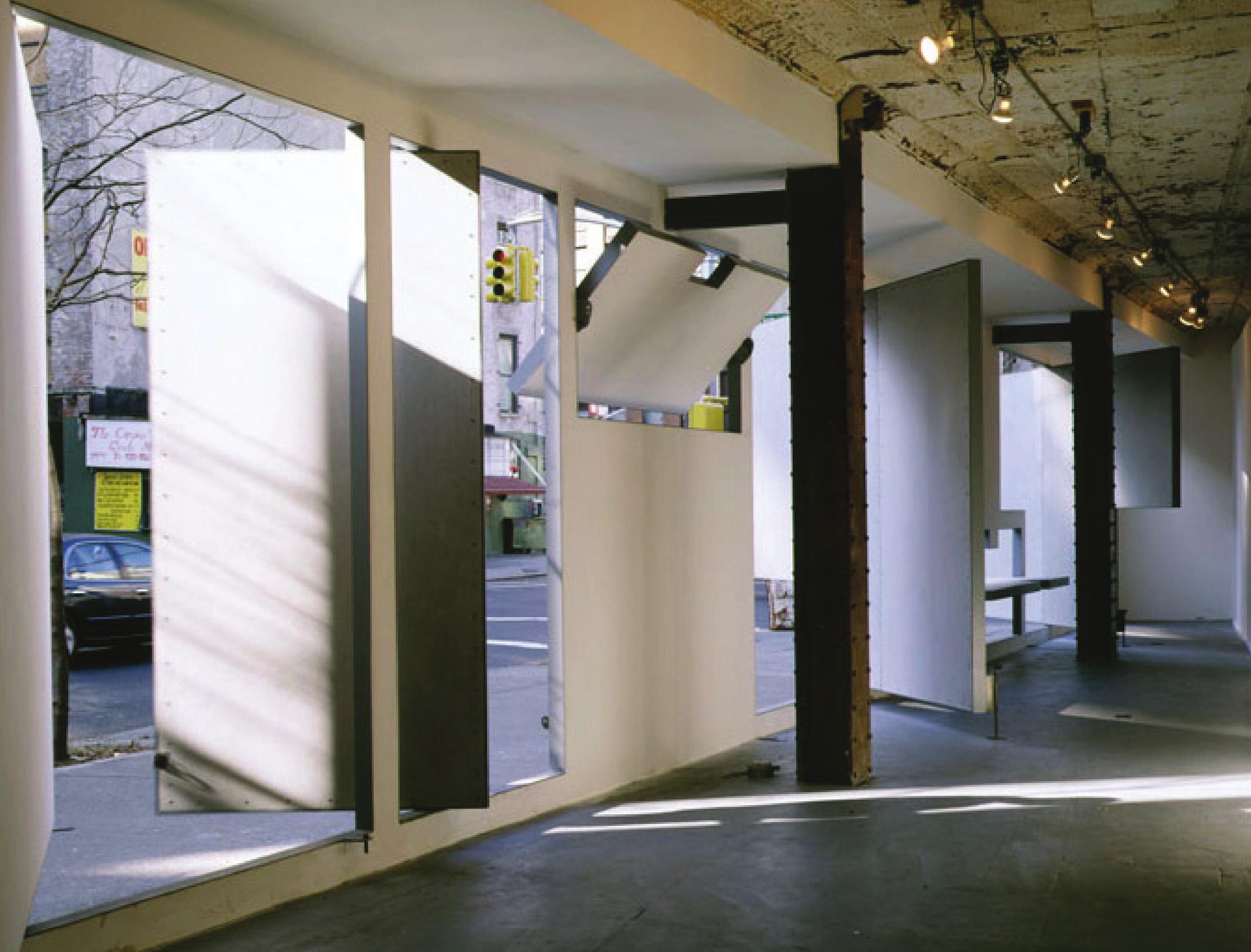


This chapter explores architectural precedents which highlight the use of movement in architecture to create a relationship between the body and architecture. Six architectural precedents have been studied ranging from the micro to macro scale. These six precedents will be analysed against the two frameworks set out on the following page. The two frameworks cover physical movement and contained movement. The physical movement framework has been adapted from Michael Schumacher's book Move and the contained movement framework has been adapted from Adam Hardy's article "The Expression of Movement in Architecture". Two different frameworks were used to assess the precedents as it was clear through the research that micro scale projects focused on physical movement whilst macro scale projects focused on contained movement. 


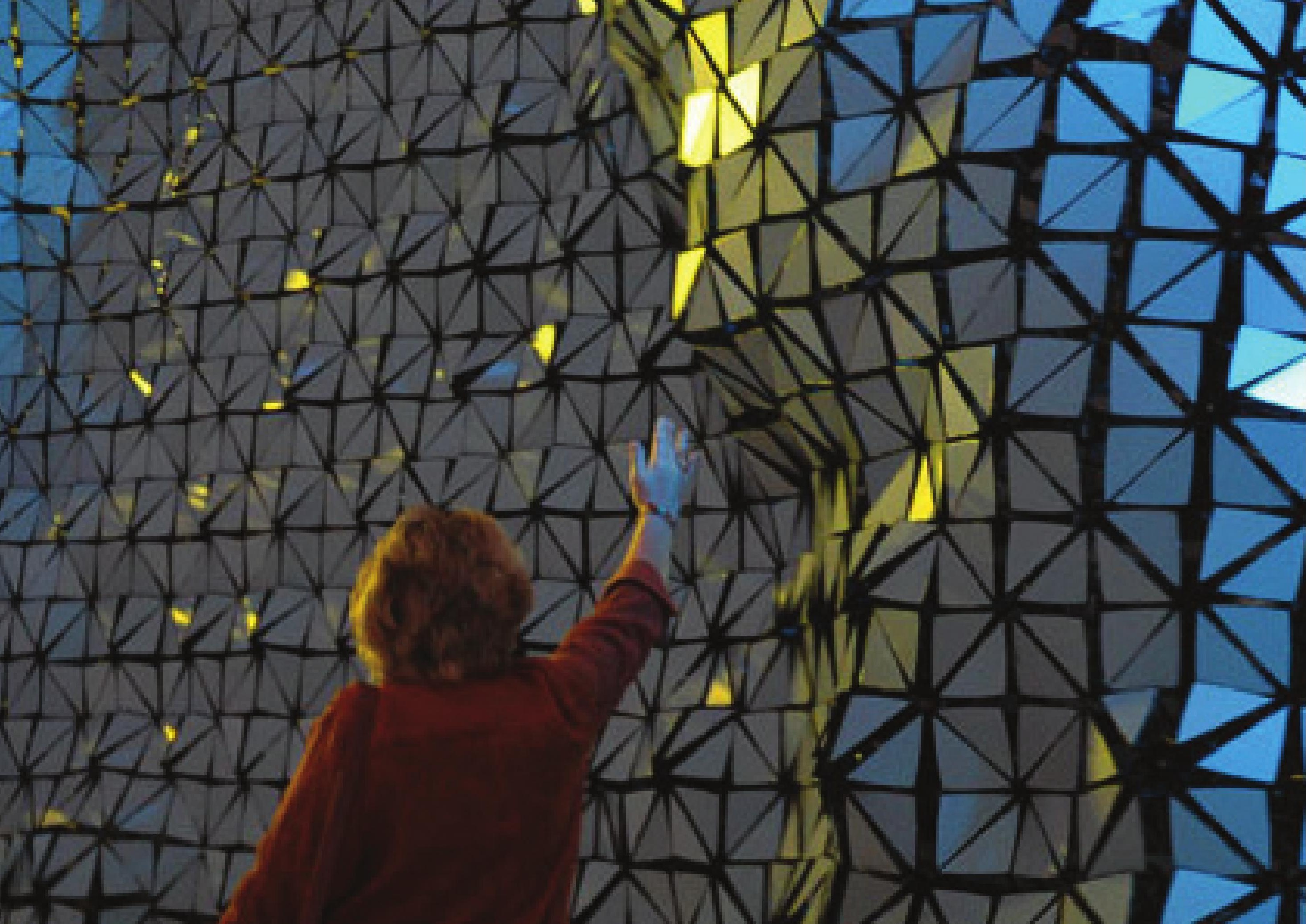


The first three architectural precedents; Party Wall (nArchitects), Erika Mann Primary School (die Baupiloten Architecktur) and The Sliding House (dRMM Architects) highlight the use of physical movement techniques in architecture. The three precedents are evaluated and reflected on against the following framework:

- Change in atmosphere - does the movement of elements cause the experience within the building to change? ${ }^{33}$

- Change in form - does the movement cause the form of the building to change? ${ }^{34}$

- Ease of realisation - can the user understand how the movement system operates and how their engagement with it will affect its movement? ${ }^{35}$
The last three architectural precedents; Mobius House (UN Studio), MAXXI Museum (Zaha Hadid Architects) and Bibliotheque Jussieu (OMA) highlight the use of contained movement techniques in architecture. These three precedents are evaluated and reflected on against the following framework:

- Projected bodily movement - can the user imagine their body's movement through the space, along a route, etc.? ${ }^{36}$

- Movement of eye and mind - does the users eyes or mind move along the surfaces and through space from form to form when looking at the architecture? ${ }^{37}$

- Shifting configurations - does the building use overlap, interpenetration, ambiguous figure/ ground relationships to allow the user to perceive movement in the form of the building? ${ }^{38}$ 


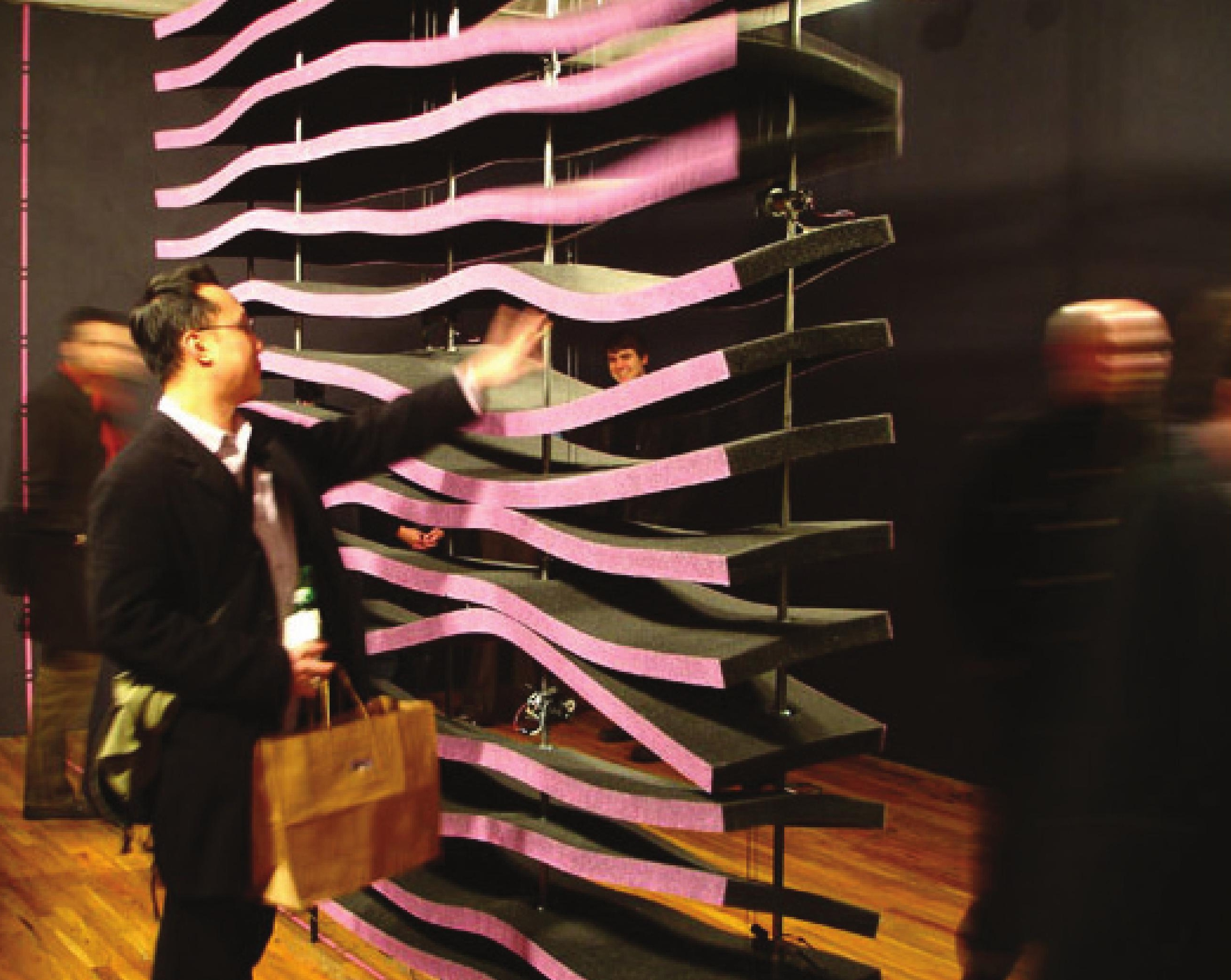




\section{PHYSICAL MOVEMENT}

\section{Party Wall - nArchitects}

The party wall was designed as an interactive installation at the Soho Gallery which created a variable barrier in the gallery space by dividing the visitors into different sides of the room. ${ }^{39}$ Proximity sensors were used to pick up people's movement around the installation and change the form of the barrier according to this movement.

\section{Change in atmosphere}

As the form of the barrier is dependent on the user's interaction with it, the barrier is able to change the experience in the space. As one moves closer to it, the barrier opens up in areas to let light and sound through to the other side. This creates a different sensory experience for the user interacting with it on the other side.

\section{Change in form/Ease of realisation}

As user's move around the installation, the form of the barrier changes. Users are able to understand that it is their interaction with the barrier that causes the form to change. Through this understanding, users become more aware of their movements around the installation and interact in certain ways to manipulate the form of the barrier

Through using sensors that pick up on user movements, nArchitects have created an installation that influences people's movement around a barrier. The barrier acts to engage the body with architecture through a mutual interaction between the two entities. 


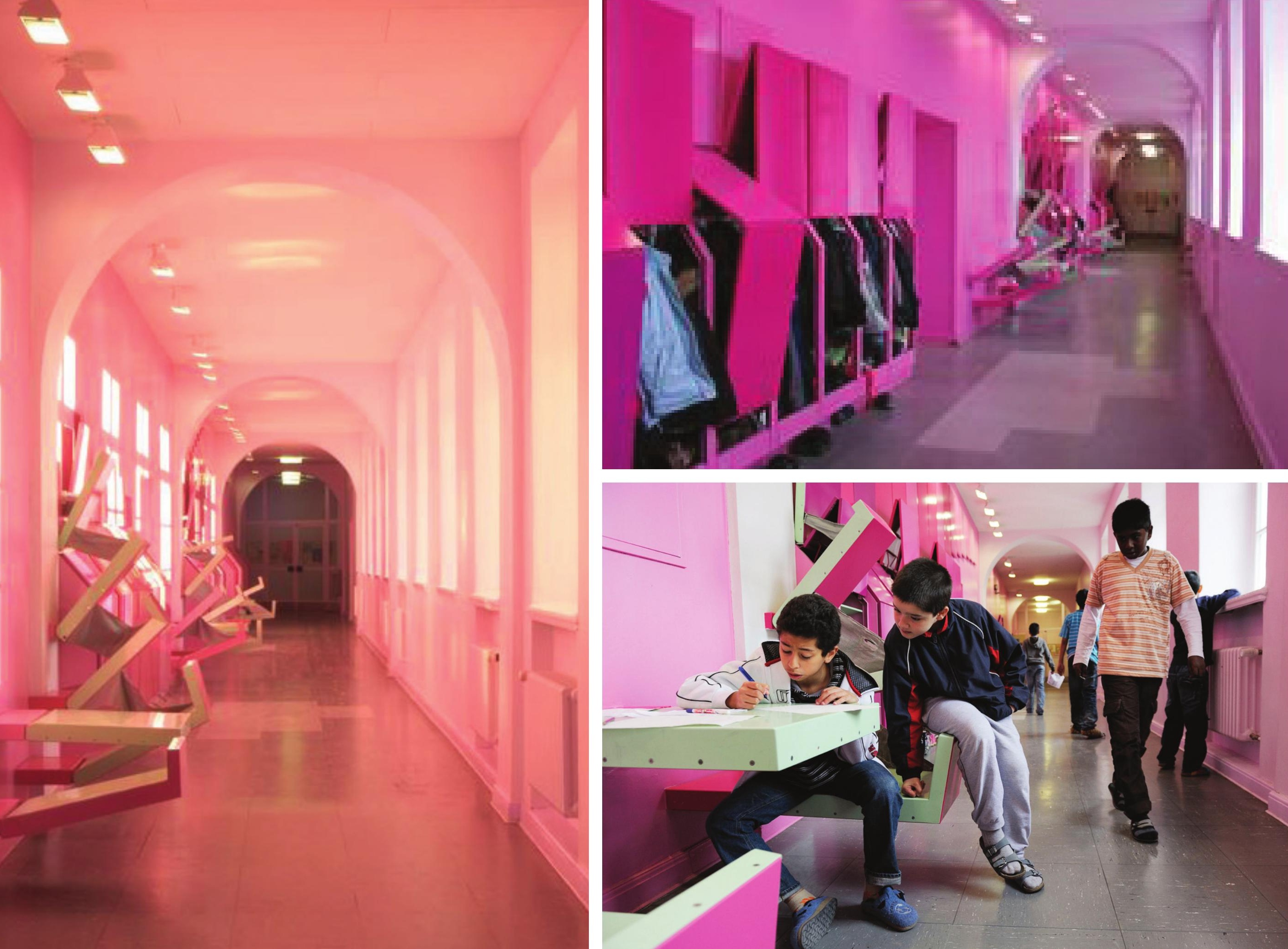




\section{Erika Mann Primary School - die Baupiloten Architektur, 2003}

The renovation of the Erika Mann Primary School was designed in collaboration with students and their parents. Together "they devised a fantasy world entitled The Silver Dragon [in which the] individual architectural elements on each storey symbolises the personality of a fictional dragon". ${ }^{40}$ The second floor of the building illustrates this concept through the use of folding tables and benches which groups of students can gather around.

\section{Change in Atmosphere}

The atmosphere of the corridors are affected by the movable panels. Depending on the positions of the panels, light and shadow within the space varies. This creates different spatial experiences for the students as they move through the corridor.

\section{Change in form}

The flaps (tables and seats) are able to be folded down and halted at any position as required by the students. This creates an "ever-changing modular system of movable elements in the corridor that offer the children an engaging area to sit, meet and play". ${ }^{41}$ The form inside the corridor is never the same creating a different experience every time the students walk past. The movement of the students through the corridor is dependent on the flaps and whether they have been folded down or not. By using movable elements in this school, the architects have created a reciprocal interaction between the students and the architecture where one's actions impacts the other.
220

41 Ibid. 


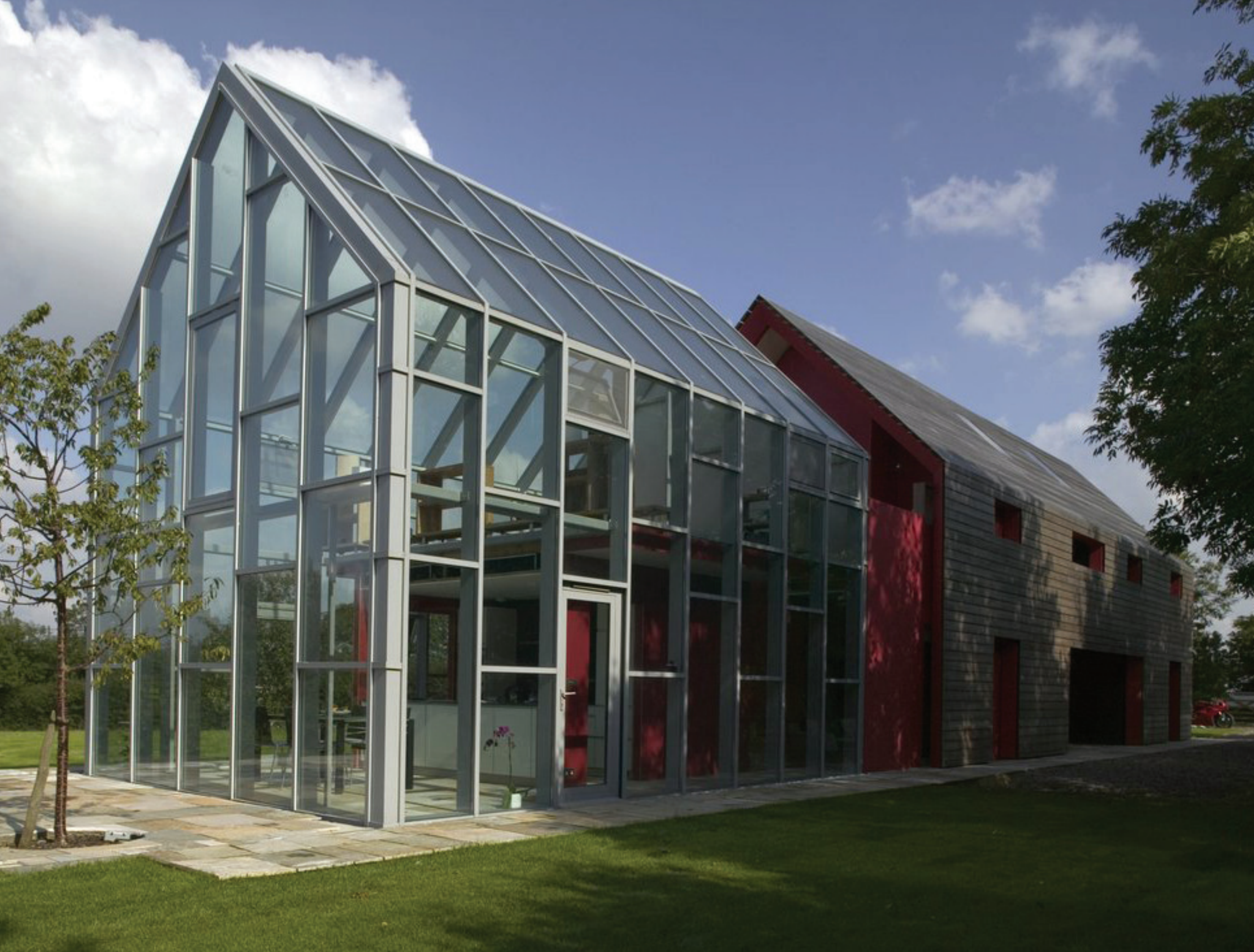




\section{Sliding House - dRMM Architects, 2009}

The sliding house uses movement as a means to create different spaces in the house. The house has been designed in three parts - the main building, a garage that is slightly off axis, and an annexe. The movement in the building occurs through a second wall and roof structure which envelopes the entire house. ${ }^{42}$ This envelope is controlled by motors and is able to move along the length of the house on railway tracks.

\section{Change in atmosphere}

With this movable envelope design, the architects have allowed the atmosphere and experiences that are gained from the building to be controlled by the user. The extent to which the user chooses to move the envelope will create different levels of openness within the house. As the envelope is moved along the length of the house, the experience of light, sound and openness is altered.

\section{Change in form}

The form of the house is also altered through the movable envelope. "When [the envelope is] parked in one of the many positions, a whole range of different spatial situations can be created". 43 The house can be made to look as if it has a covered courtyard with an open living area or vice versa. The architects have used a simple movement method to create a variety of experiences and spatial forms for the user.

\section{Ease of realisation}

The use of motors to control the movable envelope allows the user to "vary the overall building composition and character according to season, weather, or a remote-controlled desire to delight". 44 The user is aware of how the envelope moves and is able to change its position depending on their requirements. 


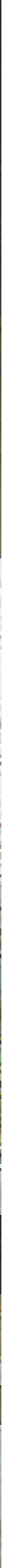




\section{CONTAINED MOVEMENT}

\section{Mobius House - UN Studio, 1997}

The Mobius house was designed as a "twentyfour hour cycle of living, working and sleeping". ${ }^{45}$ The house has been organised along two intertwining paths which allow for two people to work separately in their private spaces but also live together in the shared spaces. The moments along the paths that connect create the living and sleeping spaces, whilst the points where the two paths are separate create the working spaces.

Projected bodily movement

As the house has been designed as two intertwining paths, "[t]he ramped and stepped journey through the house is of the utmost importance and that experience is ultimately the best way to understand the Mobius House". ${ }^{46}$ Users can perceive their body's movement along these paths which allows them to become aware of their movement through the house. Their journey through the house engages their body's movement with the architecture.
Movement of eye and mind

The form of the house depicts the two paths and its interconnected areas allowing the users to become aware of areas of the house where their movement might connect with another person's movement in the house. Through a simple strategy of using interlinked paths to create an architectural form, UN Studio have created an architecture that engages the user through their understanding of movement within the building.

Shifting configurations

Since the house used the Mobius strip as its precedent, the inside becomes the outside and vice versa. The interior walls protrude out to become the façade and the use of materials change at every directional point along the house so that there is no clear difference between what is outside and inside. ${ }^{47}$ However once built, the walls define a boundary between the exterior and interior. Glazing, however, has been used to 


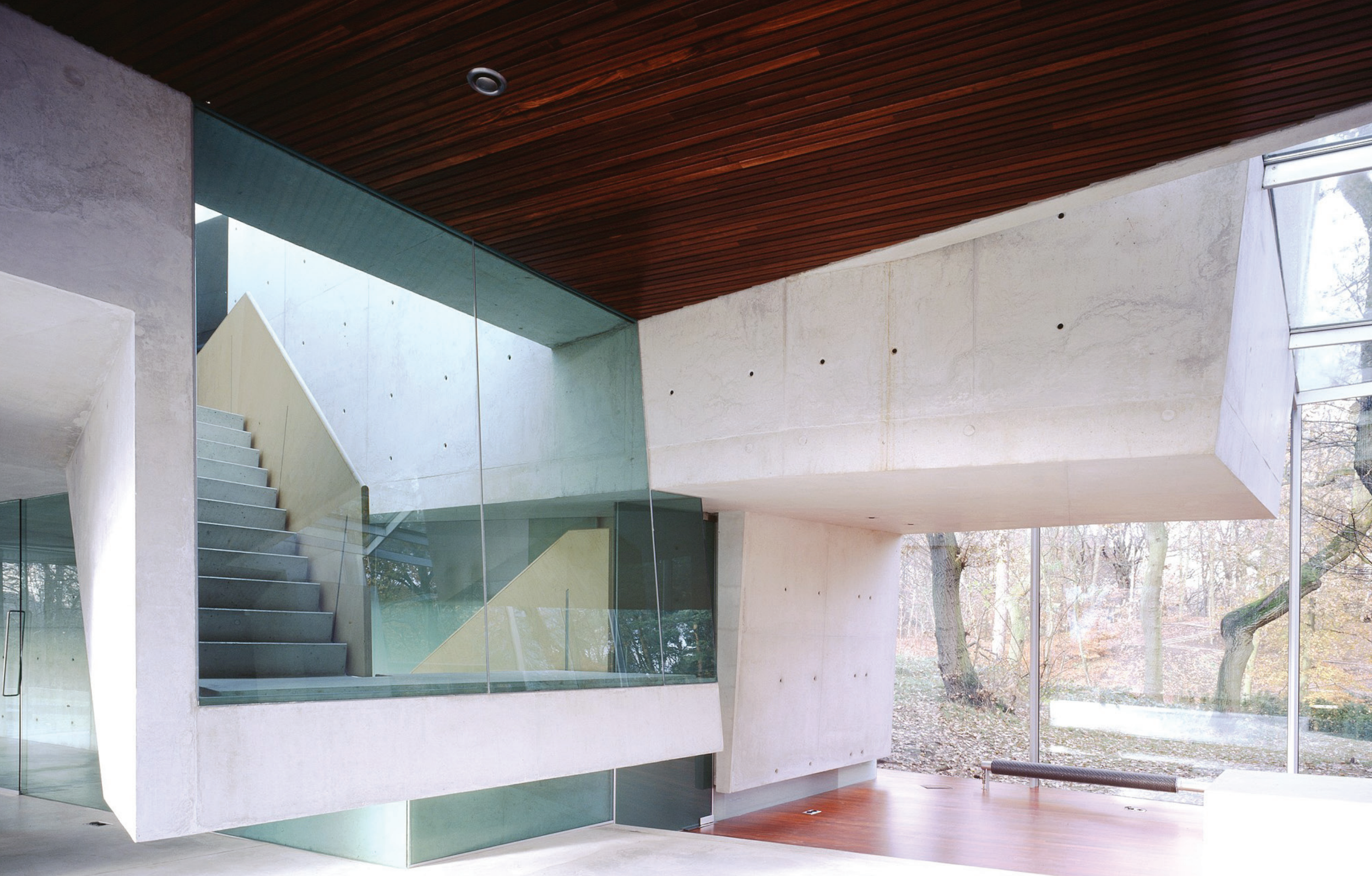


question this boundary of connecting the exterior with the interior. Finally, the overlapping of materials and facades creates a visual perception of movement in the form for the user. They are able to view the movement in the form and at which points the trajectory of the movement changes. 

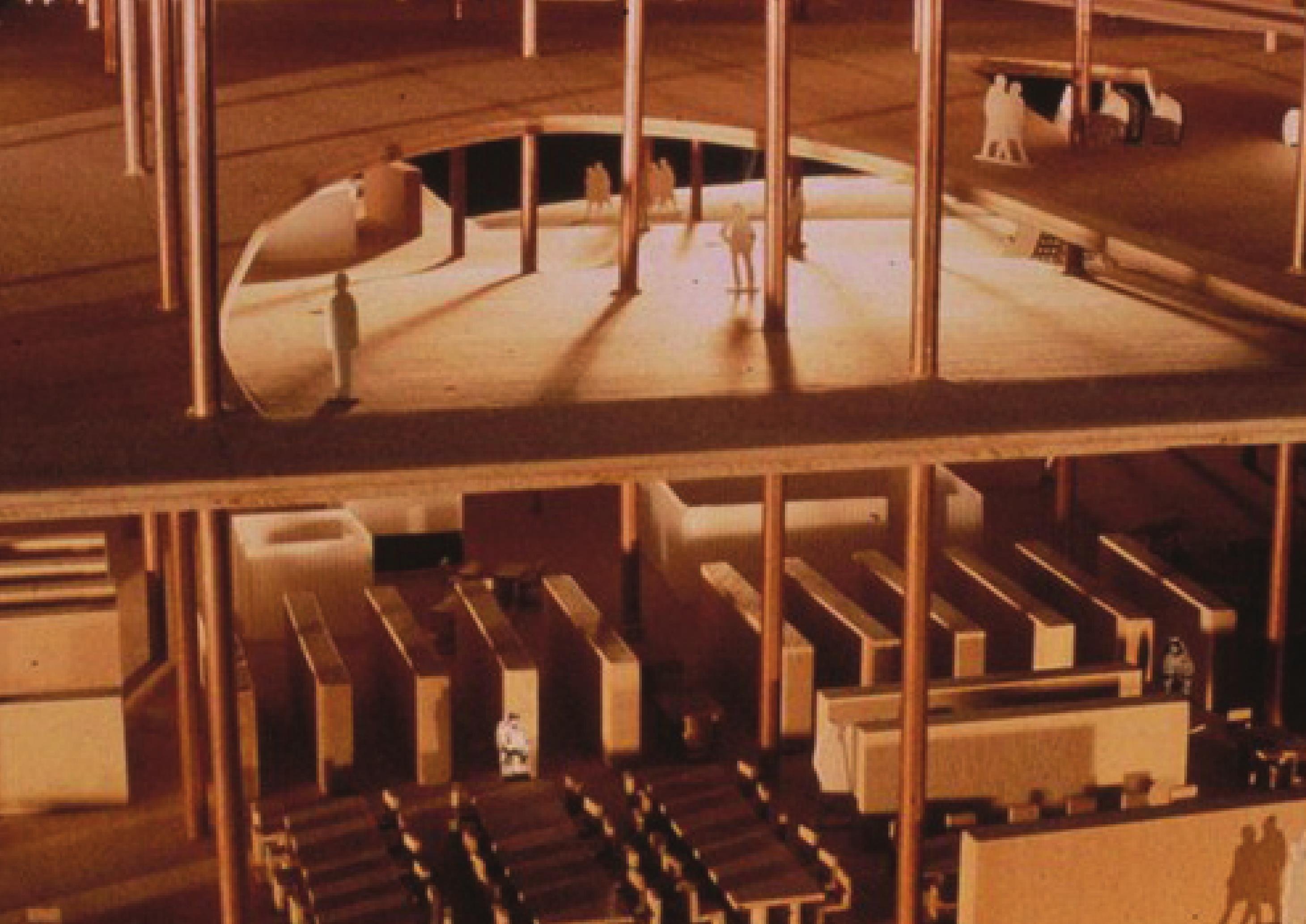

48

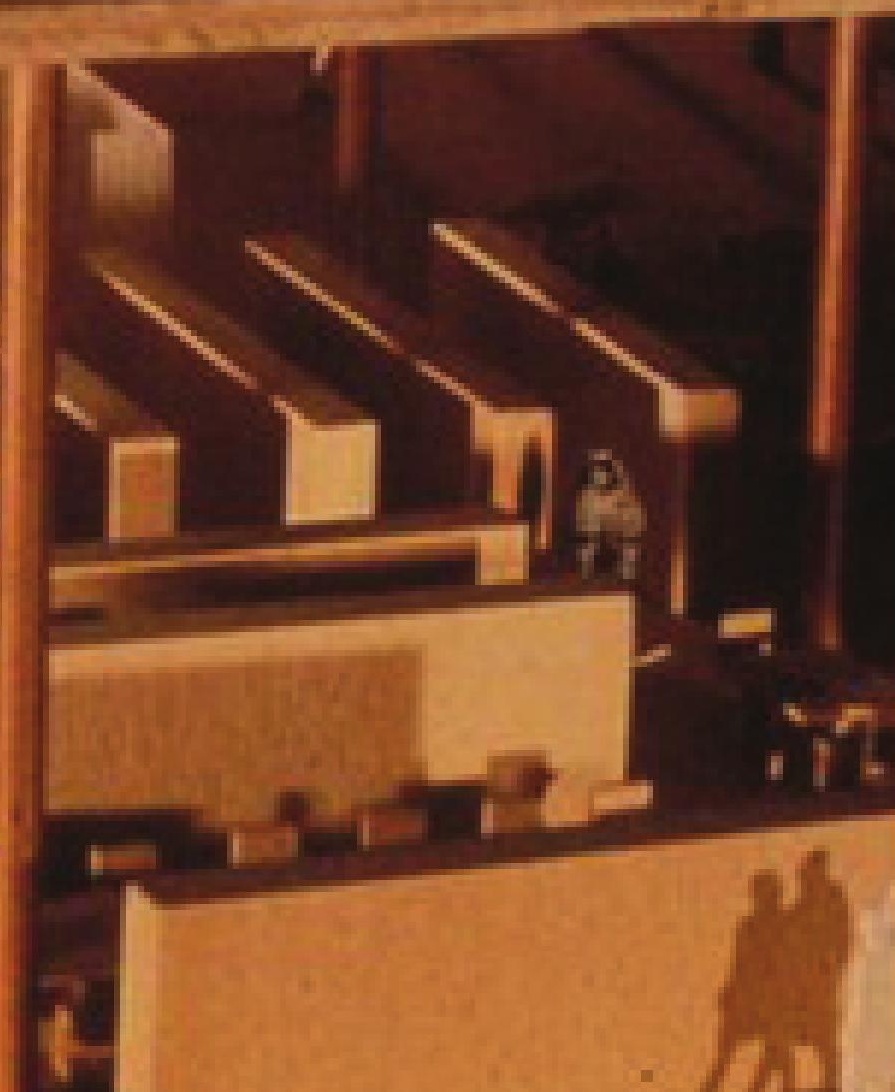




\section{Bibliotheque Jussieu - OMA, 1993}

When designing the two libraries at Jussieu, a technical university in Paris, OMA questioned the norms of how a library should be designed and instead opted for a building in which the movement of the space creates an architectural experience for the user. Instead of stacking the different levels of the library on top of each other, the levels have been folded to create one continuous path through the library which provides views between the levels. ${ }^{48}$

Projected bodily movement/Movement of eye and mind

The students using the library move through the library as if they were experiencing an urban landscape filled with books and information creating for Jormakka a "vertical, intensified landscape in which the campus network of streets and parvis culminate". 49 This manipulation of levels into one long architectural promenade inside the building, provokes the students to continue moving through the library. They can understand the path that they must take as their eye and body moves along the manipulated levels.

\section{Shifting configurations}

The architectural promenade actively engages the users as there is a progressive revealing of shelves, restrooms and computer labs along the path giving the impression that the building is constantly changing as you move through it..$^{50}$ Students are able to understand their bodies' movement through the space as they encounter different surfaces and areas.
48 Jormakka, Flying Dutchmen, 37.

$49 \mathrm{lbid}$.

50 lbid., 35-36 


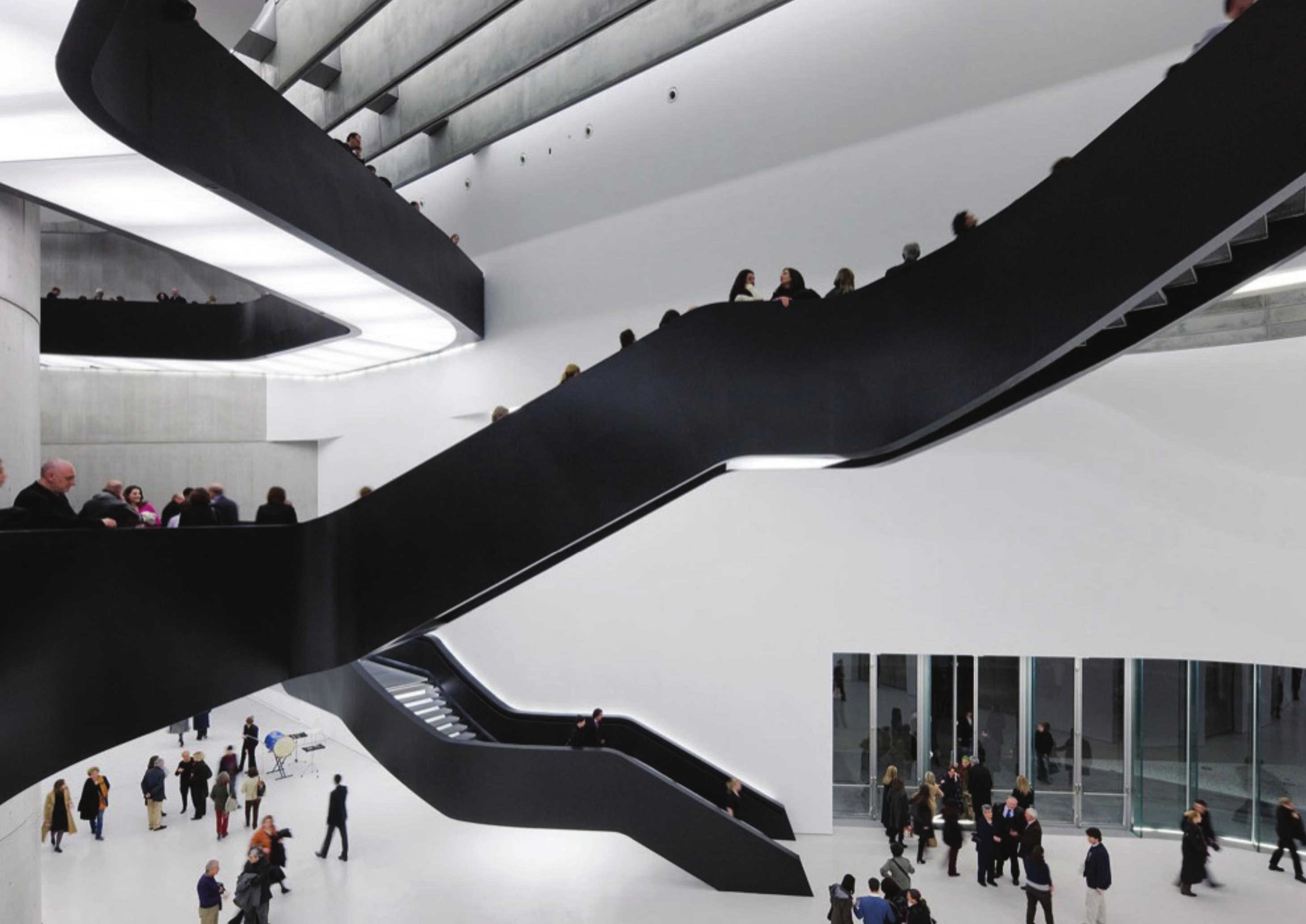


MAXXI Museum - Zaha Hadid Architects, 2009

The MAXXI Museum, which has been designed as the new national museum of contemporary art and architecture in Italy, engages visitors in a vibrant and fluid space that conveys movement through architectural elements. The museum is constructed using structural concrete walls, allowing the interior spaces to be column free. The curvilinear flow of the interior is further emphasised through the glass fibre reinforced concrete fins that run along the length of the ceiling. The space is kept neutral to not distract from the work on display. However the stairs, escalators and ramps provide a dynamic quality within the building and accentuates the movement paths.

Projected bodily movement/Shifting configurations The building interlocks and weaves together into the central foyer which "impressively dramatizes movement: the multi storey space is interlaced over the entire height of the building with black stairs and translucent bridges with glowing undersides". ${ }^{51}$ Colour has been used by the architects to highlight the movement paths, to make users immediately aware of how their bodies would move through the space. The use of stairs and ramps that overlap and connect with one another also allows the users eyes to wander through the space and aids way-finding.

\section{Movement of eye and mind}

The fins that run along the ceiling act to depict the movement paths along the building. The user's eyes are directed along the building through the fins curvilinear shape, which points in the direction that one should move through the building. The simple use of fins on the ceiling, has enabled the architects to create another level of engagement in the building. 


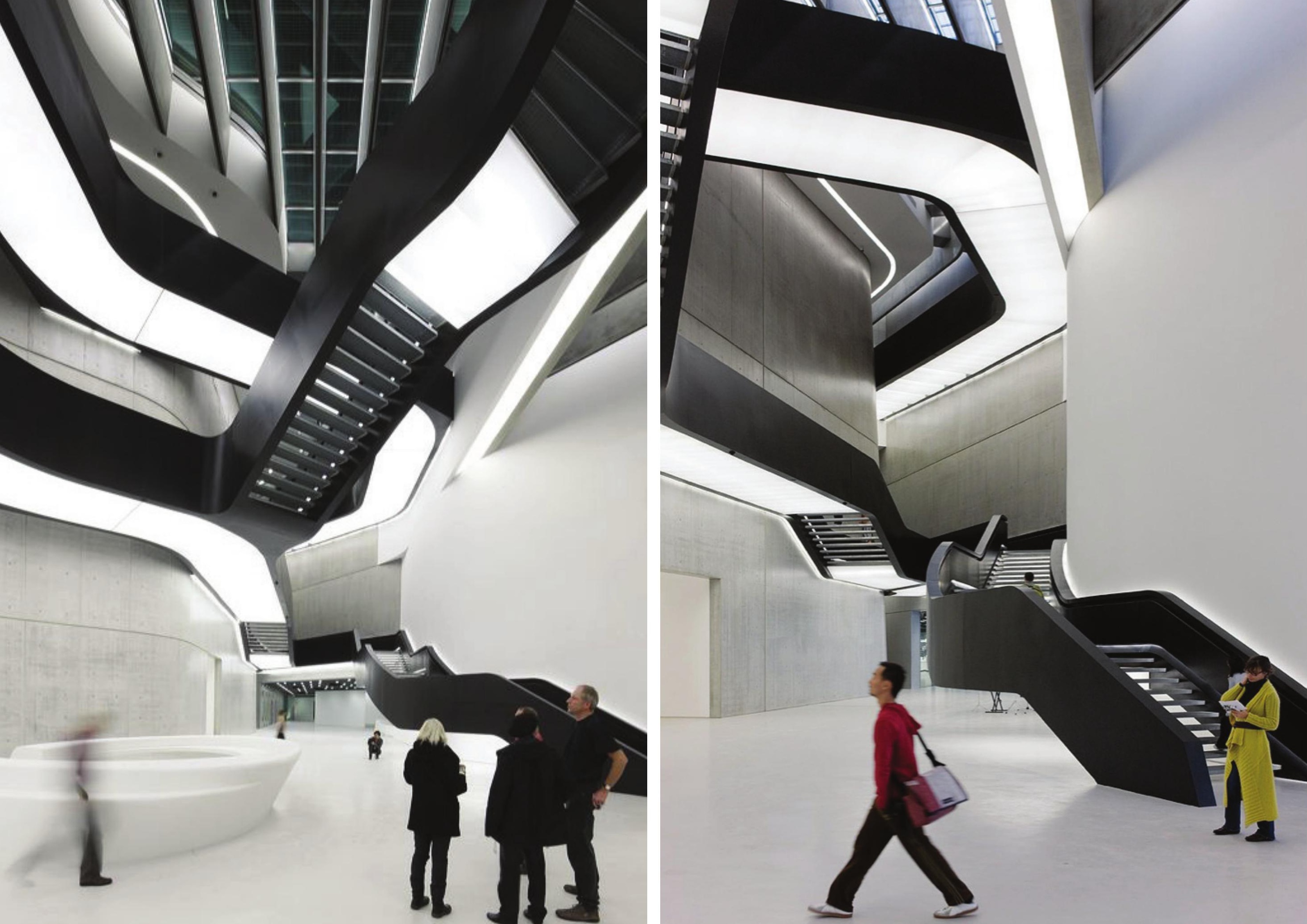


The architectural precedents studied form a basis for understanding how movement has been used in the past to create engaging architecture for its users. The precedents which use physical movement highlight how a personal interaction with architecture creates a more engaging experience of the space. The ability for users to interact and reconfigure the spaces themselves in all three precedents highlight how a tactile engagement with space creates a bodily experience. However when the scale of the architecture was increased, the architects approached movement in a different way. The focus shifts to contained movement which highlighted how movement could be expressed in architecture to create engagement between the body and architecture at larger scales. The strategies presented in all three of these precedents focused on the form relating directly back to the body and its movement. These strategies provide a foundation for the three architectural outcomes in the following chapter. 



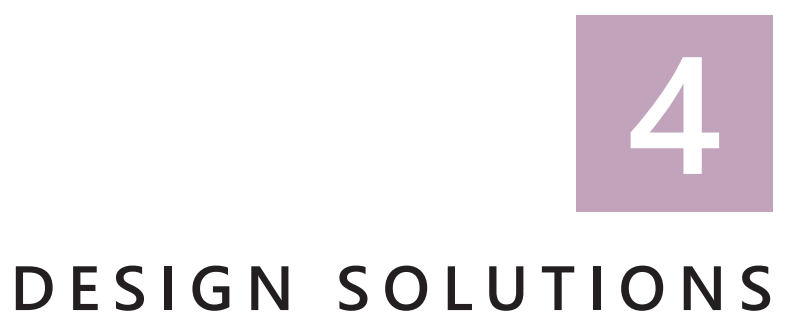




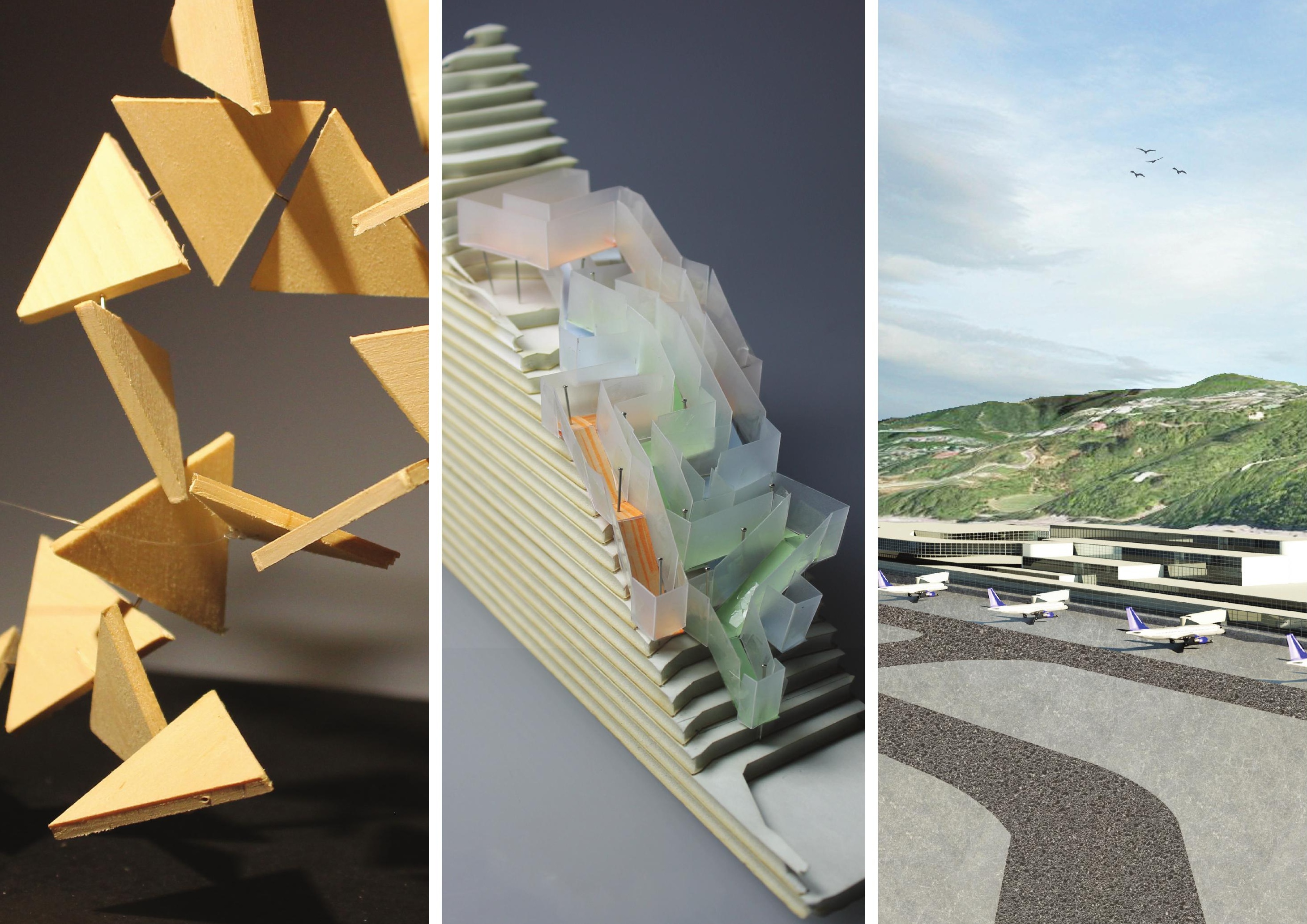


Three architectural outcomes were designed to explore how movement can be used as an architectural driver to create engagement between people and architecture. The architectural precedents investigated in the previous chapter were used to inform the ways in which movement was used in the installation and two buildings.

The first design was an installation which explored the relationship between movement and architecture at a micro scale using physical movement. The second building designed was a house that explored both physical and contained movement at a medium scale. The final building that was designed was a transport hub which explored movement at a macro scale using contained movement methods.

The timeline on the following page outlines each of the design tests for the three outcomes and at which point the precedents from the previous chapter has informed the design. The precedents have been split up into physical and contained movement to understand how the increasing shift in scale has influenced which precedents were used at each design test stage. 
DESIGN PROCESS TIMELINE

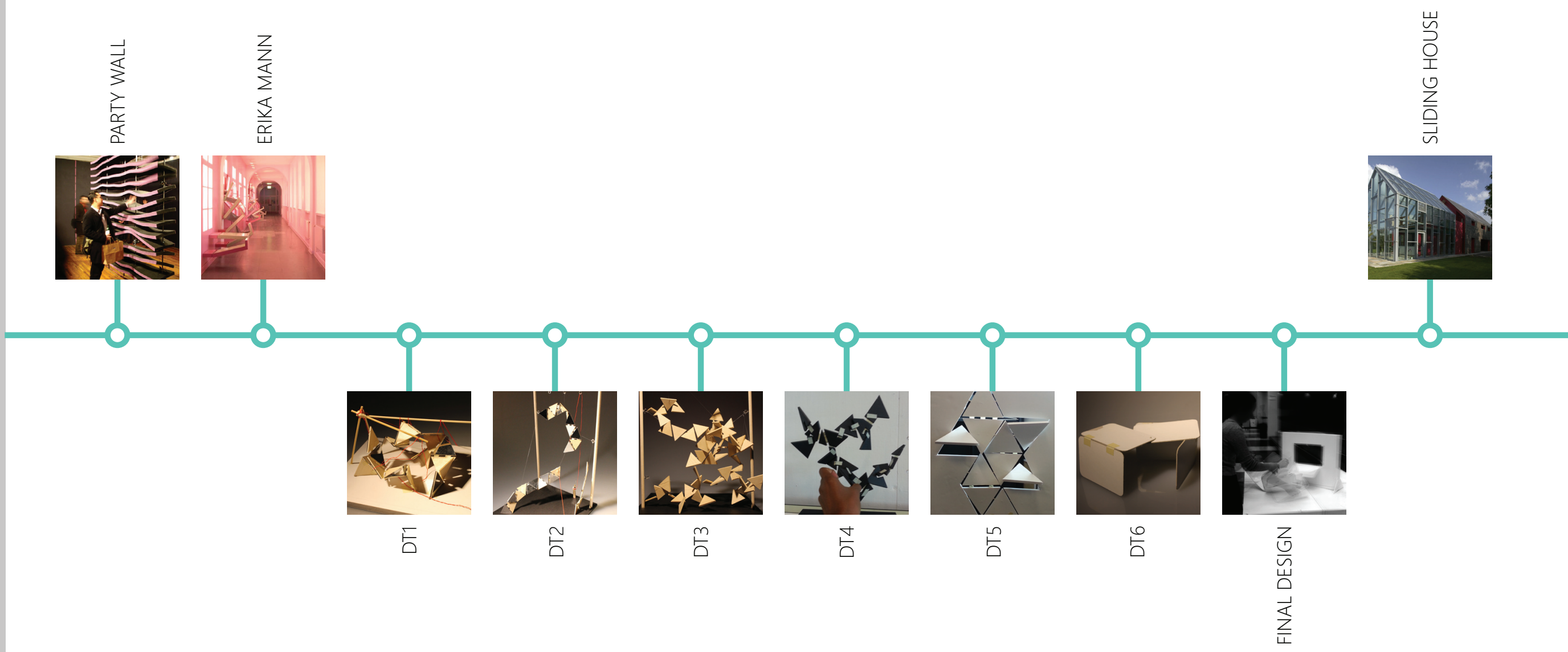




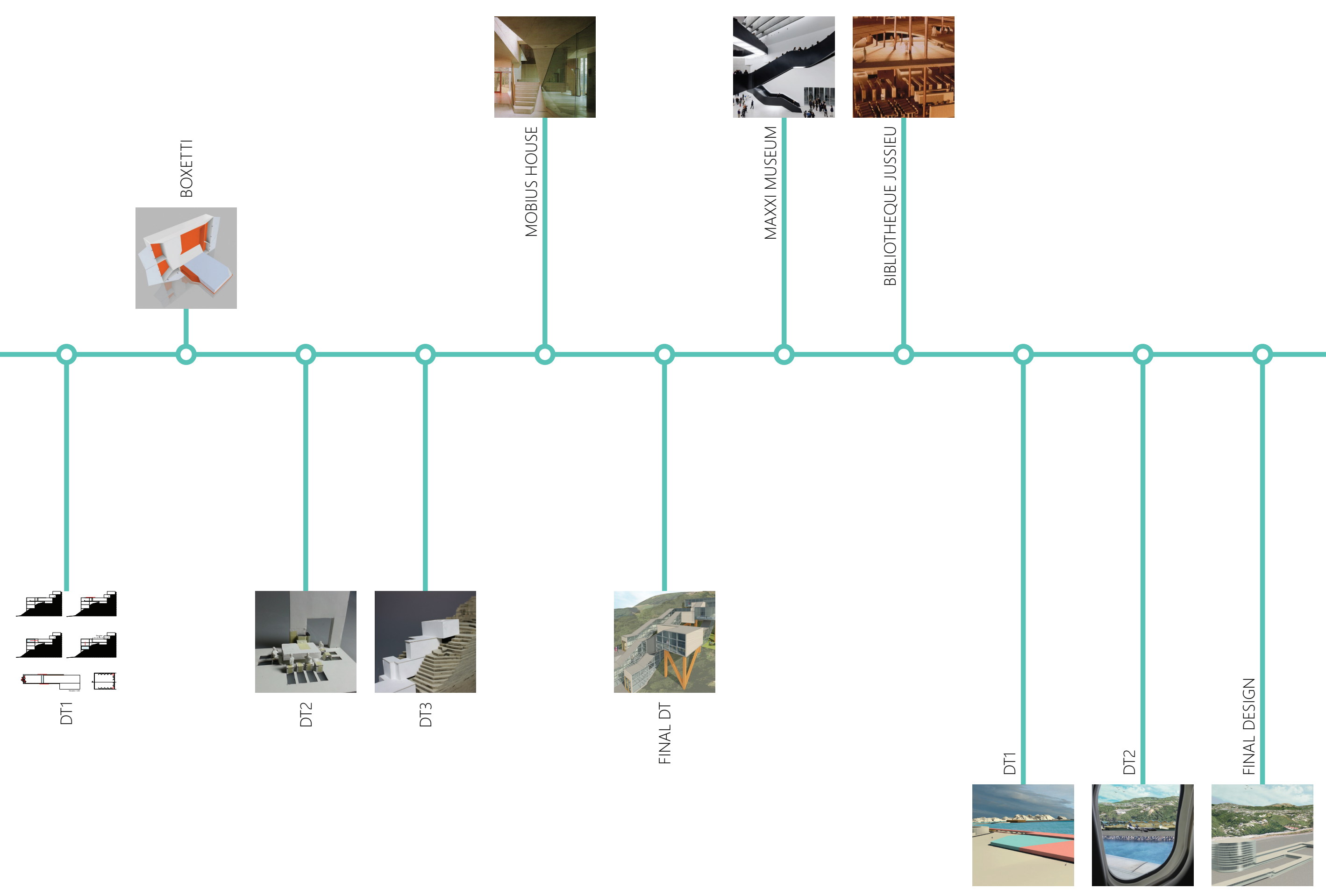



I NSTALLATION

MICRO SCALE DESIGN 
The installation used physical movement in the design to test the relationship between a moving installation and the body. Design investigations were tested using physical models as they provided a direct relationship with how the installation could be controlled by the user and aided in the design development of the installation. ${ }^{52}$ Rotation was used to create movement as it "causes the direction of a body in space to change while its position remains the same". ${ }^{53}$ This meant that users were able to interact with the installation and move the pieces along its axis of rotation without altering the position of the pieces in relation to one another. This directional change in the pieces created a dynamic and flexible installation which continuously altered the user's interaction with the installation.

The first few design tests used triangular shaped pieces jointed together to create the form of the installation. Triangles were chosen as the pieces, as once jointed together, they could be easily rotated and moved in relation to one another without obstructing the movement of other pieces. At the initial stages of design testing (Figures 4.5-4.14), the installation was envisaged to be hung from the ceiling and surrounding walls. 


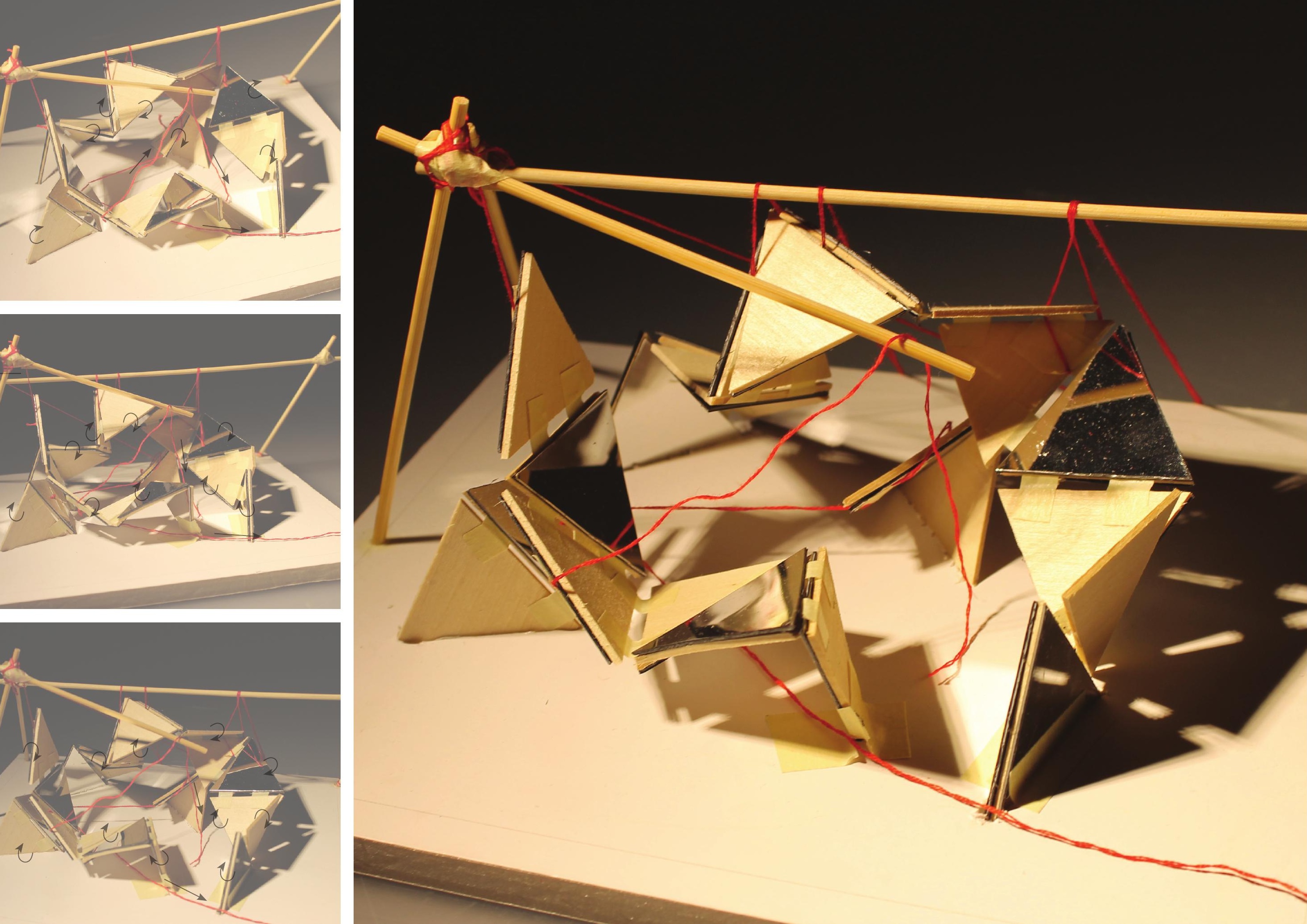




\section{DESIGN INVESTIGATION}

\section{DESIGN TEST 1 - FLAP}

Hinges were used as the first method of design to create movement. This meant that the triangular pieces of the installation were only able to be flapped open and closed. Users were able to interact with the installation through the physical motion of pulling. All the pieces in the installation were hinged to one another and some pieces also had strings attached to them. When a user pulled on one of the strings, the piece attached to it would move causing the other pieces jointed to this piece to also change its form. Since the pieces could only be flapped open and close, the interaction between the user and installation was limited. The physical motion of pulling was too simple to engage the user constantly. However this limited interaction provided a basis for the development of how other jointing methods could be used in conjunction with hinges to create greater levels of interaction with the installation. 



\section{DESIGN TEST 2 - FLAP + TWIST}

A combination of hinges and pin joints were used to create movement in this design. Along with pieces that were able to be flapped open and close, other pieces could now be twisted along their axis of rotation. The pulling motion was still used to control the pieces that were hinged but the motions of pushing and twisting were also used by the user to control how the pin jointed pieces were twisted. The combination of the two different jointing methods allowed for a greater level of interaction between the user and the installation as the user was using more than one physical motion to control and influence the form of the installation. From doing this design test it became clear that having pin jointed triangular pieces created a greater interaction with the installation as the movement of these pieces in relation to each other was able to change the form more drastically than the hinged pieces.

\section{DESIGN TEST 3 - TWIST}

In this design only pin jointed triangular pieces were used in the design test to create the form of the installation. As the pin joints allowed for the pieces to be twisted, users could push and twist the pieces in order to manipulate the form of the installation. As each piece of the installation was jointed to one another, the pushing or twisting of one piece by the user would cause several other pieces to also twist in relation to the piece that was moved by the user. Due to this constant change in form of the installation users were able to interact with the installation in different ways. Even though the interaction with the installation is continuous, there was a lack of depth to this interaction as the triangular pieces maintain their shape when moved. A further level of dynamic change was required to create greater levels of engagement. 


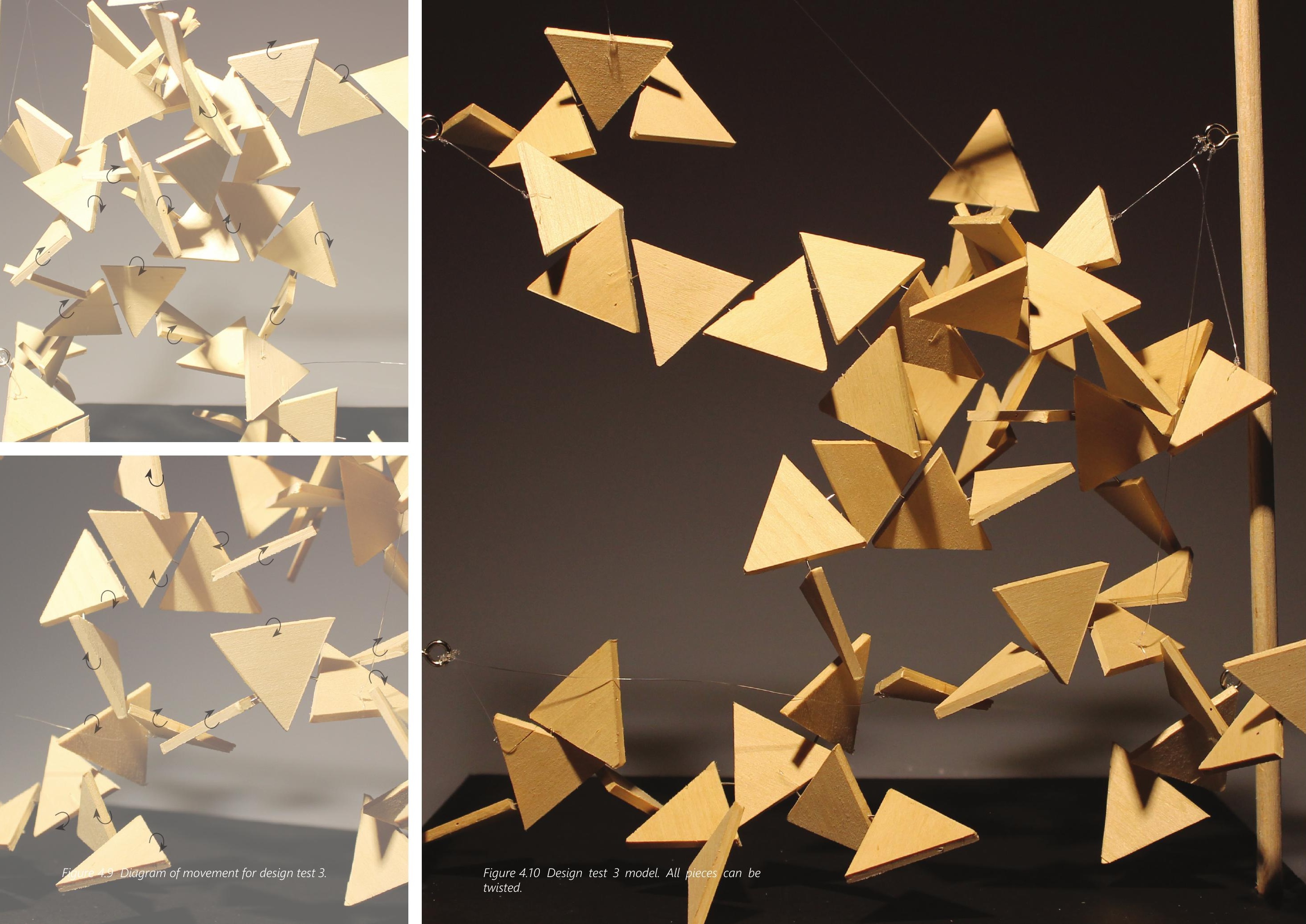




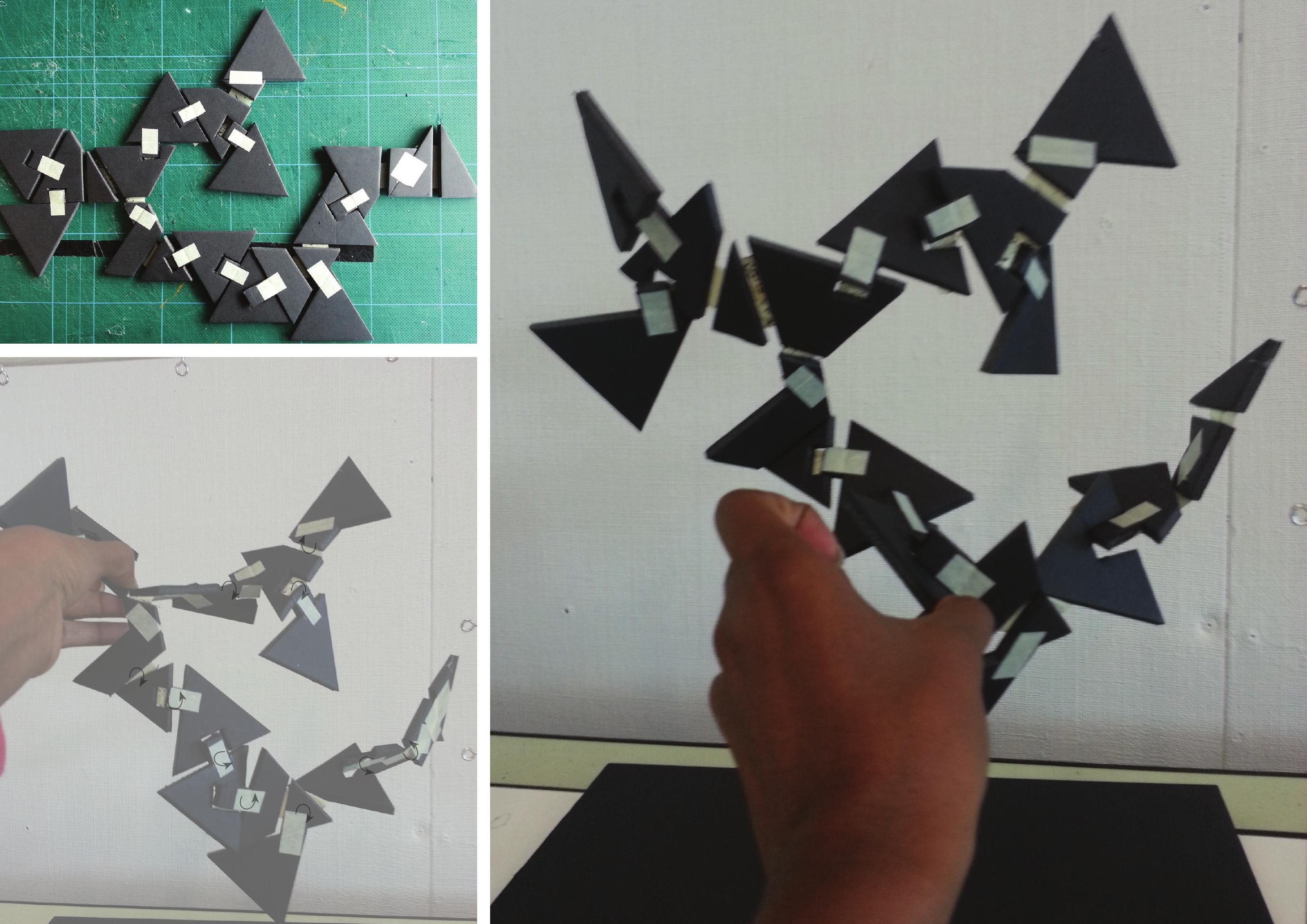




\section{DESIGN TEST 4 - FLAP}

Hinges were used again in this design test. To make the installation more dynamic each triangular piece was cut in to parts and these individual parts were then used as part of the jointing system. Having the pieces themselves be part of the jointing system created a different form to those created in the earlier design tests. However due to the parts of the triangle being the joints, when moved by the user they were unable to maintain their new position as the joint was not as strong as if external hinges or pin joints had been used. Therefore the manipulation of the form of the installation by the user was unable to occur to the same degree as the pieces did not allow for a wide range of movement.

\section{DESIGN TEST 5 - WALL}

Design test five was designed to explore how the same principles of movement as the previous four design tests could be created if the pieces were embedded within a wall. The installation was no longer hung but became part of a wall that could be pushed and pulled to alter the way user's perceived and interacted with the wall. The triangular pieces were hinged and pin jointed to one another and the wall. However as users tried to push and pull the pieces to make them move and manipulate the form, the connection between the pieces and the wall restricted this movement. Only some of the pieces were able to move and even those that did were not able to greatly alter the form of the installation. 

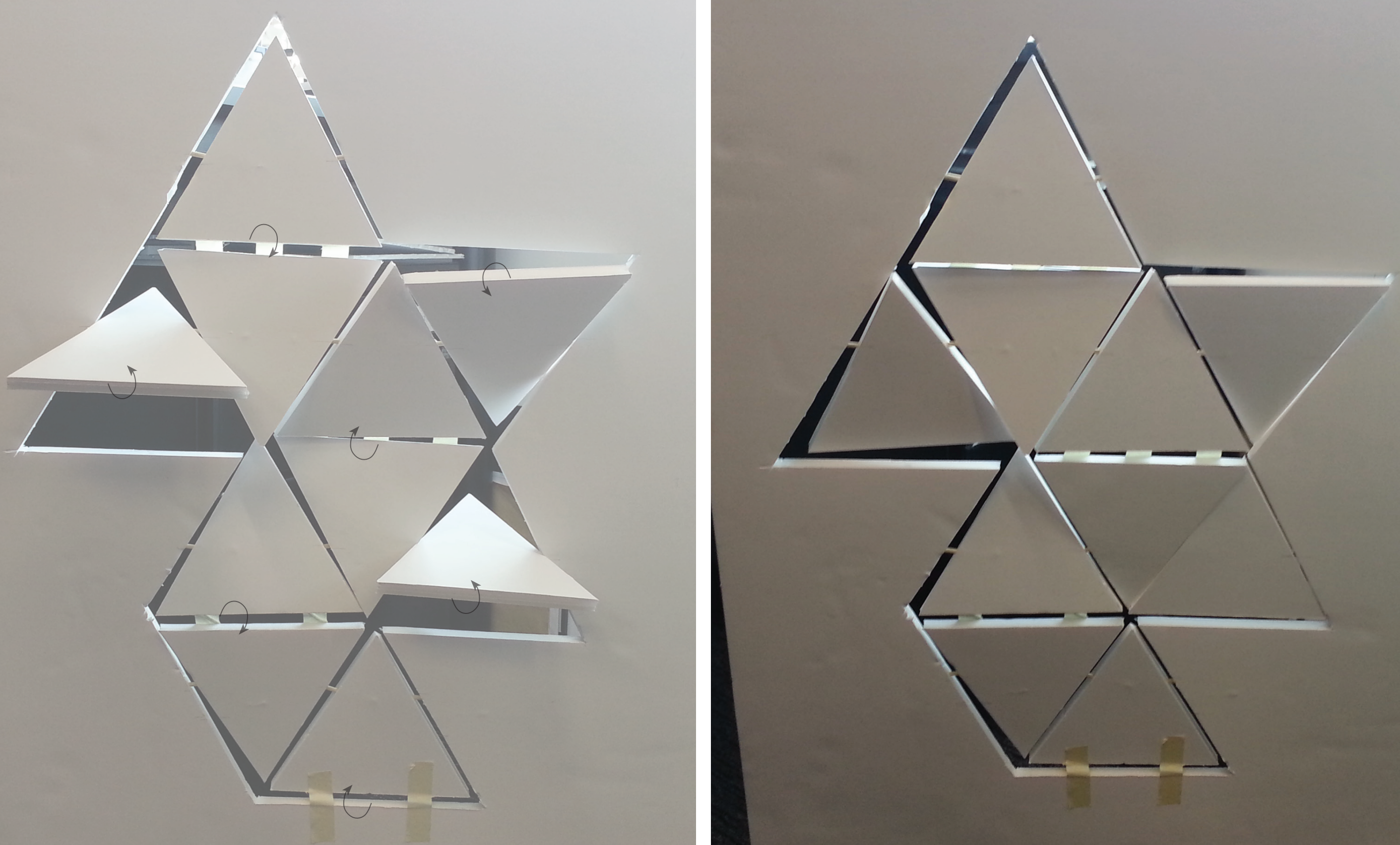


\section{DESIGN TEST 5 - RECTANGLES}

Following on from having the triangular pieces attached to a wall, design test six explored a different shape for the pieces of the installation. The pieces were now rounded rectangular shapes similar to that of a smart phone. Instead of having many pieces like the previous design tests, this design test focused on only having six pieces that were hinged and pin jointed to each other. The pieces were removed from the wall to first test the validity of the new shape in creating movement. The rectangular pieces were able to be flapped open and closed and also twisted to create different shapes and form. Even though there was a limited number of pieces in the installation the form of the installation could constantly be changed depending on the arrangement of the pieces by the user. Having rectangular pieces that were simply hinged or pin jointed to one another created an installation with greater levels of interaction between the user and installation. The user was able to rearrange the pieces to create all different kinds of forms of the installation. 

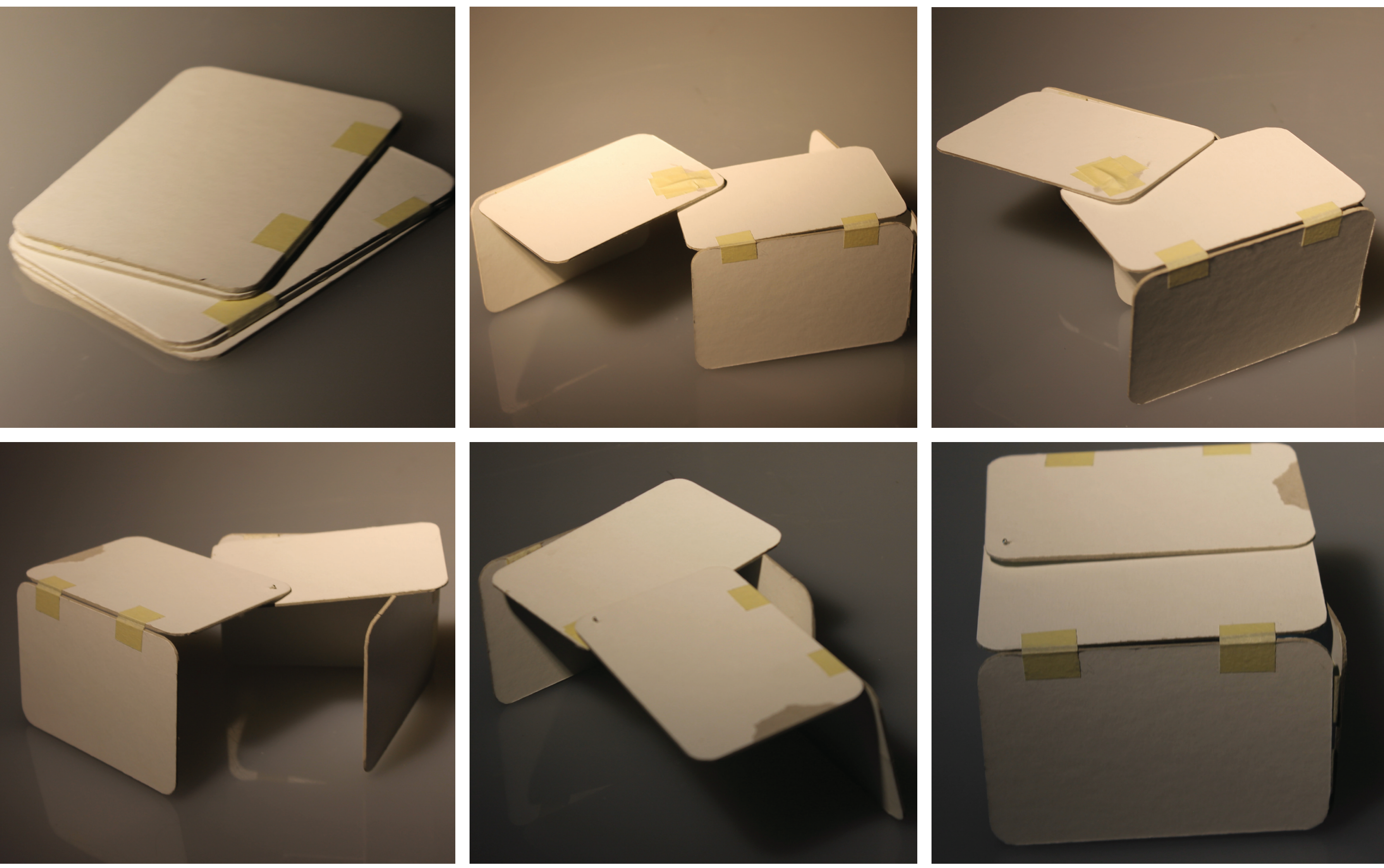


\section{FINAL DESIGN}
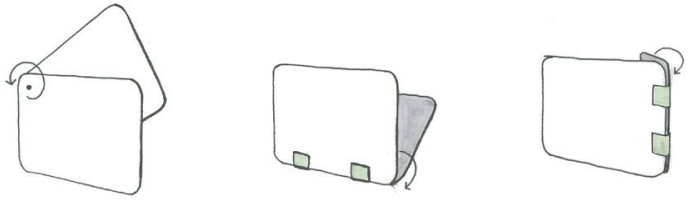

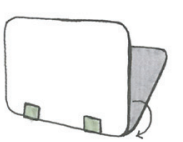

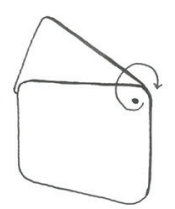

Since the rectangular pieces worked well in creating interaction between the user and the installation, the final design of the installation used the same design principles as design test six but had one piece that was attached to a wall. When all the pieces were folded up, they would be able to fit into a hole that was cut in the wall. When user's wanted to interact with the installation they would be able to fold the pieces out of the wall and start arranging the pieces that were jointed together into different forms as they saw fit. 


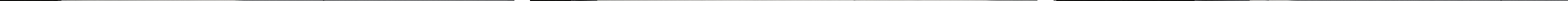


Elqure 4.19 (Facing page) Person interacting with the fhat installation in many different ways.

Figure 4.20 Person interacting with the final installation.

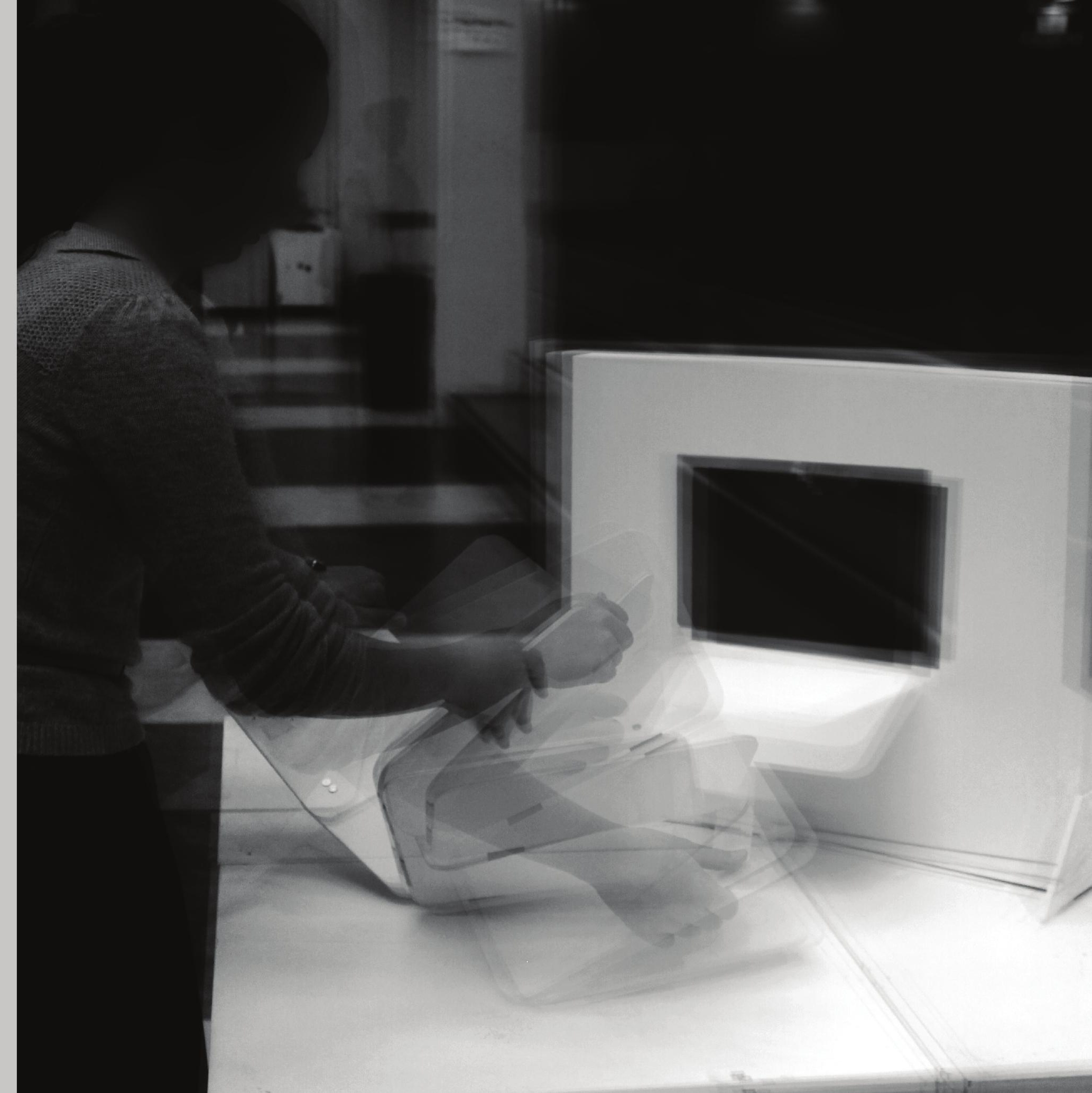




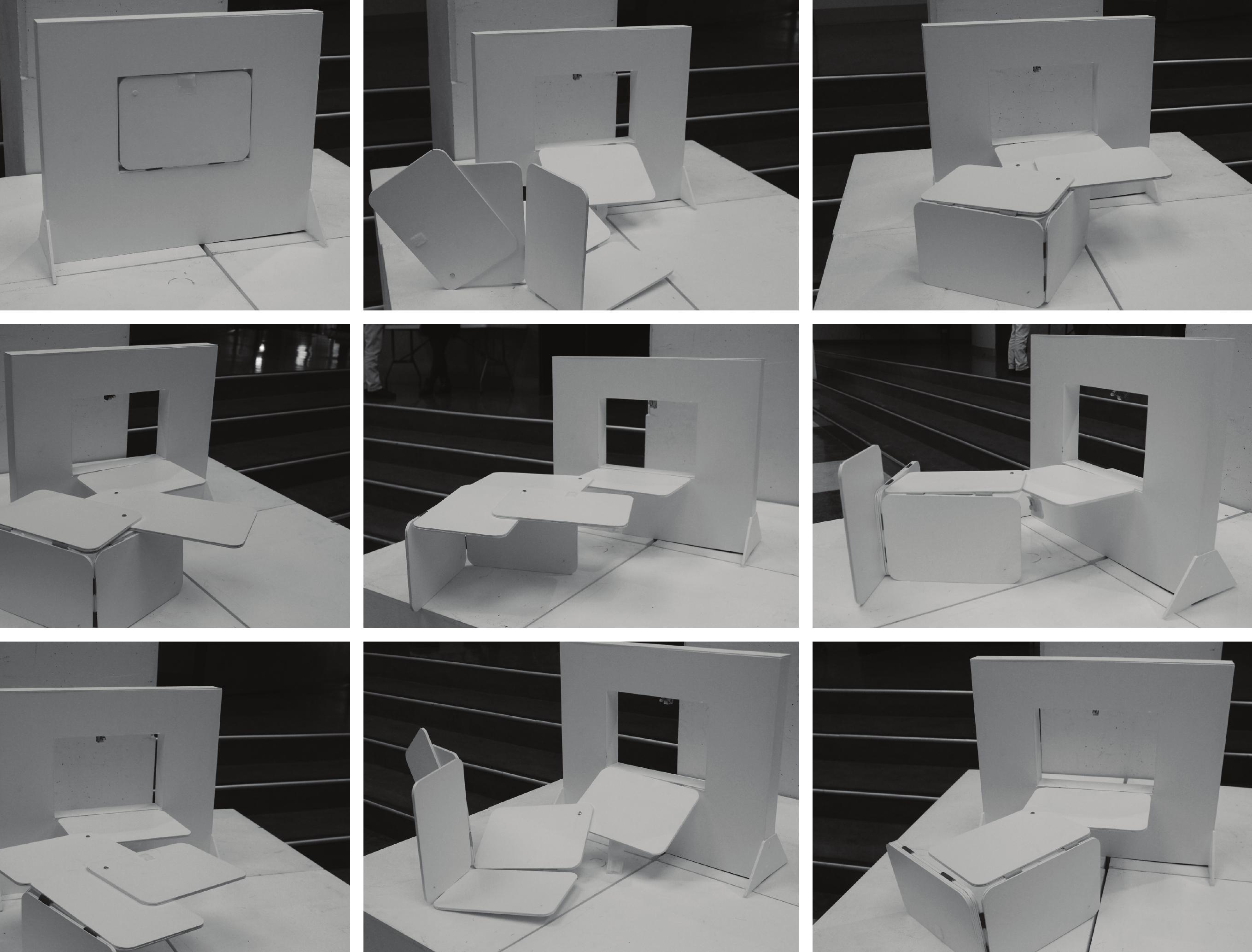




\section{REFLECTION}

The case studies were useful in determining the jointing and movement methods to be used in the design research. The same jointing methods as those used in the movable panels in Erika Mann Primary School were used in the early design tests to investigate the opening and closing movement in creating interaction between the user and the installation. The design tests that were most successful in creating engagement between the body and architecture used a combination of movement strategies such as flap and twist. This combination enabled greater levels of interaction with the installation as the form was able to change continuously in different directions.

The final design of the installation created a greater level of engagement between the user and the installation as the users were able to continuously manipulate the installation by arranging the pieces differently each time. Since the final design of the installation tested the movement of pieces that folded out of a wall, the interactions between this movement and the body were further tested in the design of the house. Walls, floors and roofs were tested to understand bodily engagement with flexible architectural elements. 



\section{MOBILE HOUSE}

MEDIUM SCALE DESIGN 
Following on from the micro scale design of the installation, a house design was used to test the proposition how can movement be used to engage the body with architecture, at a larger scale. With an increase in scale, the experiences of the spaces was also tested. Movement was used to create varying spatial experiences to engage the body with architecture.

The physical movement strategies of the house combine both rotational and translational movement patterns to create the movement. Through a combination of these two strategies more complex movements are able to be created allowing for a greater interaction with the house for the user. ${ }^{54}$ During the physical movement design tests, physical scale modelling were used to generate form as they aided understanding of how the elements would create interaction for the user.
Once physical movement had been tested, a shift to testing contained movement in the house design occurred. This shift in movement method occurred to investigate which movement method was most effective in engaging the body with architecture at a larger scale. Contained movement was explored through diagrammatic models following Hardy, as these allowed for the mapping of "abstract issues of programme, structure, circulation and site relationships" 55 to be addressed. The main contained movement strategy used in the design was projected bodily movement which allows the user to imagine their body moving through the spaces of the house by looking at the form. ${ }^{56}$
55 Mills, Designing with Models, 5.

56 Hardy, "The Expression of Movement in Architecture," 474. 


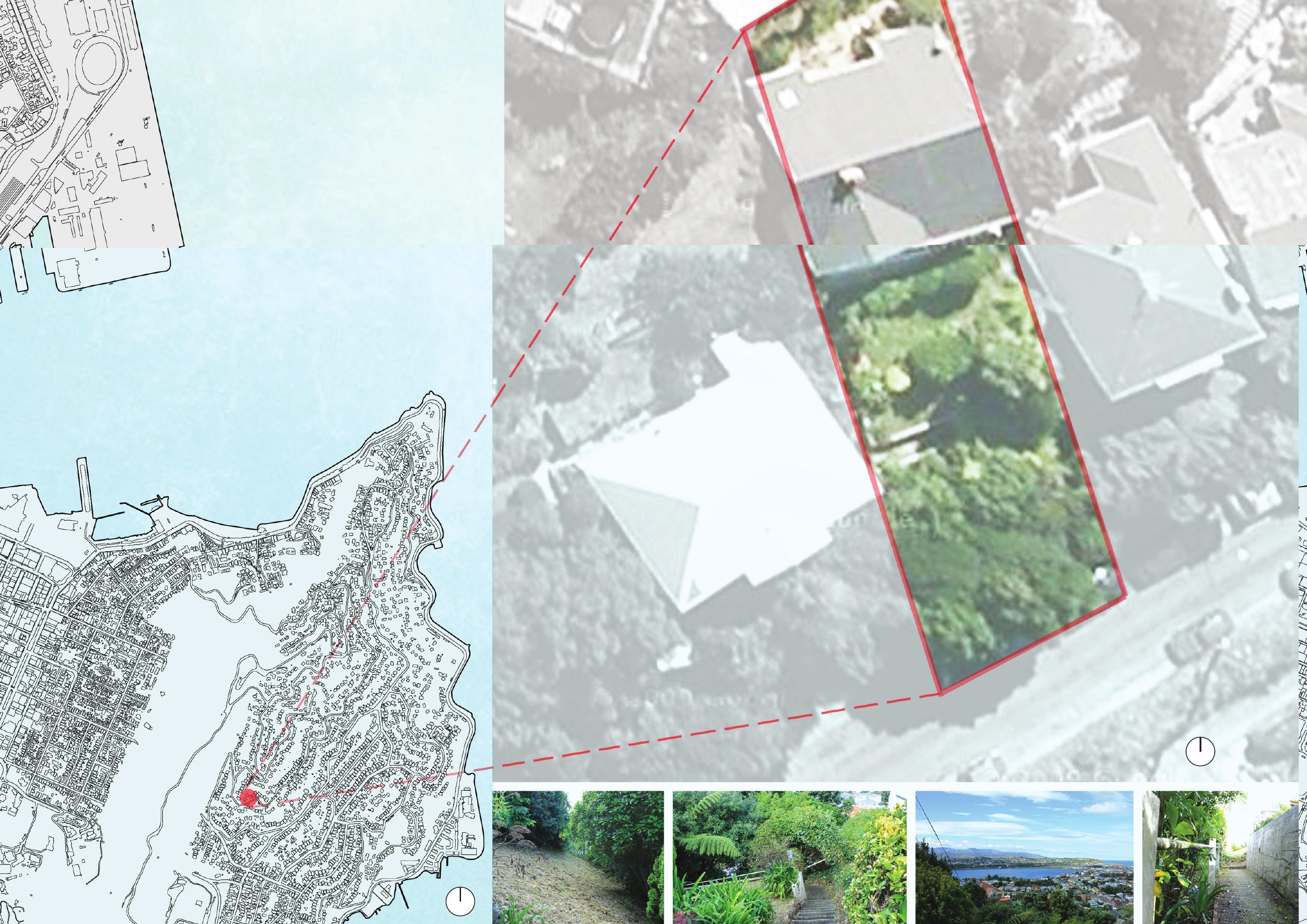




\section{PROGRAMME}

This house was designed for a couple; a doctor and a dentist. The house was to be designed so that both people could work from their home whilst having areas to entertain guests and live. This meant that the house needed to have spaces for both a doctor's office and a dental practice. Using a narrative was useful as the design of the house could be developed according to the functions in the house. ${ }^{57}$ As Cathy Ganoe argues, when users traverse through different functions in the house, their "[m]ovement through space is simultaneously external/physical and influenced by body position, as well as internal/psychological and influenced by state of mind". ${ }^{88}$ This change in function and bodily awareness of the different spaces create varying experiences in one space.

The design tests which incorporated physical design movement principles focused on how the requirements of space could be created through the manipulation of the walls and floors depending on when the space was required. The design tests using contained movement principles focused on how best to overlap and layer the spatial requirements so that people using the house could understand the areas of movement and pause through the house and be witness to both areas. ${ }^{59}$

\section{SITE}

The site for this design investigation was provided by one of the supervisors and is located at 110 Rakau Road, Hataitai. This site was chosen as it was challenging due to its long, narrow and steep conditions which presented a variety of ways of building on the site to create harmony between programme, site and movement. The site runs north to south with the southern end of the site providing views out into the greater Wellington region. 


$$
\begin{aligned}
& { }^{4}{ }^{7}{ }^{4}
\end{aligned}
$$

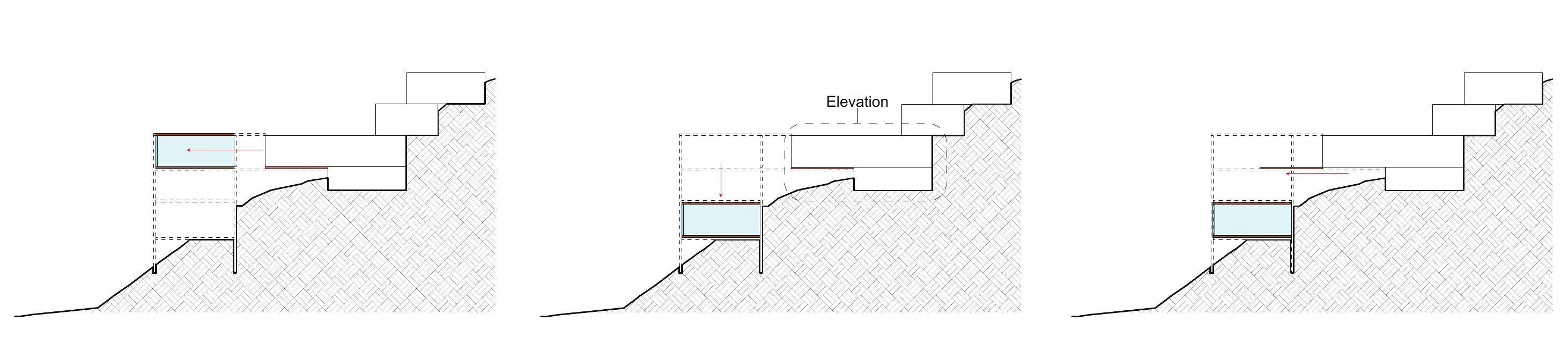

$$
\begin{aligned}
& 5 \square=
\end{aligned}
$$




\section{DESIGN INVESTIGATION}

The design tests in this investigation all aim to create flexible house designs with spaces that are multi-functional.

\section{DESIGN TEST 1 - MOVING HOUSE}

Physical movement was used as a means to create a relationship between the house, site and users. The exterior of the house is able to be manipulated and opened up depending on the requirements of the user. The second floor room on the south side of the house was able to be detached from the main area of the house, similar to that of the Sliding House precedent. This lone room was then able to be slid along tracks and sit at the bottom of the site providing a separate guest room or entertaining area. Once this room had been detached from the house, a deck is able to be slid from underneath the main house providing the users with an outdoor space to use. Through moving exterior elements of the building, the user is able to create a changeable interior depending on their requirements. 

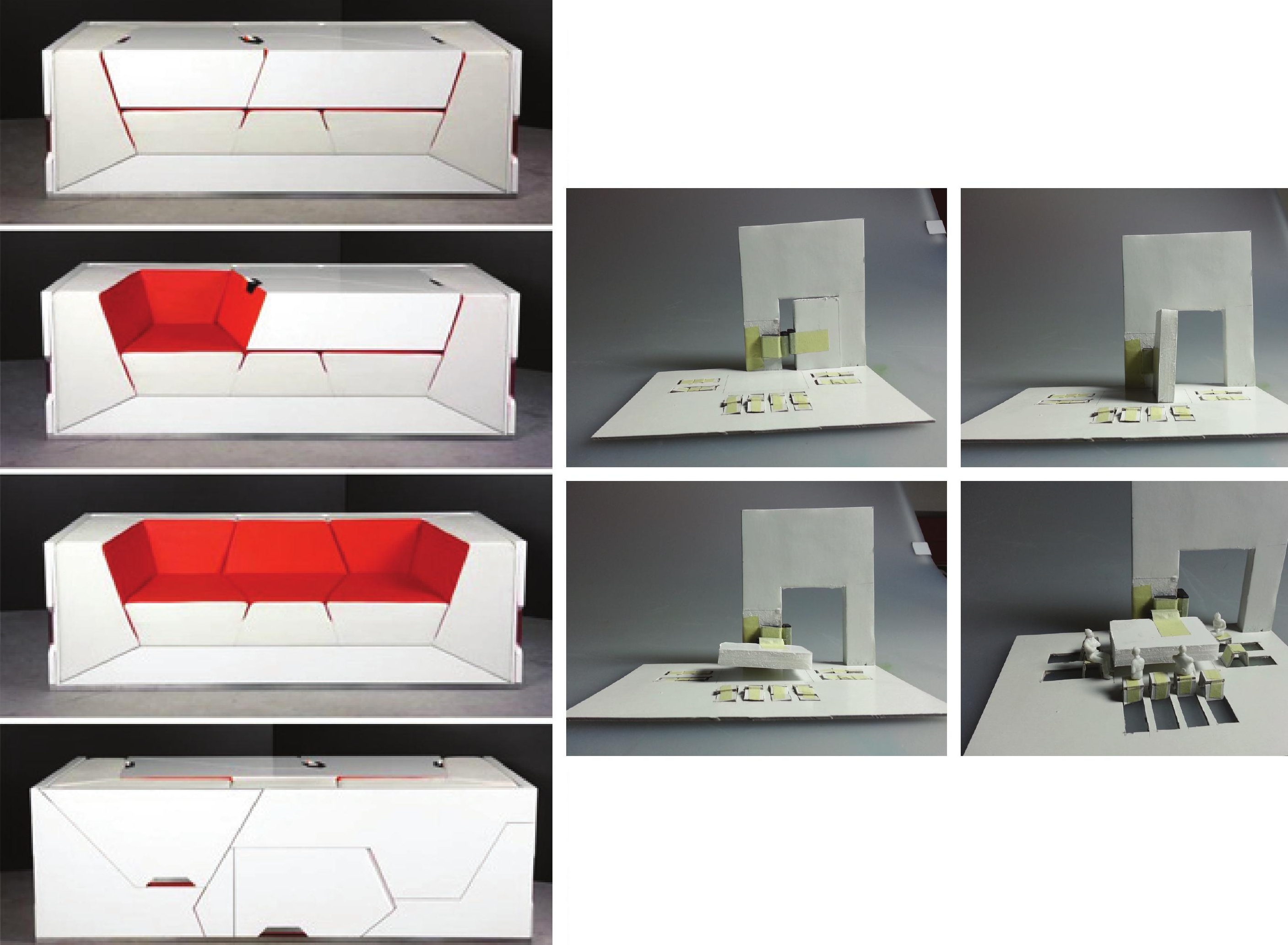


\section{DESIGN TEST 2 - FURNITURE}

Following on from design test 1 , this design test focused on the user's ability to manipulate both exterior and interior elements of the house to create different spatial arrangements within the house. In order to understand how interior elements could be used to create varying spaces, the relationship between architecture and furniture was explored. The furniture company Boxetti was studied as a precedent as they designed furniture that came prebuilt as a box that then had the furniture fold out of. By having the spaces of a house have only one singular furniture box which furniture could then be folded out of meant that users were able to constantly change the function and spatial requirements of the room. This idea of having furniture fold out from a box was translated into the house design by exploring how walls and floors could be manipulated to become furniture. A design which utilised the door and floor of a room was tested to see how this interaction between furniture and architecture could be constructed. The door when open was able to be pivoted on its axis and become a dining table. The floor surrounding this dining table could then be folded upwards and hinged to become the seats required for the table. 


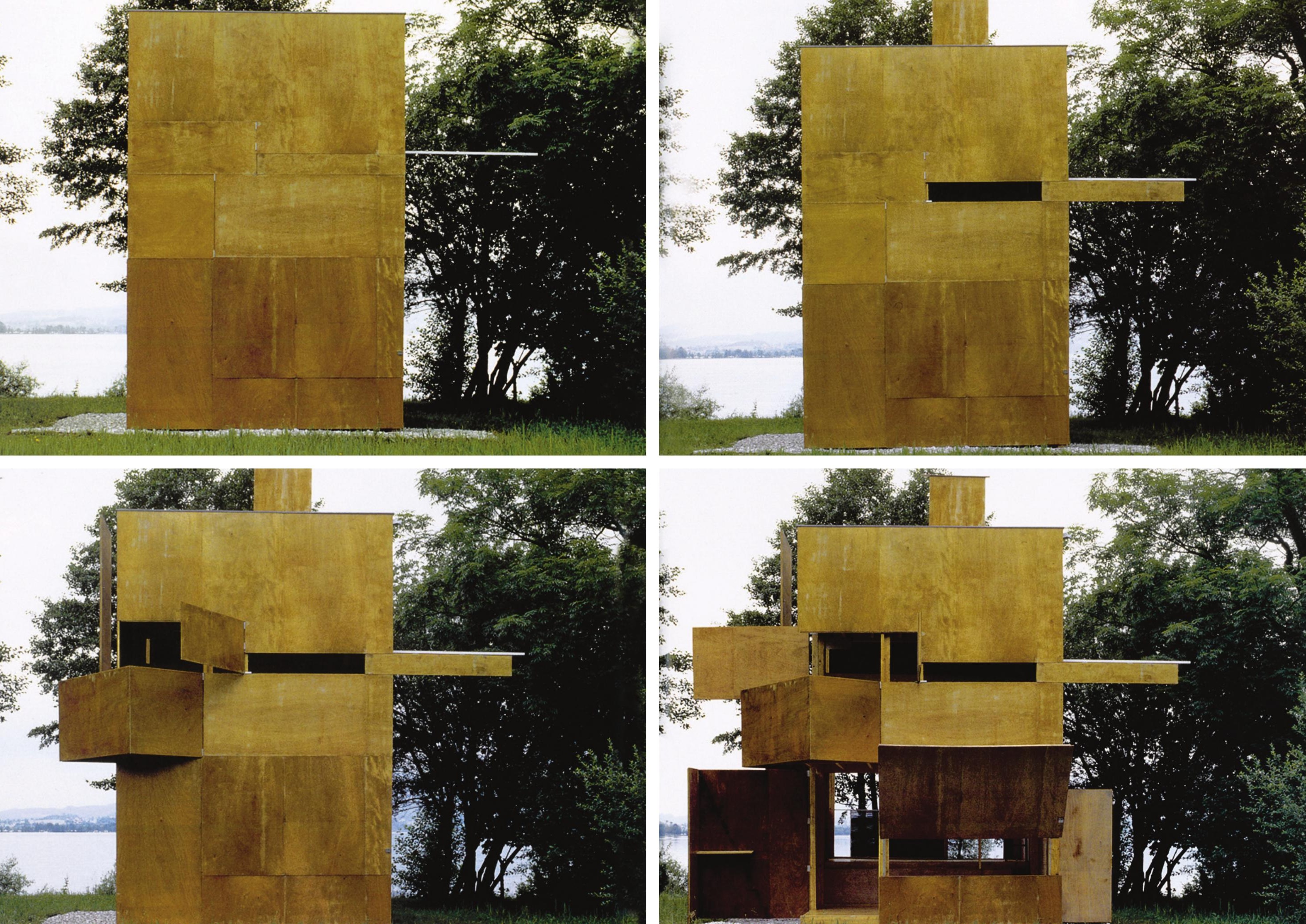




\section{DESIGN TEST 2 - FLEXIBLE HOUSE}

The relationship between architecture and furniture and how it could be utilised to create a changeable interior was the focus of this design test. The "GucklHupf" Mobile Lookout designed by Hans Peter Wörndl was studied to explore how a simple house could be designed to encompass varying forms and functions. In this example, Gucklhupf "provides the inhabitants with the ability to modify their living space, the lighting conditions within and the views of the surrounding environment according to their needs and wishes".60 The same principles of providing transformable spaces for the users have been applied to this design test.

To create a relationship between the house and site, the house was stepped up the house with each level providing outdoor access onto the site. On all the levels, users are able to pull up/down furniture from the walls or floor to create seating, tables and beds. In areas of transit where the levels change, the users can pull the stairs down from the wall. This approach is similar to Schumacher who argues that:

Ever changing configurations of separating walls create different spatial impressions. .

.. The ability to bring about these changes oneself and to experience how the spaces change as a result, connect the user directly with the building ${ }^{61}$

Using furniture that had to be physically moved and pulled down by the user created interaction with the user and the space they were inhabiting. Users had the ability to change and create the spaces they required and through their connection with the house and its moving parts their experience of the house was altered. gucklhupf-mobile-lookout/. 


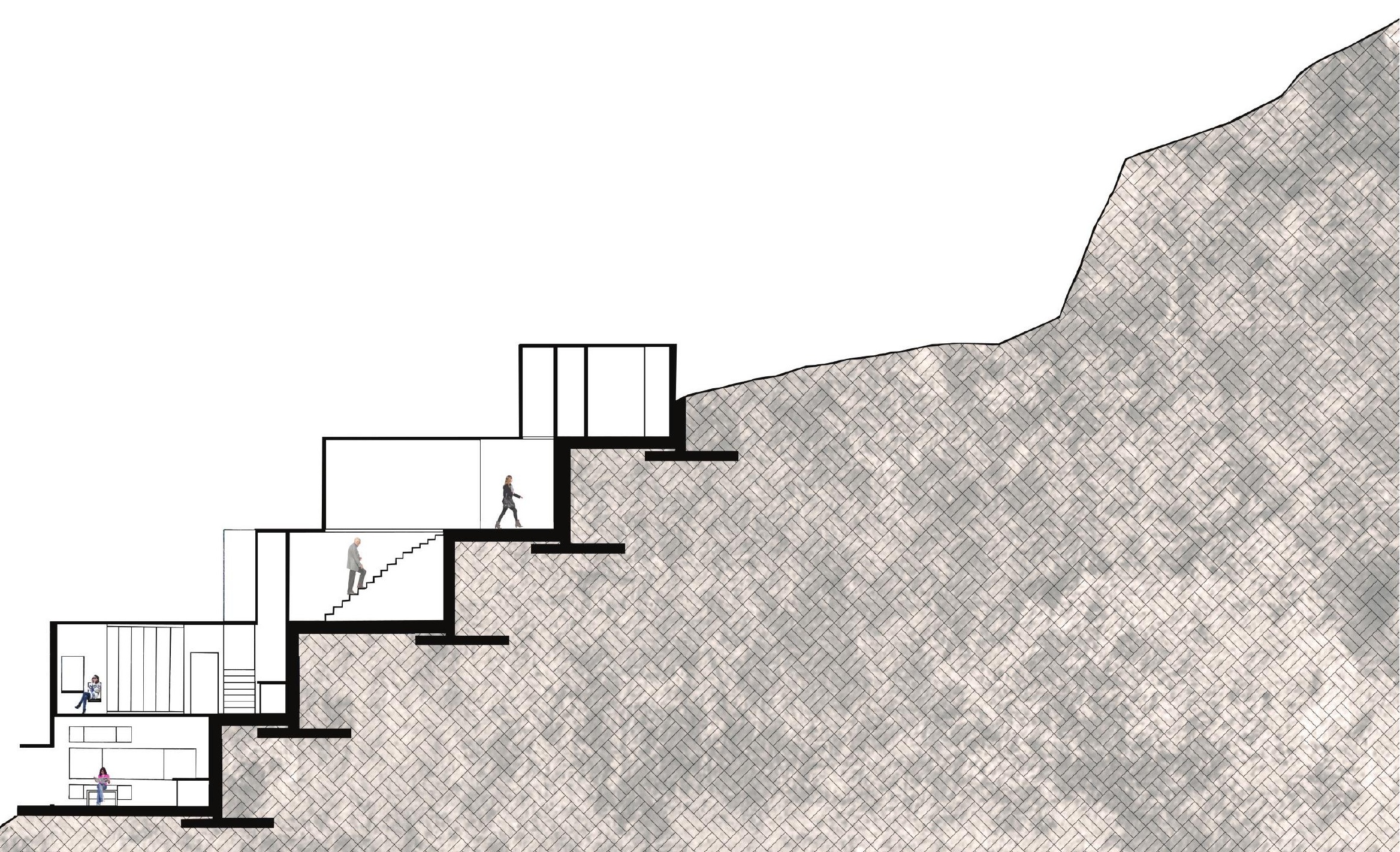




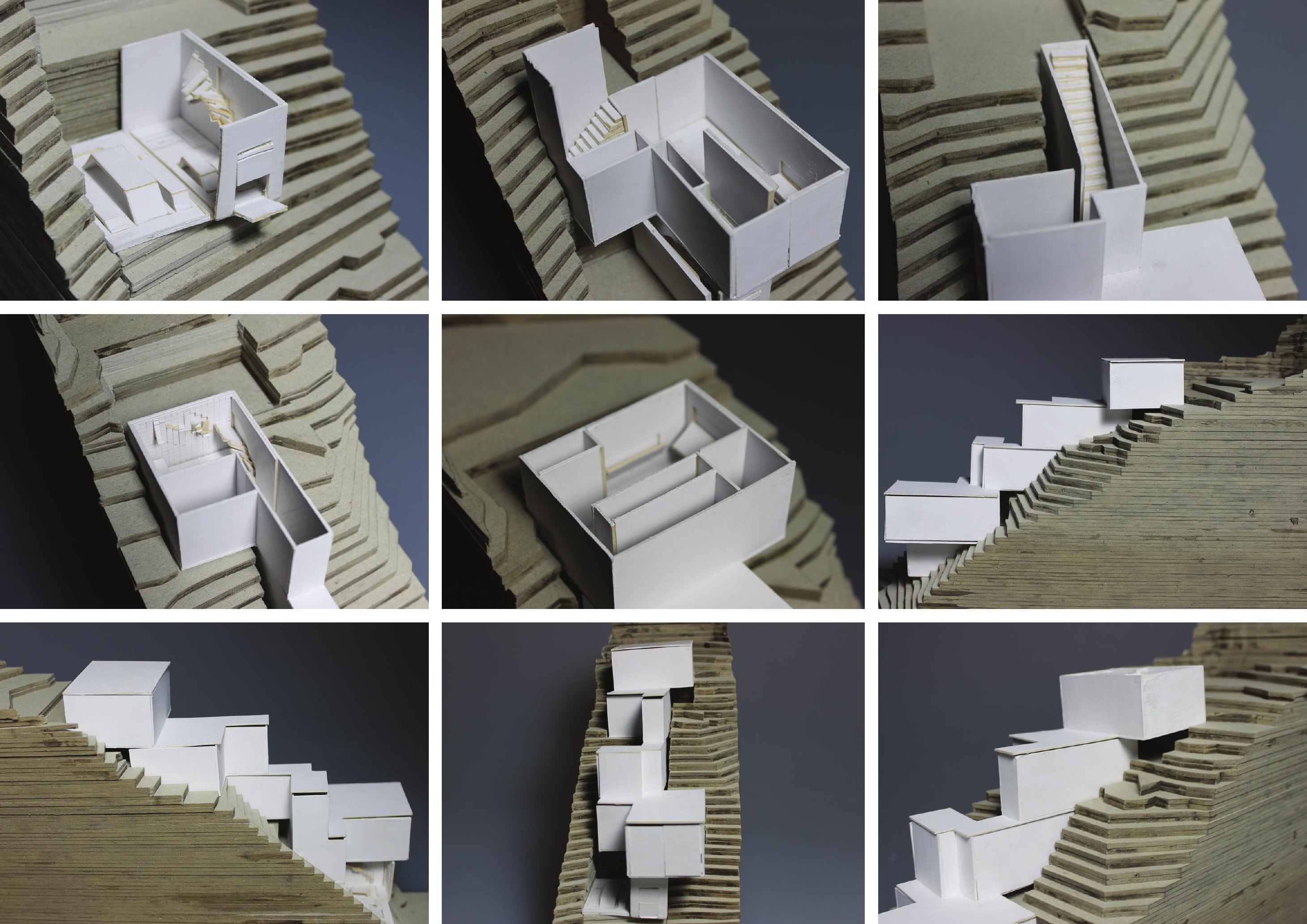




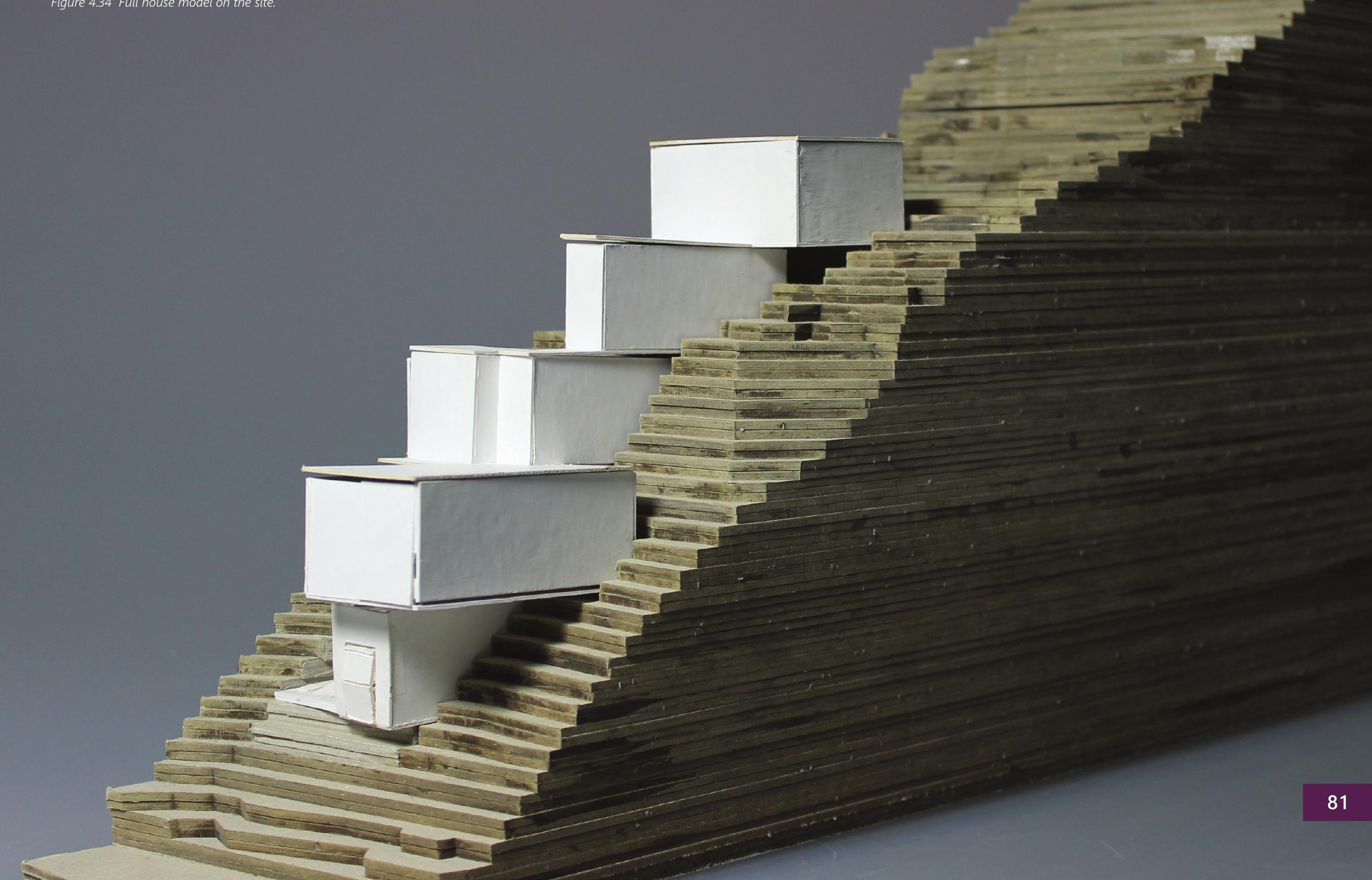




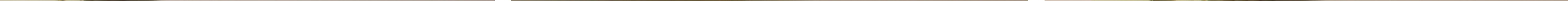




\section{FINAL DESIGN TEST}

The previous three design tests explored how physical movement could be used in the design of a house through the relationship between furniture and architecture. The user's interaction with the elements of the house such as the pull down furniture was effective as it ensured that the user was actively engaged in the spatial arrangement of the house. However due to the size of the house and the site, the sole use of pull down furniture was limiting in the spatial experiences and constraints that it created. Depending on what furniture was pulled down, the function of the space was changed but not necessarily the qualities of the space. Having tested physical movement in the house design and understanding the limitations of it, contained movement was chosen to be the driver for the next design test.

Since the house was to be designed to allow for the users to be able to both live and work in their house, the final design test explored how the house could accommodate all these functions at separate stages of movement through the house. The three main functions of the house were separated and mapped along the site through a diagrammatic model. The doctor's office and practice (blue), the dentist's office and practice (green) and the living areas (orange) have each been modelled as a path along the site. The narrative has been used in this design test to create interactions between people and the environment which "alter an individual's perception of space and time". ${ }^{62}$ Through the overlapping of paths at certain areas users walking along one path get views into the other areas of the house which causes their perception of the form of the house to change. The paths have then been extruded to start creating spaces and to identify which ones overlap and connect into another path. As with the Mobius House precedent, overlapping spaces created by the form create areas of living whilst the separated spaces become the private office areas. $^{63}$ By having the different functions of the house prescribe the form of the house, users are 


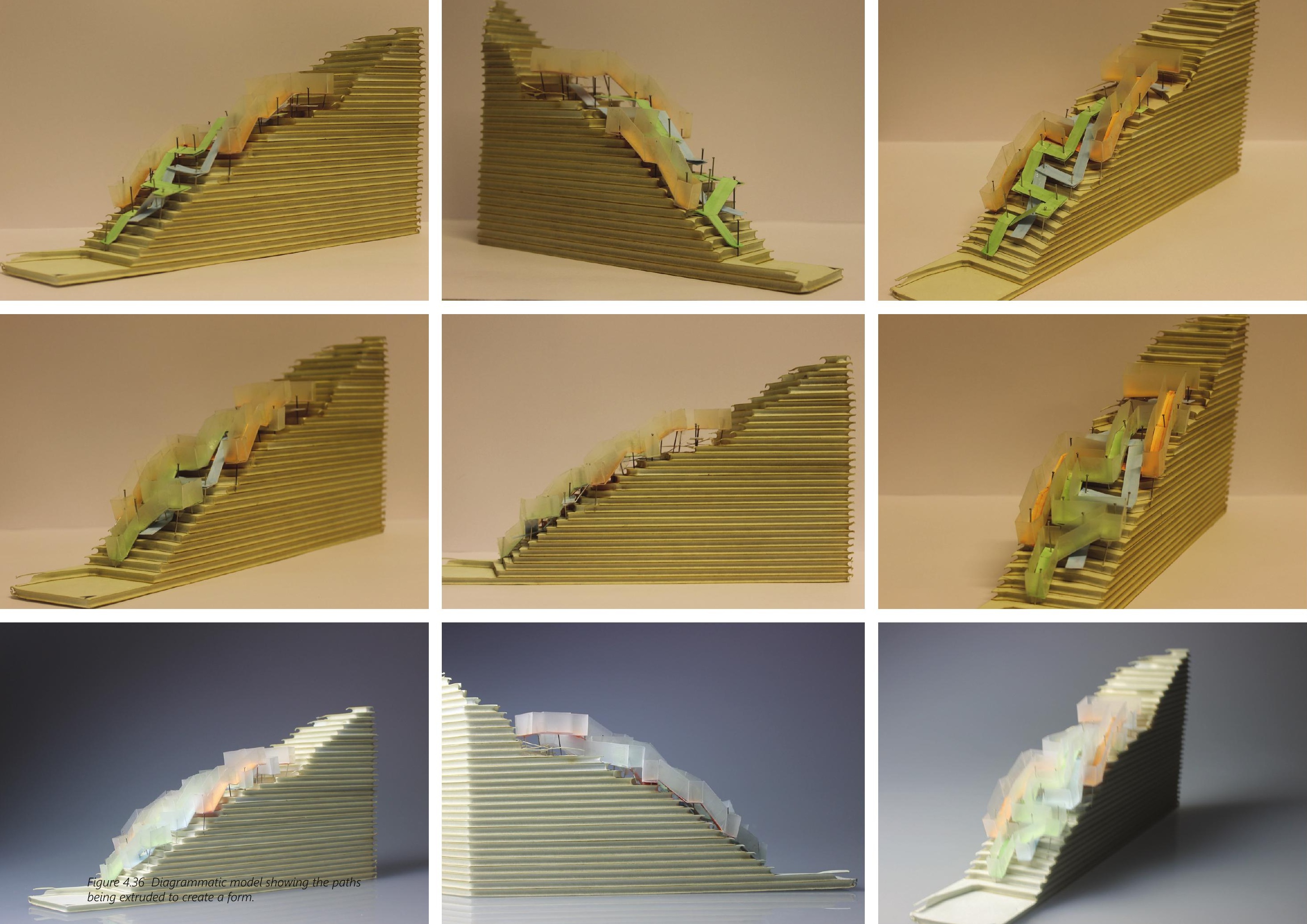




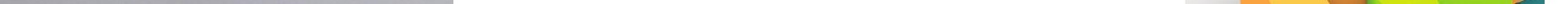

able to imagine themselves moving through the space. Also with the overlapping and interconnected spaces, users' eyes wander from space to space and start to read the building as an object that manifests movement through it.64

64 Hardy, "The Expression of Movement in Architecture" 474

Figure 4.37 (Left) Plan view of model.

Figure 4.38 (Centre) Sketch plan of how spaces could be arranged in the house. Scale 1:200.

Figure 4.39 (Right) Extruded computer model of sketch plan. 


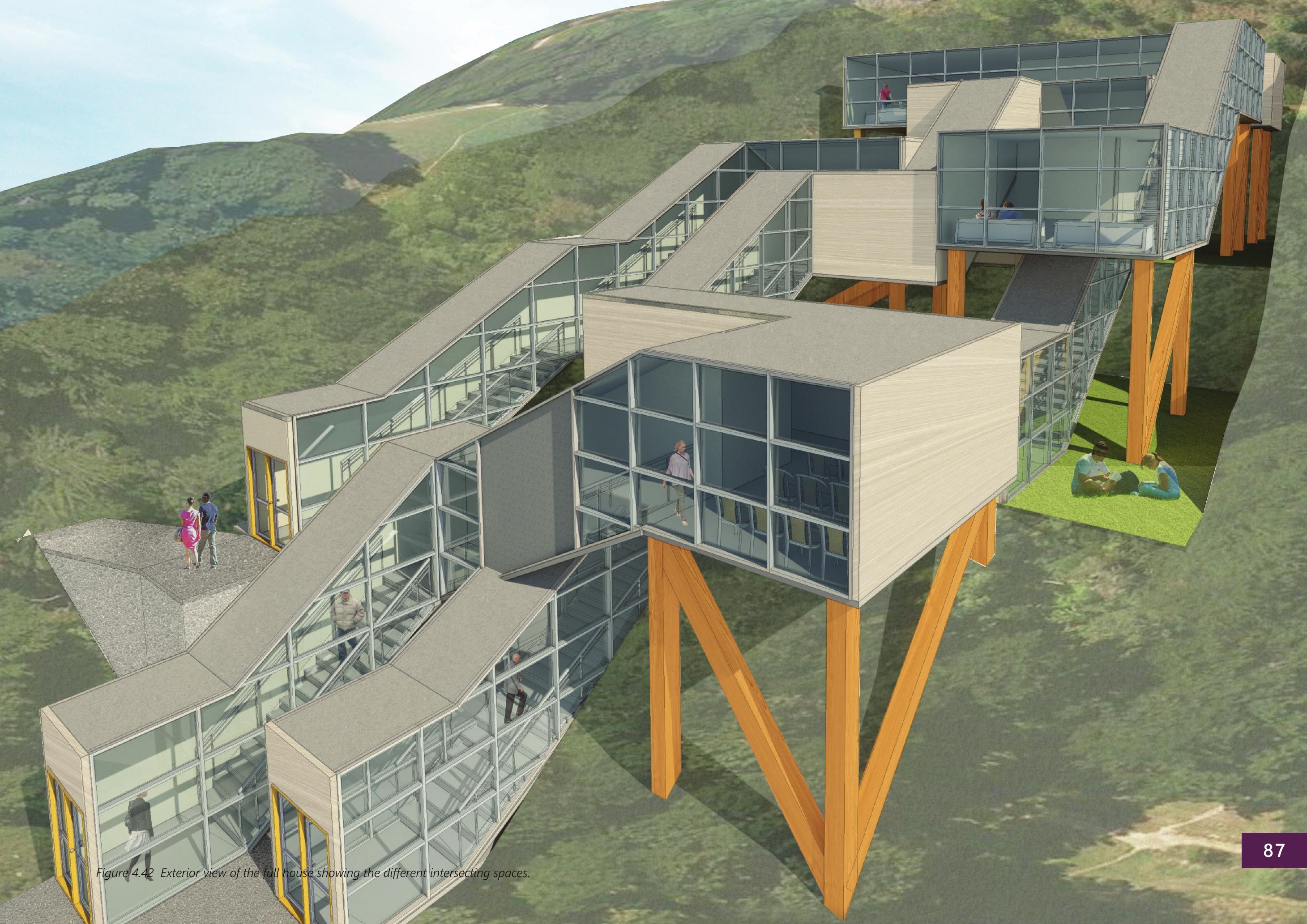




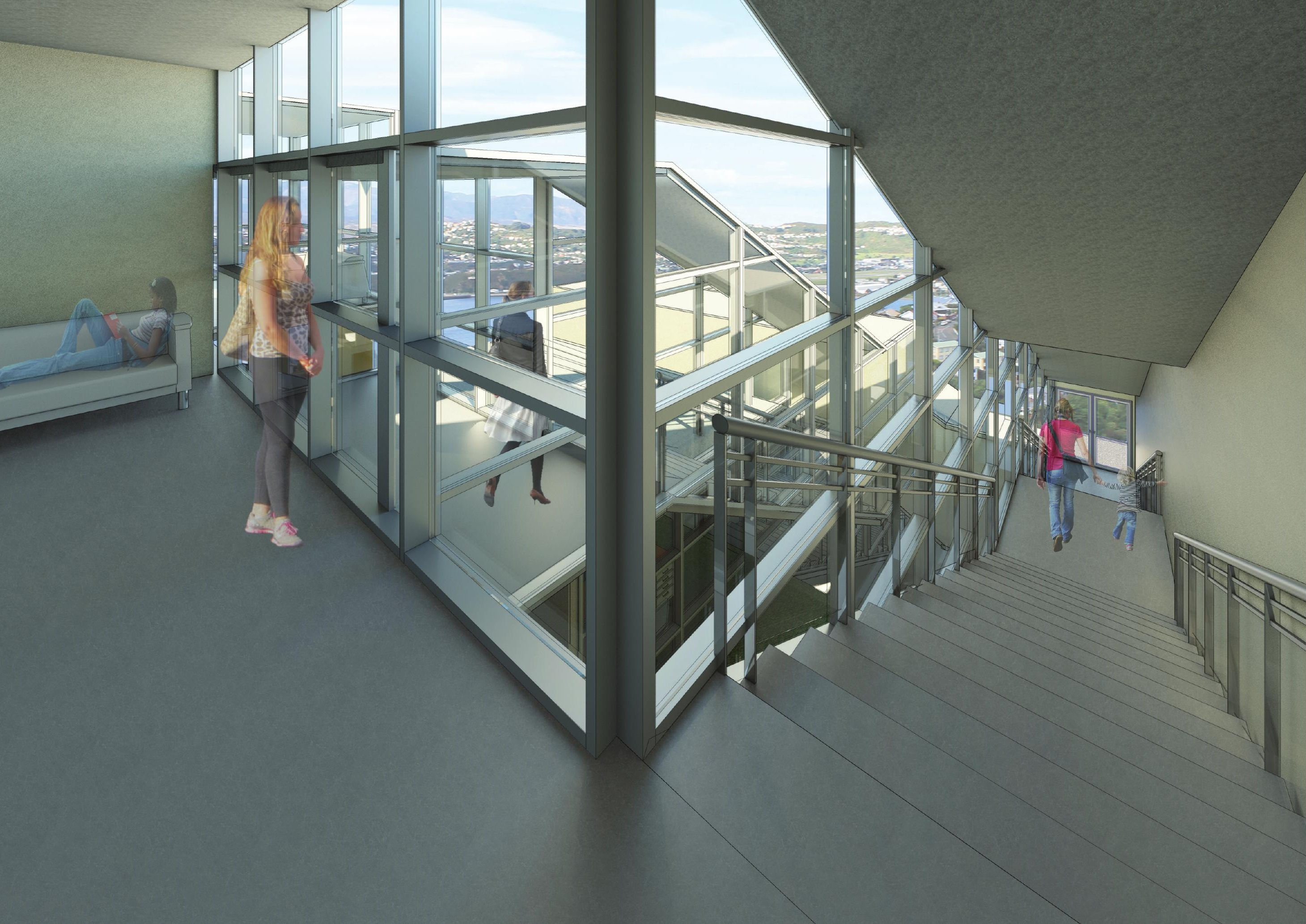




\section{REFLECTION}

A final house design was not resolved but the understanding gained through design test four provides a basis for further study into creating contained movement in the design of a transport hub. The design tests that explored physical movement in the house design were useful as they highlighted the limitations of using physical movement in medium scale design. The user's ability to create different spatial qualities through the movement of architectural elements allows users to engage with the building. ${ }^{65}$ However as the pull down furniture only changed the function of the space the direct engagement between the user and architecture and its spatial qualities did not occur. Moving onto exploring contained movement in the final design proved a useful investigation as it revealed how functions of a building could be mapped along a site to convey the notion of movement through a space. The diagrammatic modelling method proved useful in understanding the relationship of the function paths to each other and the site. They provided a quick way of understanding how the form of the building looks to allow users to understand themselves moving through the space. This understanding gained in creating contained movement was taken forth into the design of the transport hub. 



\section{TRANSPORT HUB}

MACRO SCALE DESIGN 
With a final shift in architectural complexity and scale, the transport hub explored how contained movement could engage the body with architecture in a large scale transport hub. The transport hub used contained movement strategies similar to the house, to create varying spatial experiences for the user to enhance their engagement with the space. The method used in the design tests were scale physical models. The strategies used to create contained movement in the transport hub consisted of using forms that guide the user's eyes through spaces and around surfaces. The overall form was designed to allow the user to imagine their body moving through the space. ${ }^{66}$

This sub-chapter has been split up into three sections. The first section investigates the programme for the transport hub. The second section analyses the site and its connection to the existing movement paths in the Greater Wellington Region. Lastly the third section consists of three design tests which focus on using movement to engage the body with architecture. 


\section{PROGRAMME}

The transport hub consists of an international airport, train station and ferry terminal. This programme was chosen as it directly related to the movement of people through a building. The combination of three different transportation programmes within one building creates a complex layer of movement paths. Arriving and departing passengers for all three different transport types and how these passengers move from one to the other had to be accommodated.

The airport provides the greatest complexity in terms of programme as there are certain rules surrounding security and how users move from one space to another. As this new international airport was to be designed to replace the existing airport in Wellington, it needed to accommodate an increase in passenger and aircraft numbers. ${ }^{67}$

The movement paths between these spaces are shown in Figure 4.44. Since the transport hub accommodates a train station and ferry terminal, different airport terminal types were evaluated to determine how the programmes could be vertically segregated but also linked. ${ }^{68}$ The most efficient way to create a transport hub with all these programmes was to have a multi-level terminal.

Two different airports are evaluated in the next section to gain an understanding of the functional requirements of an airport.
67 "2030 The Master Plan January 2010," Wild 10, 2014, https://www.wellingtonairport.co.nz/ documents/Wellington-Airport-MasterplanJanuary-2010.pdf. 


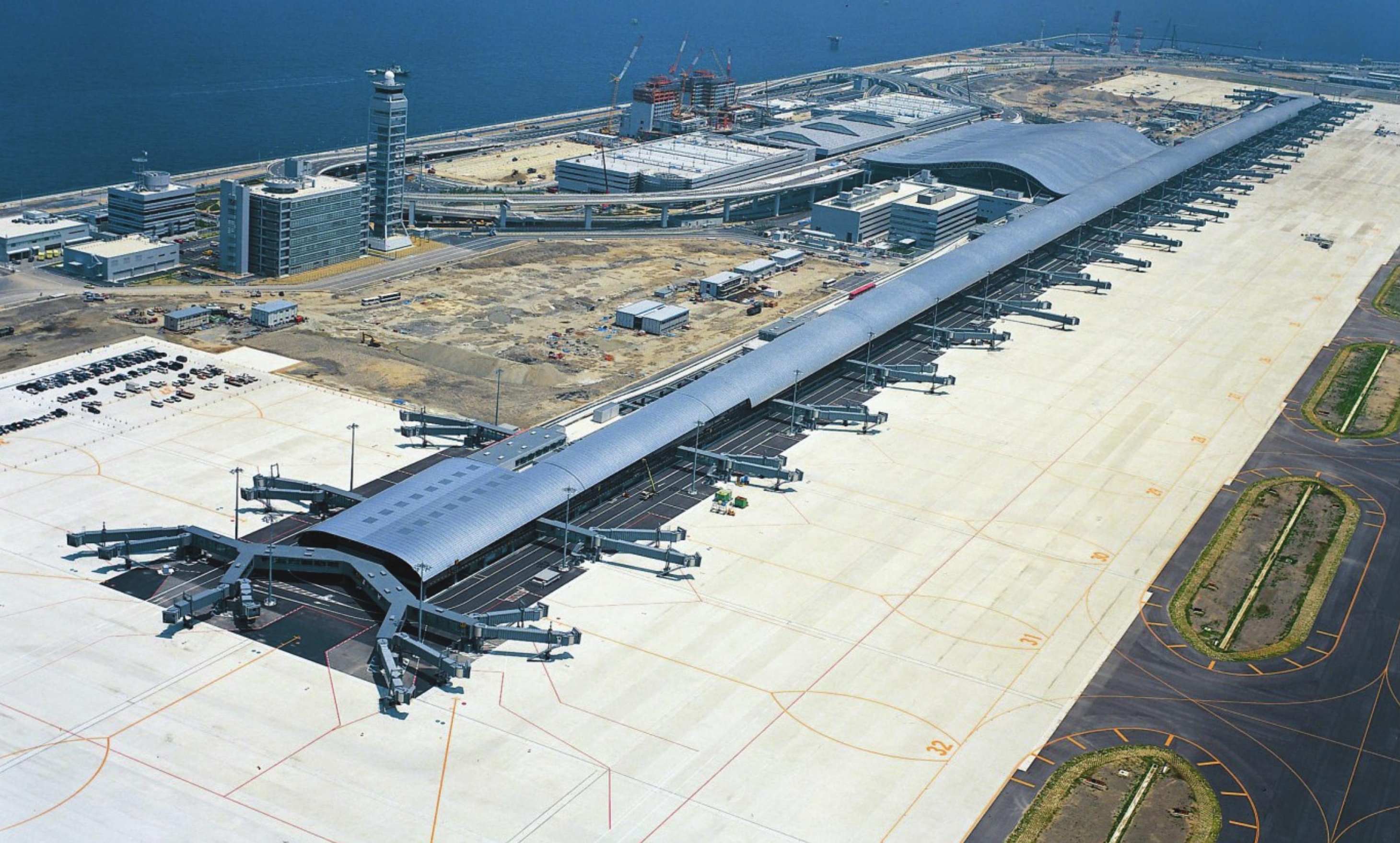




\section{PROGRAMME PRECEDENT ANALYSIS}

\section{Kansai International Airport - Renzo Piano Building Workshop, 1994}

Two typological precedents have been studied to understand how airports have been designed and constructed in the past.

Kansai International Airport was built on an island in the Osaka Bay. The design of the terminal is meant to represent a glider in plan. ${ }^{69}$ The main terminal building reflects the fuselage of the gliders whilst the boarding gates are positioned along the wings of the glider. The building has been designed as a long linear building which extends the length of the island. The main terminal building allows for unobstructed views out to the planes due to the open departures level. ${ }^{70}$ Even though the building has used a glider to influence its form, unless you are flying in or out the building you are unable to experience this form. The interior of the terminal does not reflect the airborne quality of the glider and is lacking in guiding users movement through the space. The airport satisfies the functional requirements of an airport through the arrangement of the different areas and allows the user to understand a path through the building. However no emphasis has been given to creating internal spaces that highlight the movement paths within the building. 


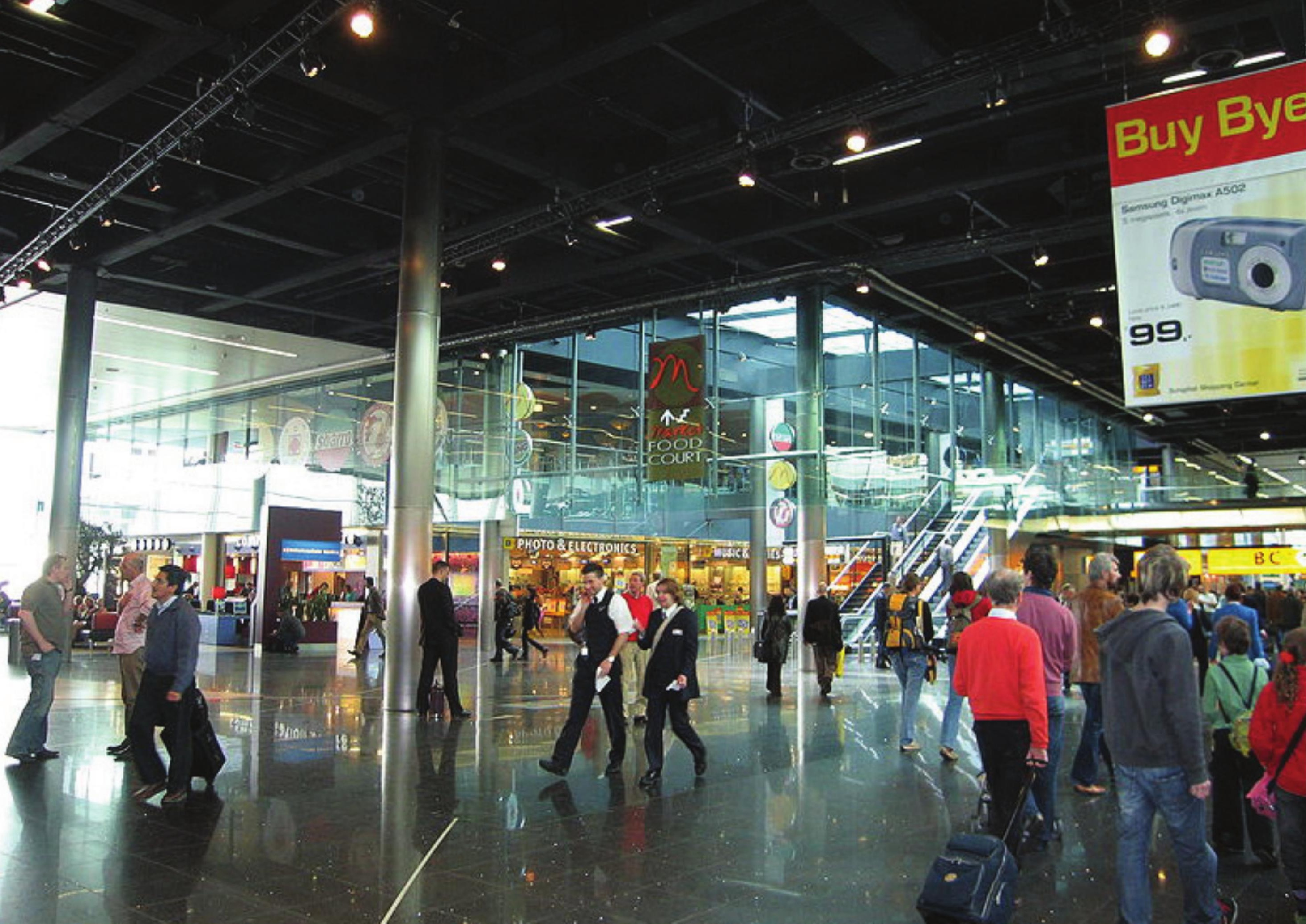




\section{Amsterdam Airport Schiphol - Benthem Crouwel NACO, 1995}

The Schiphol Airport terminal has been designed over the existing mainline train station so that a connection between the train station and the terminal building could be formed. By removing parts of the ground floor of the two arrival halls, passengers are able to see both planes and trains come and go. ${ }^{71}$ Through this, the terminal has created visual links between the levels of the building to allow people to understand the vertical movement of the space. However apart from this opening up of the ground floor, there has been no other work done in the interior of the building to further highlight the movement paths within the building. Users gain an understanding of the different transport nodes in the airport through signs but are unable to read the movement through the building from its form and interior spaces. In terms of the design for the transport hub, this airport highlights an effective way of opening up the different floors of the building to create visual links between the different transport

nodes.
The two airports studied above have been designed to provide maximum functionality within the terminal areas. The spaces inside follow on from one another and are located to provide the most efficient path for passengers to take so that security within the terminal is not compromised. The two precedents provide strategies for designing the transport hub at a programmatic level. However as functionality is desired in the precedents, both highlight a lack of spatial experiences within the terminal with more of an emphasis on the overall form. The next section of this chapter focuses on design that explores functionality but with a focus on testing the body's engagement with architecture through movement strategies.
71 "Schiphol Plaza, Amsterdam Airport Schiphol", Benthem Crouwel Architects, benthemcrouwel.com/portal_presentation airports/schiphol-plaza. 


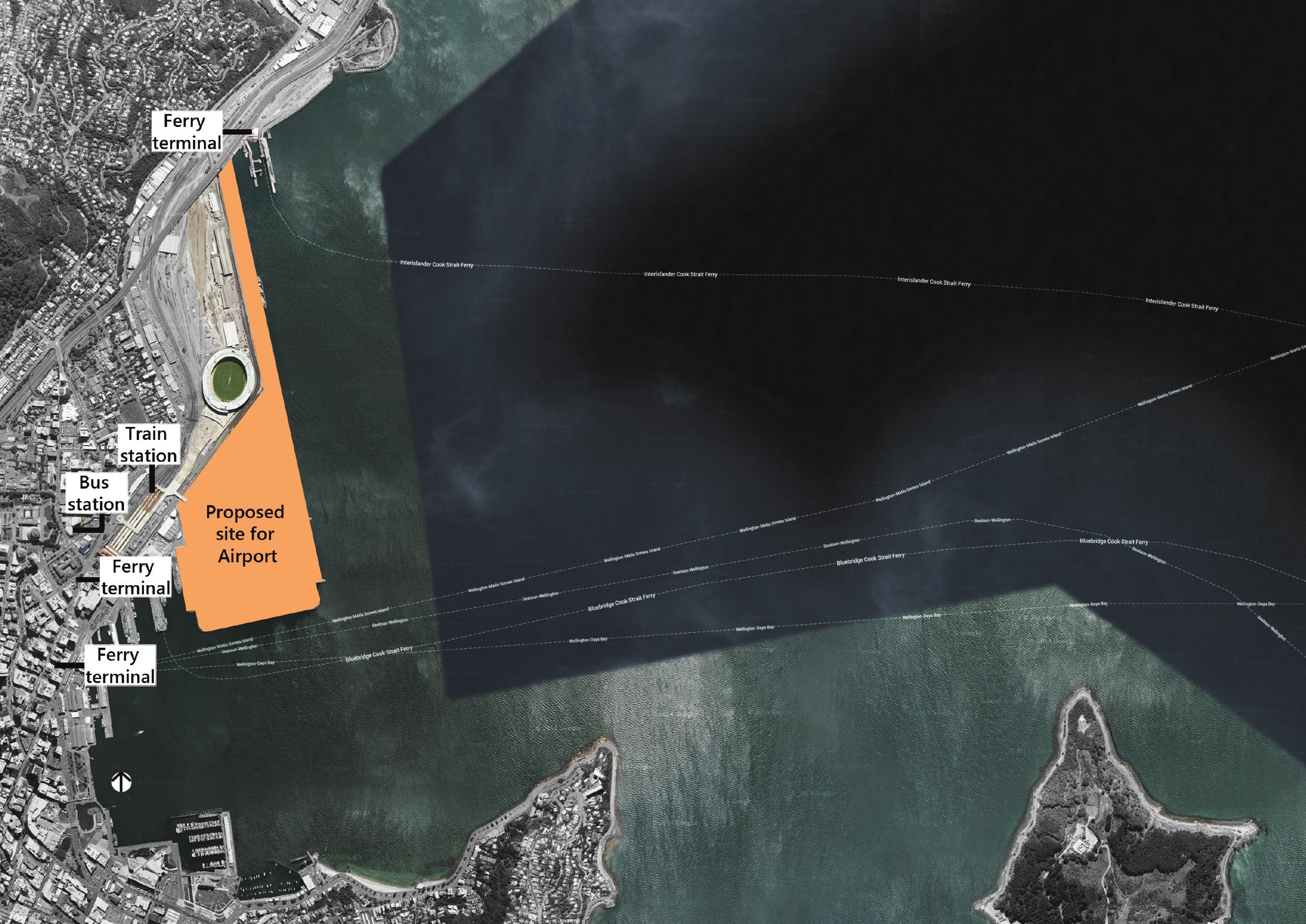




\section{SITE - WELLINGTON HARBOUR}

When considering a site for the transport hub, a major factor that needed to be addressed was the length of the runway, its orientation and whether or not the site could accommodate all three different transport modes. The orientation of the runway is determined by the prevailing wind direction in the area ${ }^{72}$ which means that for Wellington the runway must run in the north to south direction. In order to maximise movement of both people and transport in and out of the hub, a central Wellington City site was preferred over the existing Wellington Airport site. The initial proposed site was next to the existing train station near the Wellington Harbour.

Figure 4.49 shows the site analysis and the placement of the runway at different sizes and points along the site as part of preliminary research. As the runway needed to be $3 \mathrm{~km}$ (minimum) in length to accommodate jumbo jets to land ${ }^{73}$ at Wellington Airport, it was evident that the best location for the runway would be out near
Ngauranga with the terminal building remaining at the site next to the existing train station. Initial design tests were completed with this terminal and runway separation on the site which proved that having the two separated would not work in terms of efficiency. The size of the building was much larger than what was required and the distance between the terminal and the runway was too far for users to walk. Therefore in later design tests the location of the transport hub was moved to where the runway was situated (Ngauranga). This meant that all movement paths and transport nodes could be centralised within the one building.
72 Civil Aviation Authority, "Advisory Circular AC139-6: Aerodrome Design Requirements, (2011): 27.

73 Ibid., 28 


\section{RUNWAY SIZES AND CONFIGURATION OPTIONS ON SITE}

OPTION 1:

CURRENT WELLINGTON AIRPORT RUNWAY

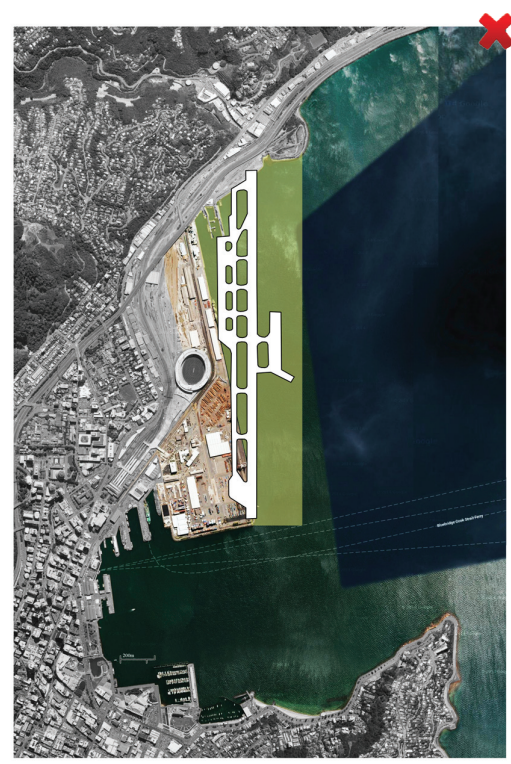

Possible land area needing to be reclaimed

IL

- Runway length does not disrupt the path of the ferries

- Small area of land needing to be reclaimed to accommodate runway

\section{2. negatives}

- Runway too short for large aircrafts to land and take-off on
OPTION 2:

CURRENT CHRISTCHURCH AIRPORT RUNWAY

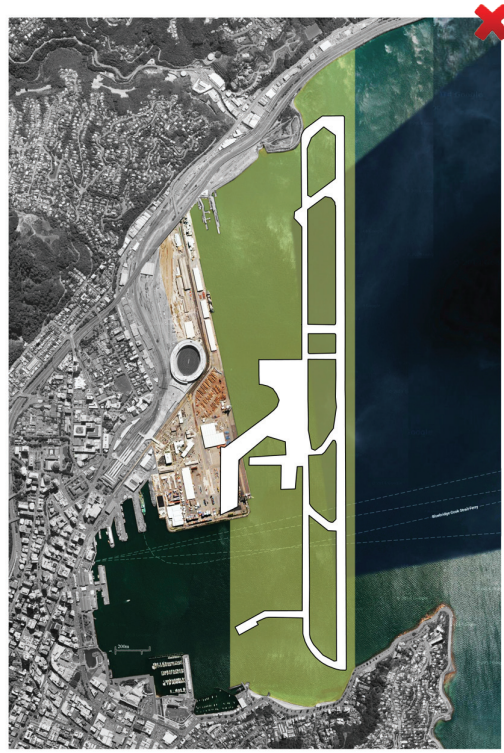

Possible land area needing to be reclaimed

בֵ POSITIVES

- Long runway allows for larger aircrafts to land'

4 NeGATIVES

- Large area of land needs to be reclaimed in order to build runway

- Ferry terminals have to be moved as the runway will block the usual route of ferries entering Wellington

References:

1. Civil Aviation Authority, "Advisory Circular AC139-6: Aerodrome Design Requirements," (2011): 28.

2. "Strange Airport: Gilbraltar, World's Only Airport Runway Intersecting a Road," Amusing Planet, accessed August 22, 2014

http://www.amusingplanet.com/2011/11/gibraltar-airport-worlds-only-airport.html.

3. "Madeira Airport - An Award Winning Structure," Interesting Engineering, accessed August 22, 2014

http://interestingengineering.com/madeira-airport-an-award-winning-structure//

4. Brian Edwards, The Modern Airport Terminal: New Approaches to Airport Architecture 2nd ed (New York: Spon Press, 2005). for image sources.

Figure 4.49 Analysis of runway size and configuration on site.

OPTION 3:

3.1km RUNWAY GOING THROUGH STATE HIGHWAY 1

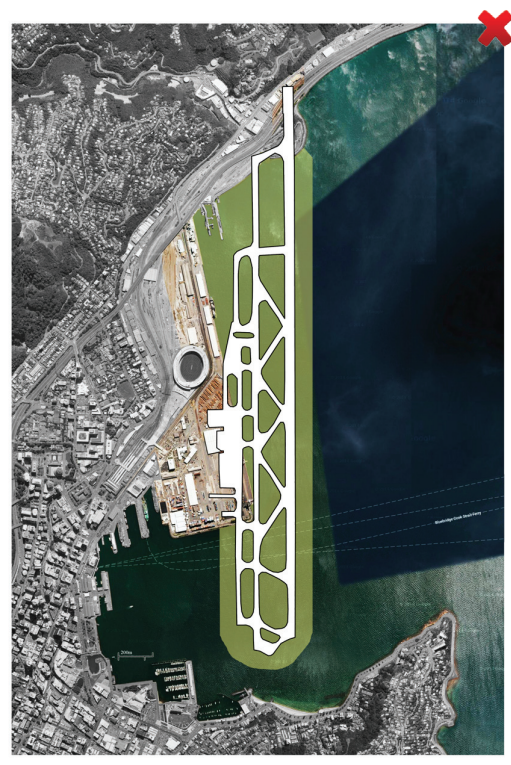

Possible land area needing to be reclaimed

๕ POSITIVES

- Runway length allows for a B747 to land

- Moderate area of land needing to be reclaimed to build runway on

\section{NEGATIVES}

- Ferry terminals have to be moved as the runway will block the usual route of ferries entering Wellington

- Disruption to traffic along SH1 as the cars will have to

stop every time an aircraft is needing to take-off or land $\mathrm{d}^{2}$

PRECEDENTS

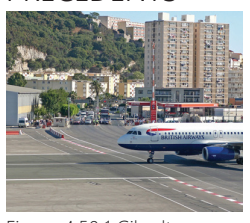

Figure 4.50 .1 Gibraltar

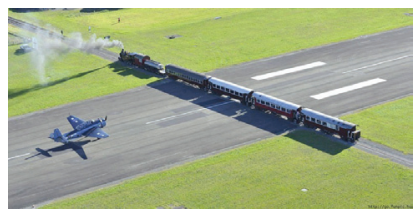

OPTION 4

3.1 km RUNWAY ON BRIDGE OVER STATE HIGHWAY 1

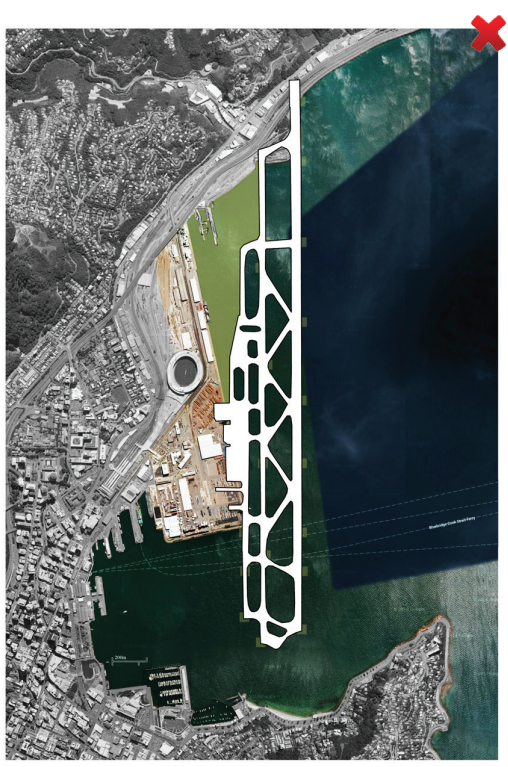

Possible land area needing to be reclaimed

๕ POSITIVES

- Runway length allows for a B747 to land

- Small area of land needing to be reclaimed

- Cars can travel along SH1 without any disruption

from aircrafts trying to take-off or land ${ }^{3}$

- Ferries are still able to follow their usual route

under the bridge (maybe minor diversion needed)

7 negatives

- Will have to reclaim land or do extensive excavation to build the columns to support the bridge

PRECEDENTS
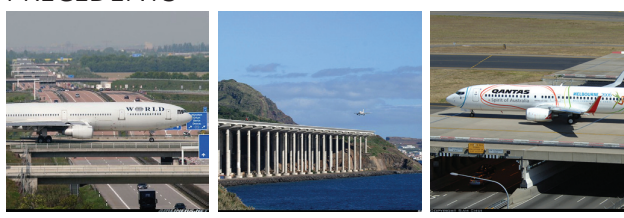


\section{OPTION 5:}

3.1km RUNWAY AT NGAURANGA INTERSECTION

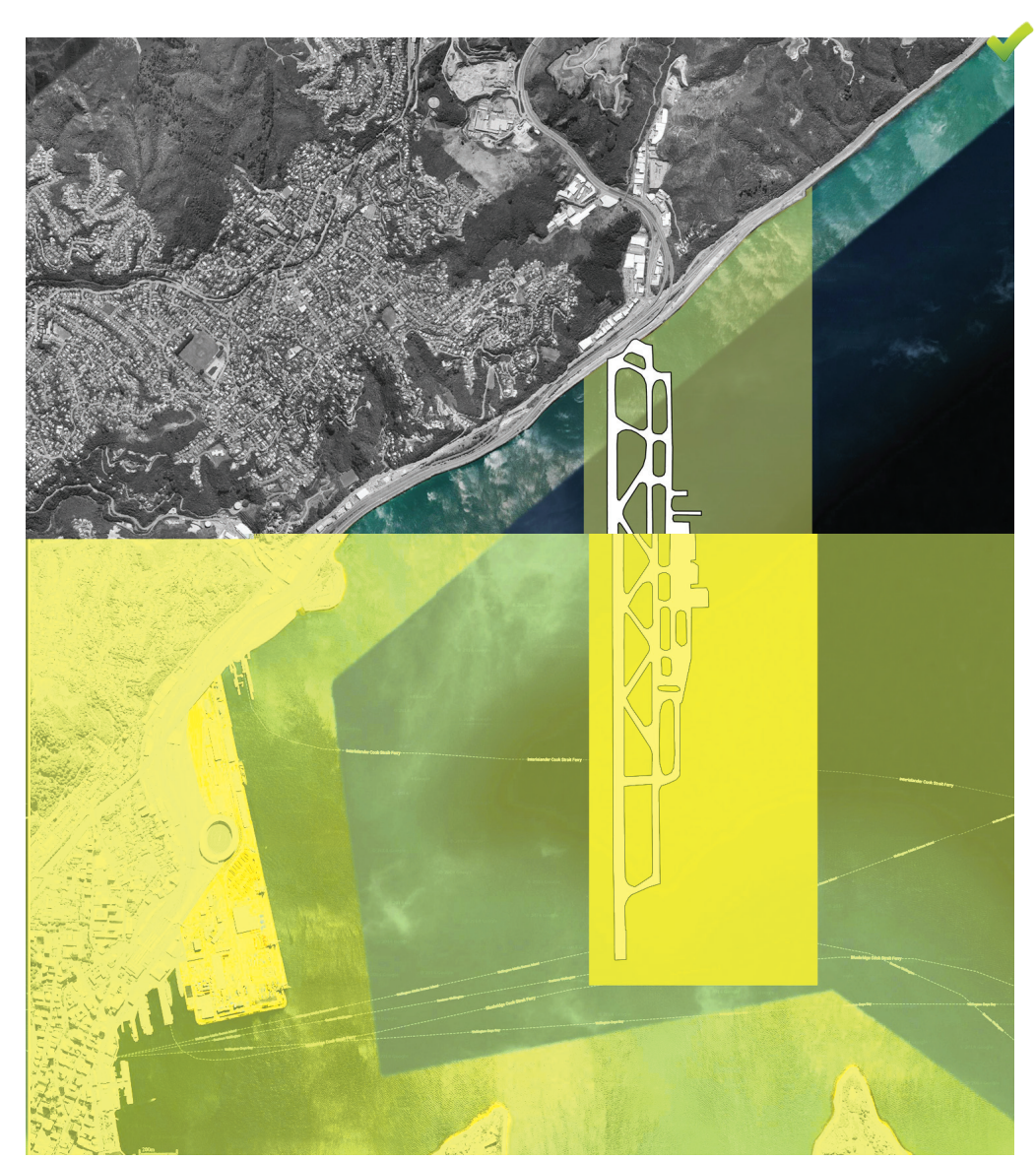

Possible land area needing to be reclaimed

IL

- Runway length allows for a B747 to land'

- Runway does not take up the entire harbour and block of all views

- Located where SH1 connects with SH2 - makes travel for domestic

passengers much easier

- Distance between terminal and runway not too far - travel between two will be faster

\section{NeGATIVES}

- Terminal building and runway separated

- Train/bus has to be set up between runway area and terminal to transport passengers between the two ${ }^{4}$

- Runway runs through the usual routes of the ferry services - they will have to be moved

\section{OPTION 6:}

3.1km RUNWAY AT LOWER HUTT/PETONE INTERSECTION

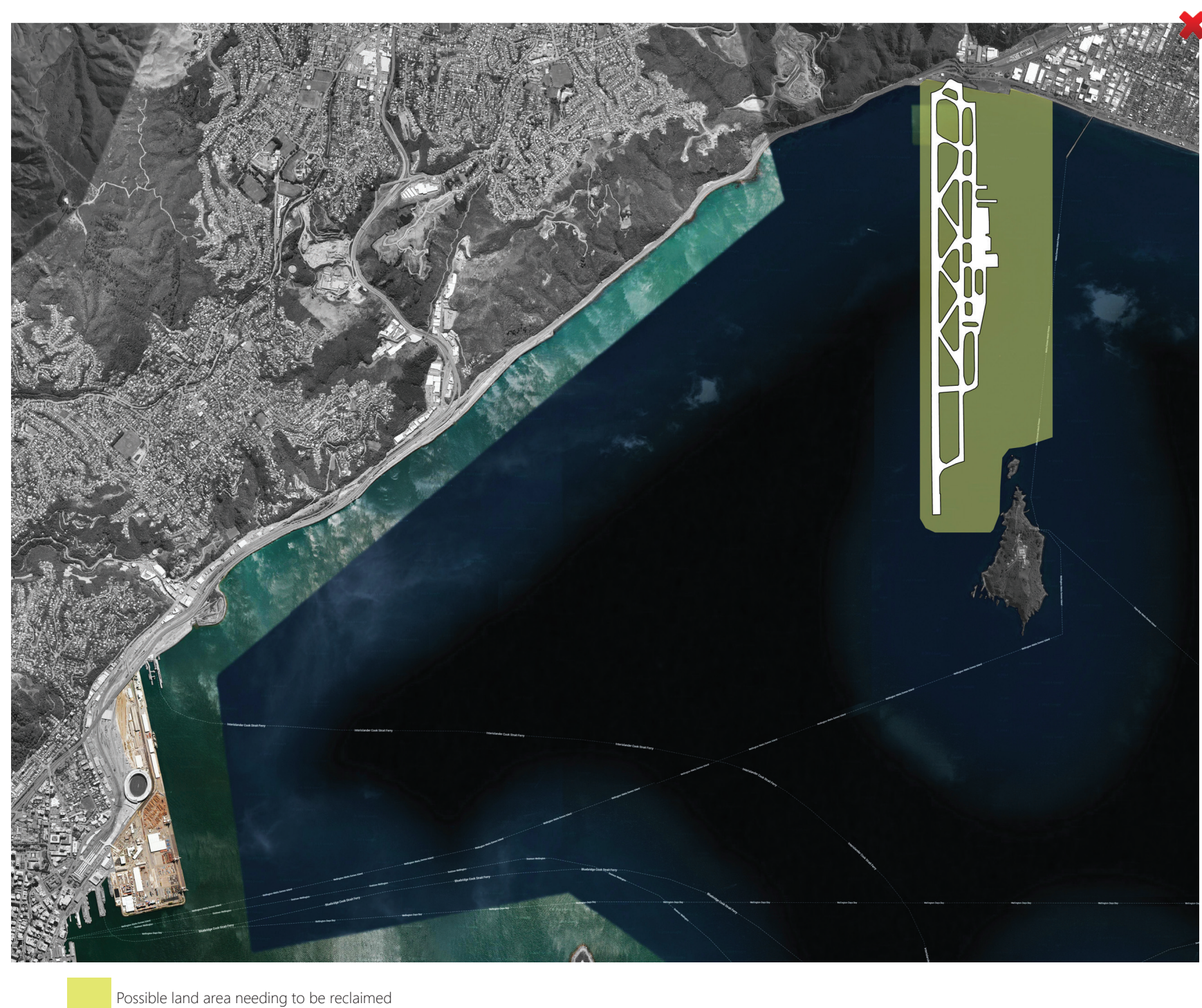

\section{ב}

- Runway length allows for a B747 to land ${ }^{1}$

- Ferries are still able to follow their usual route

with no disruption from runway

- Connects Wellington City with Lower Hutt and Petone

\section{NEGATIVES}

- Terminal building and runway separated

- Long distance between terminal building and

runway - travel time too long with traffic

- Train/bus/ferry service has to be set up between

runway area and terminal to transport passengers between the two ${ }^{4}$ 


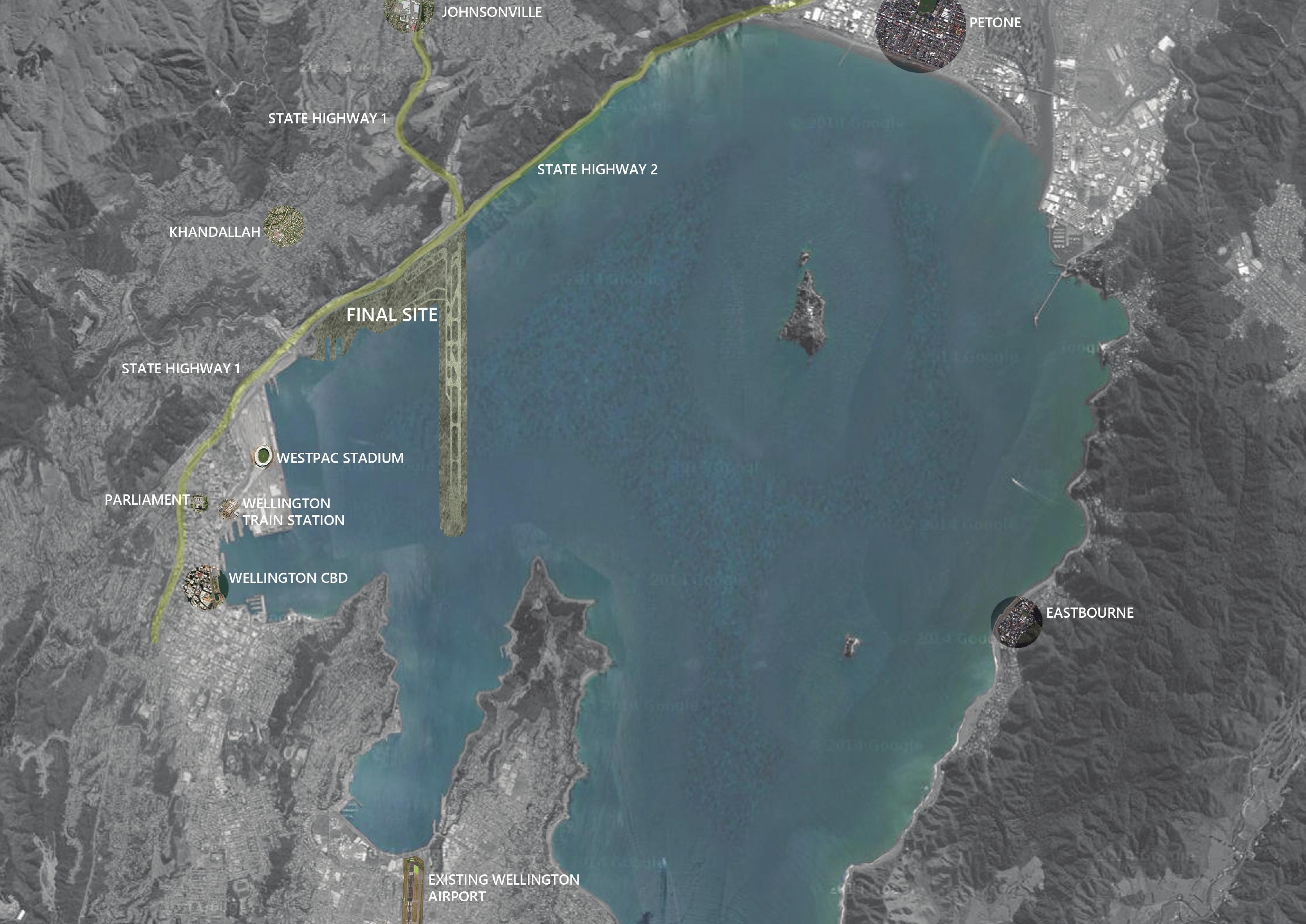




\section{DESIGN INVESTIGATION}

\section{FINAL SITE - NGAURANGA}

As the transport hub was speculative in design, a provocative site was chosen as the final site to address the design proposition. This site was valued over a practical site such as the current location of the airport, as existing movement paths in the area could be used and enhanced through the design.

\section{DESIGN TEST 1 - PLANNING STUDIES}

Initially two planning options along the site were explored. The planning studies enabled an understanding of how the different space requirements could be arranged on the site to connect people from the city through the terminal building and into the runway area. The spaces that needed to be placed in certain areas or next to another space was determined through this exercise. Completing the planning studies provided a functional option as to how the transport hub could be designed but did not address the proposition of creating an experience of movement for the user. 
Planning Study 1 - Combined International and Domestic

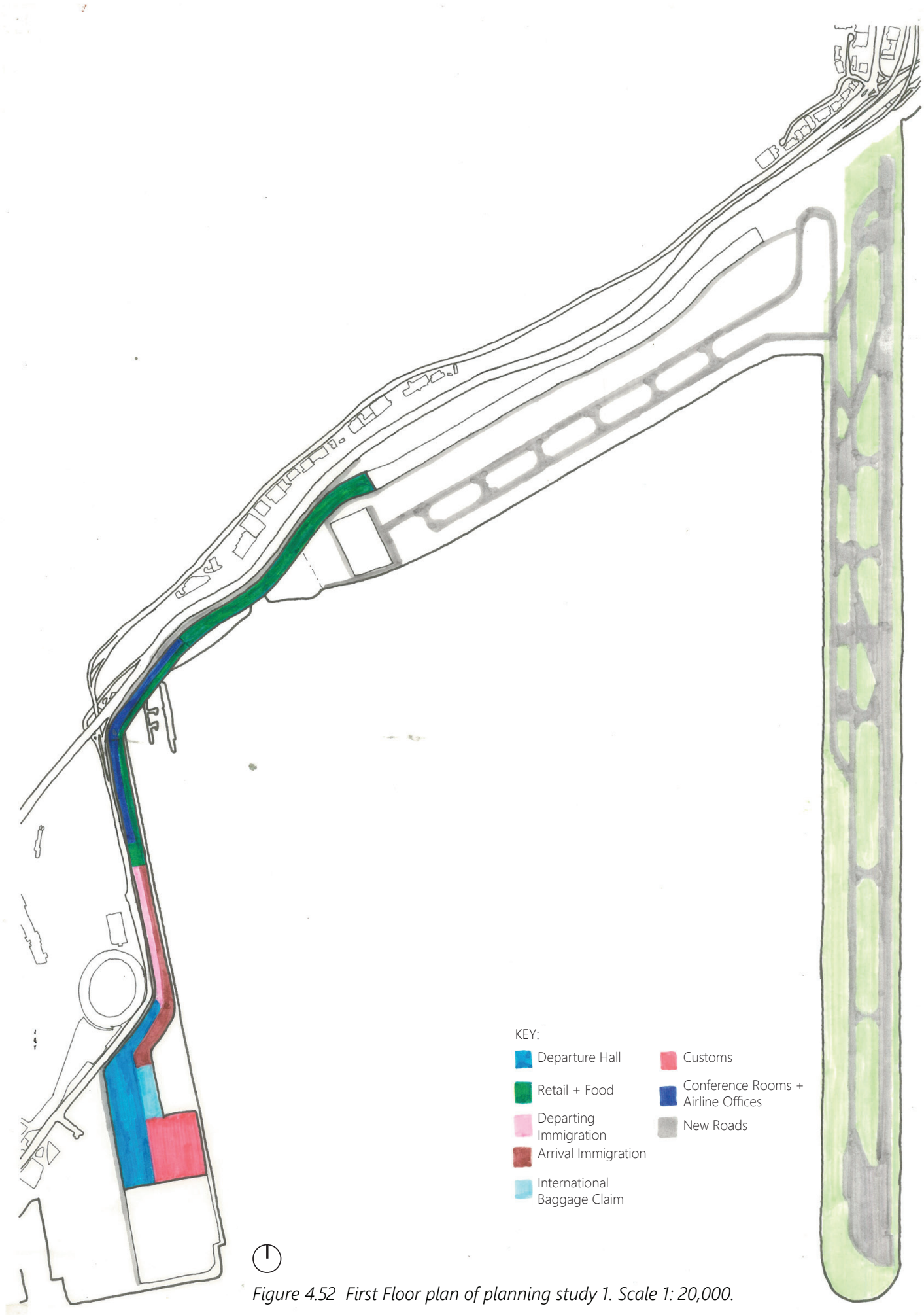




\section{DIAGRAMMING MOVEMENT}

An intermediary stage in the design process was an analysis of the movement patterns based on the planning studies. In order to understand how the movement of people and transport could occur throughout the site, movement diagrams of both transport and users were drawn and analysed. The diagrams were able to highlight all the different movement paths that would be activated within the transport hub. These diagrams would form the basis for the following two design tests as they showed areas where separation needed to happen and areas where the three transport nodes could be linked. 


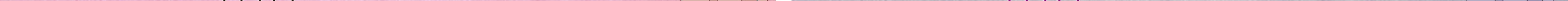




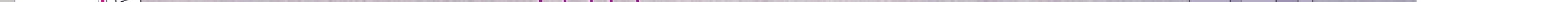


TRAIN - DEPARTURES

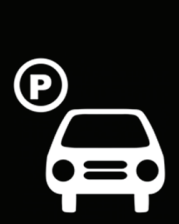

PARKING

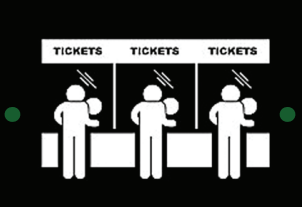

TICKET PURCHASE

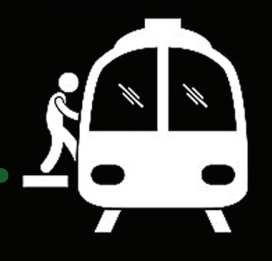

DEPARTURES
TRAIN - ARRIVALS

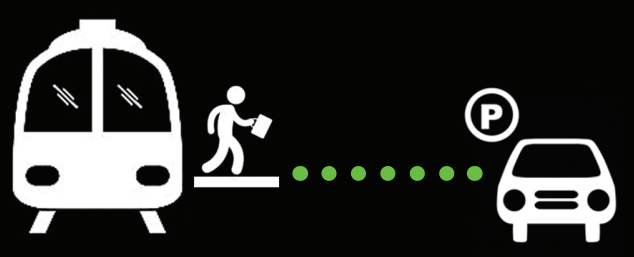

ARRIVALS
FERRY - DEPARTURES

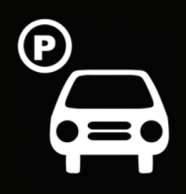

PARKING

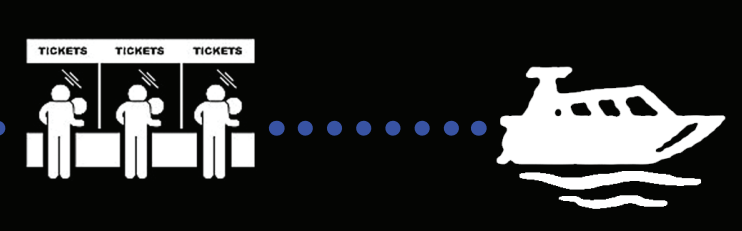

DEPARTURES
FERRY - ARRIVALS

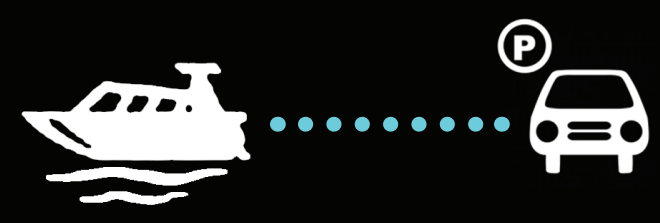

ARRIVALS

PARKING

AIRPORT - DEPARTURES

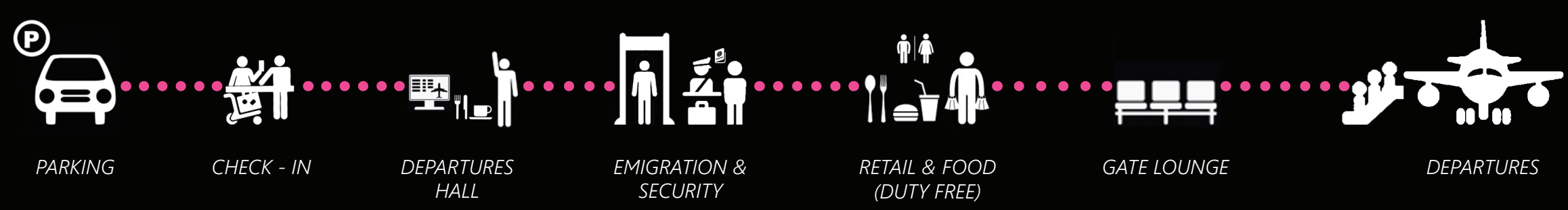

AIRPORT - ARRIVALS

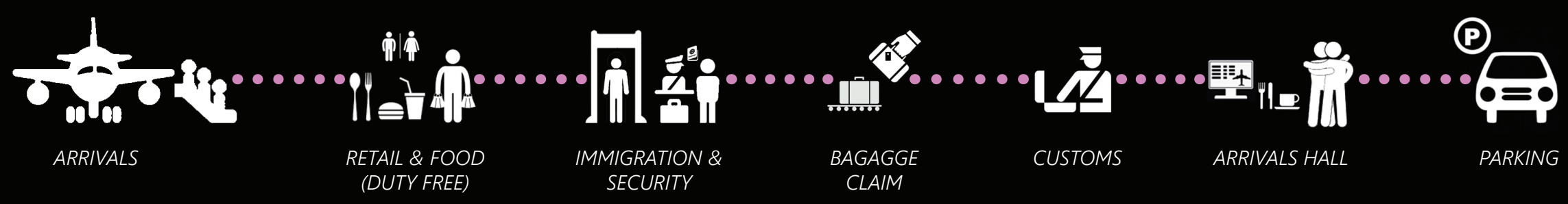




\section{Vertical Shuffle - Test 1:}

- Parking on top floor.

- Ferry terminal and train station on ground floor.

- Departing areas on top floor.

- Arrival areas and gate lounges on second floor.

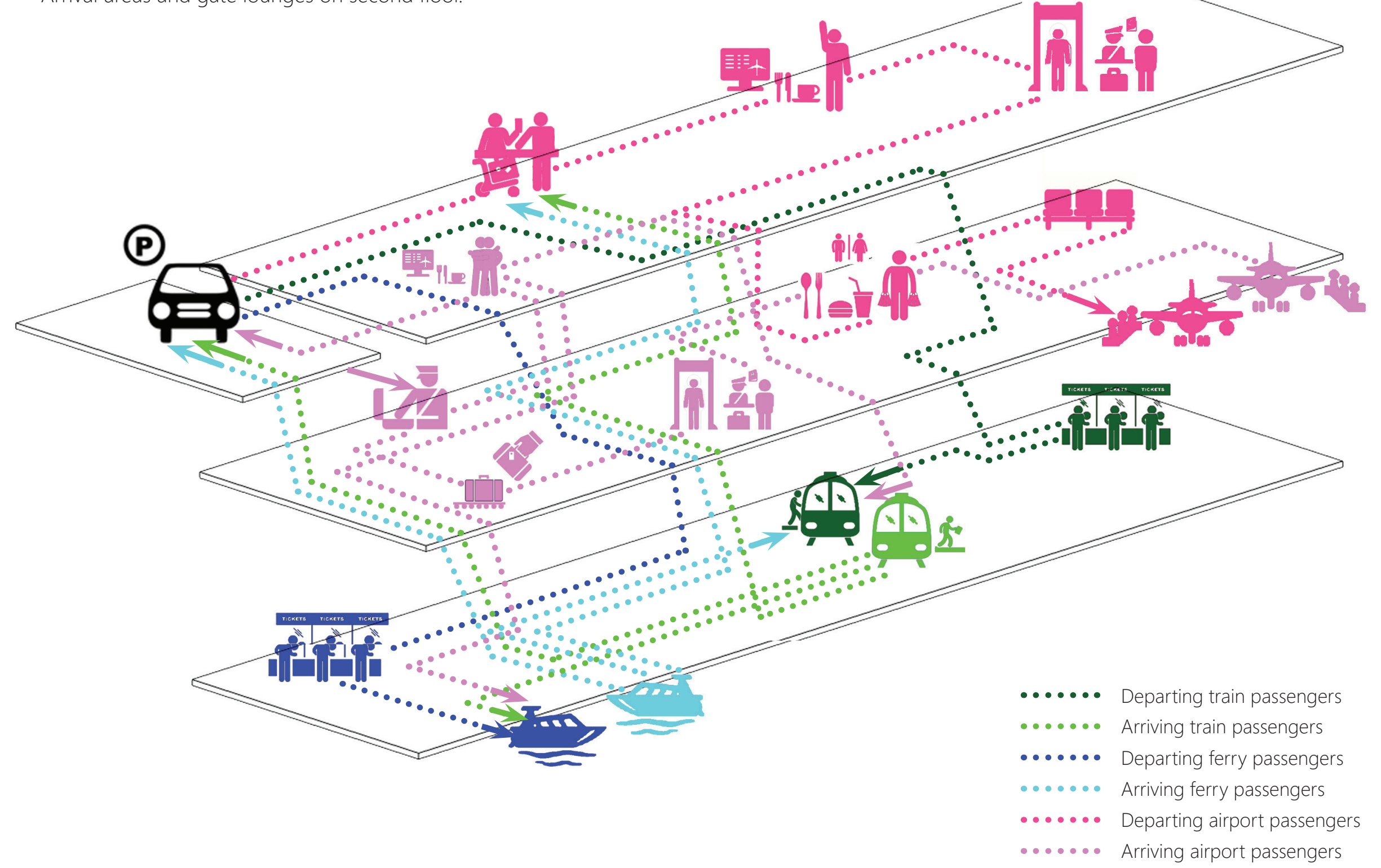




\section{Vertical Shuffle - Test 2:}

- Parking on all floors.

- Ferry terminal and train station on ground floor.

- Departing areas on top floor.

- Arrival areas and gate lounges on second floor.

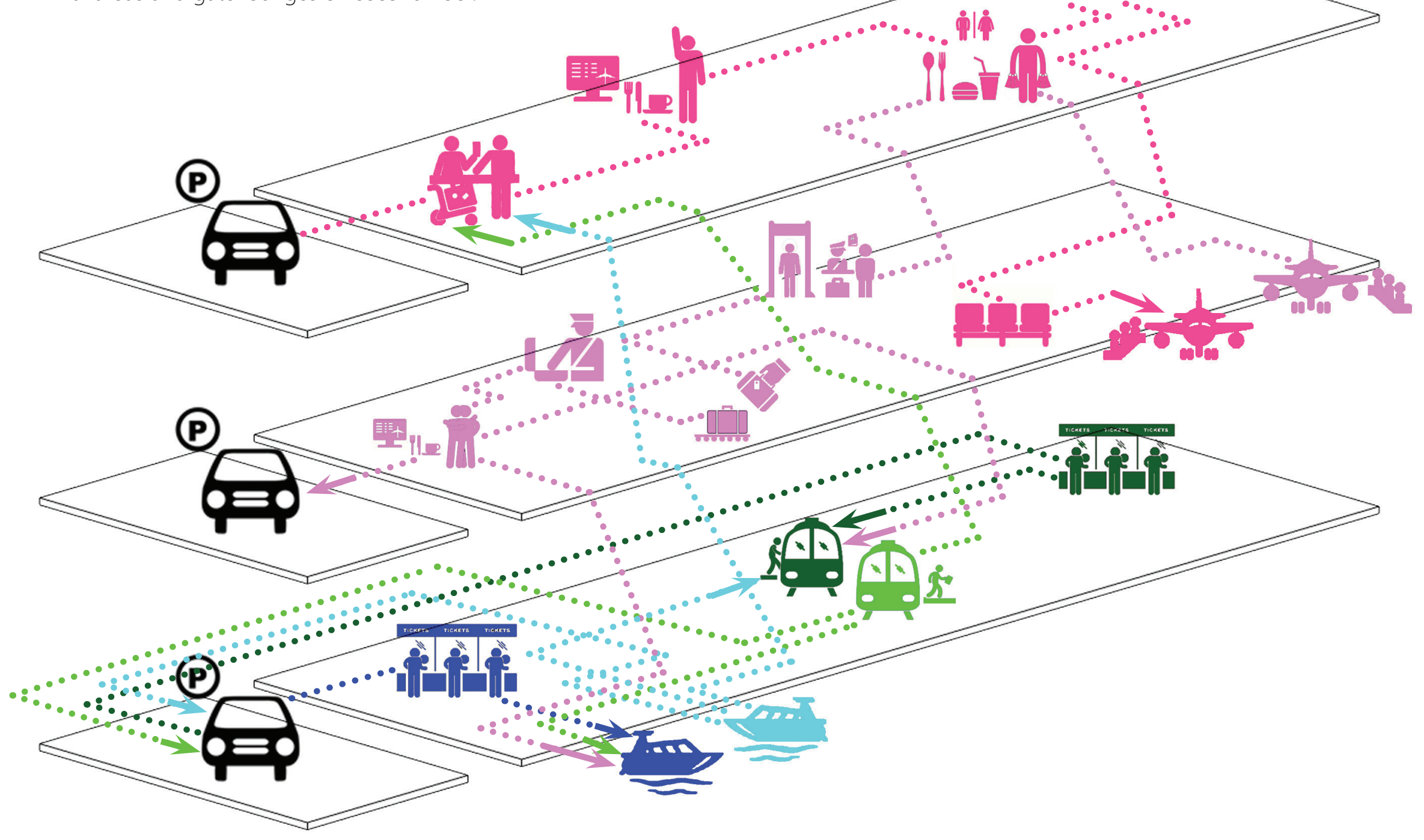




\section{Vertical Shuffle - Test 3:}

- Parking on ground floor area.

- All check in and ticket areas, ferry terminal and train station located on ground floor.

- Departing areas on top floor.

- Arrival areas and gate lounges on second floor.

This test was chosen to design from as it provided a centralised check in area with visibility to all three transport types.

$$
\text { second floor. }
$$
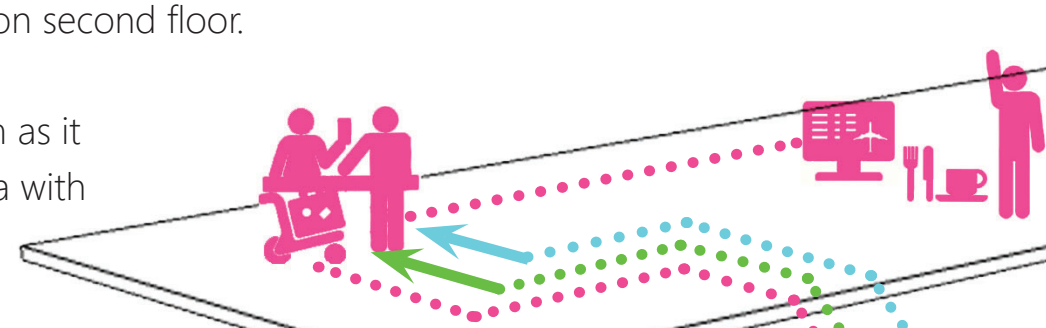

………
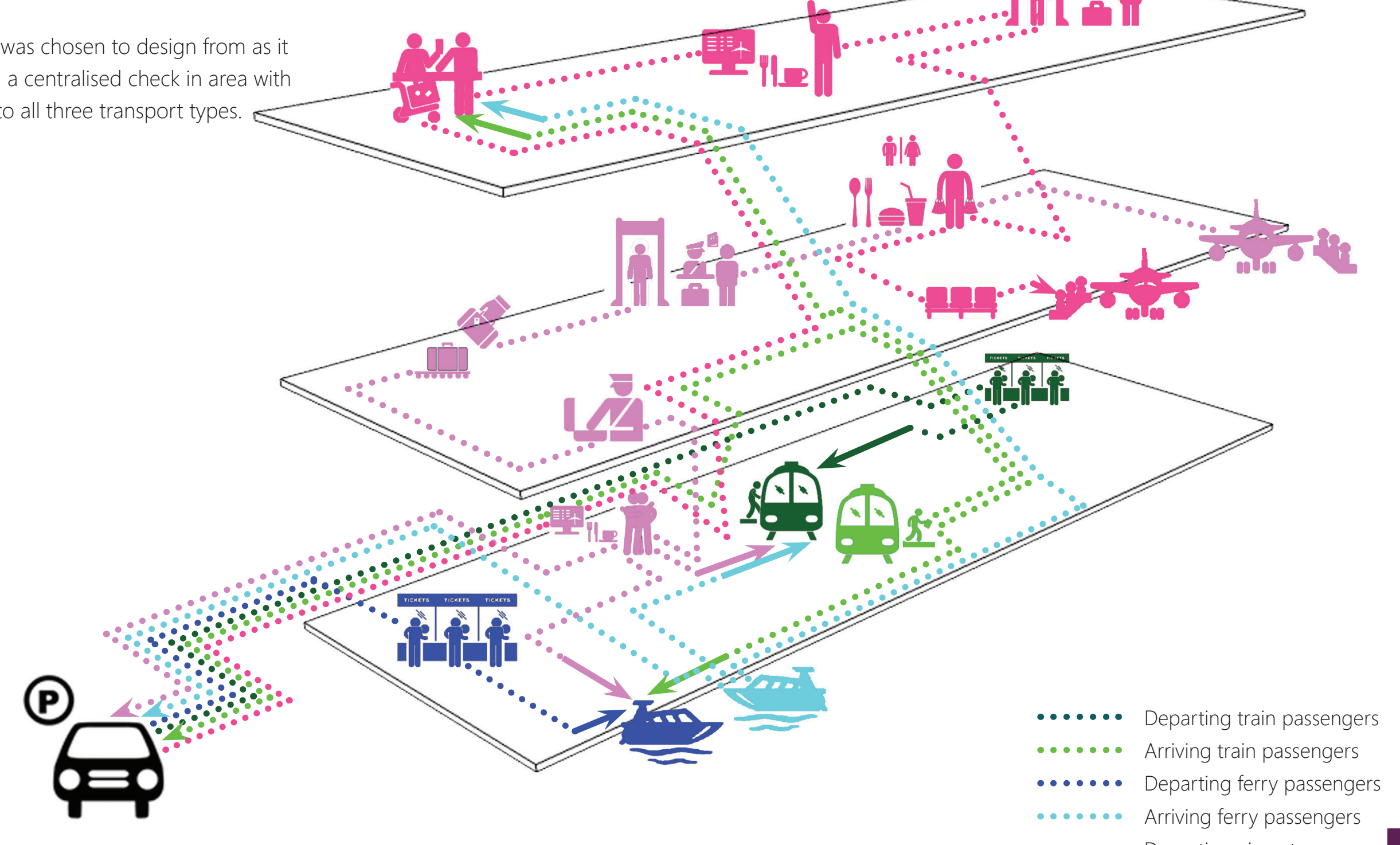


\section{Vertical Shuffle - Test 4}

- Parking on ground and second floor.

- Ferry terminal and train station on ground floor.

- Check in and ticket areas for all three transport types on second floor.

- Departing areas on top floor.

- Arrival areas and gate lounges on second floor.

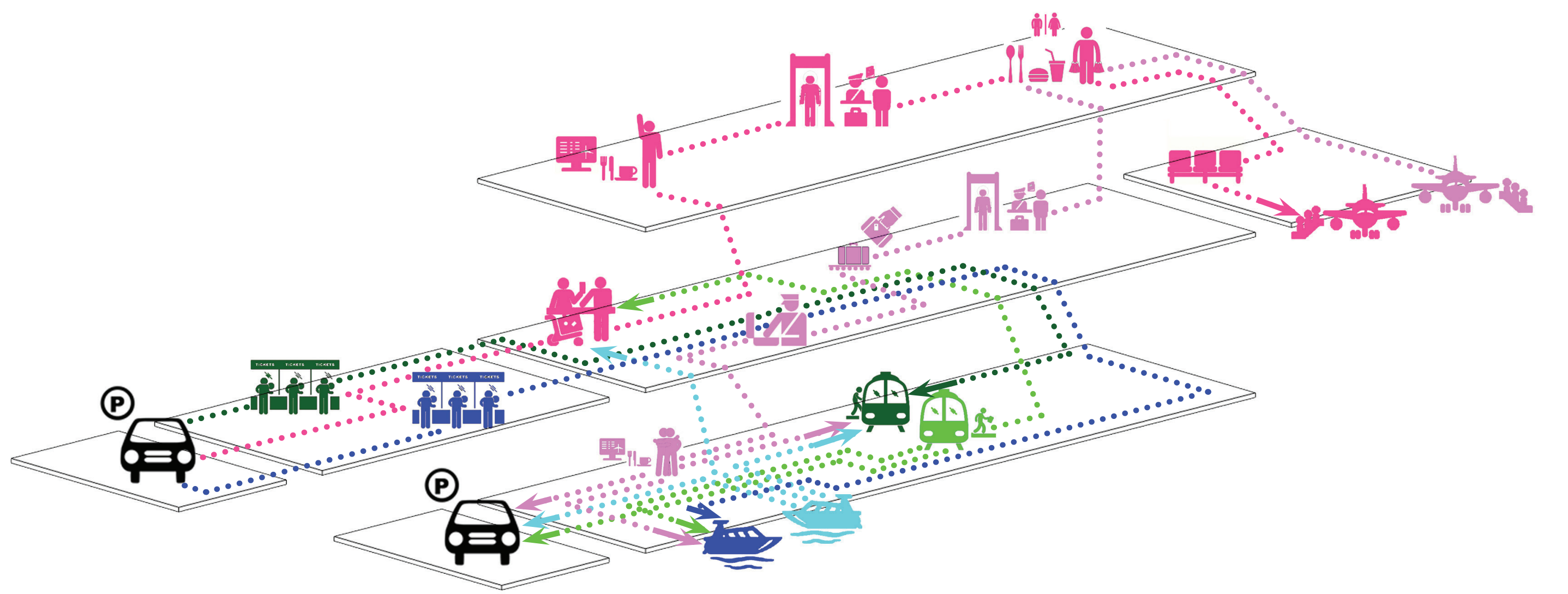

Departing train passengers

$\ldots . .$. Arriving train passengers

...... Departing ferry passengers

$\ldots \ldots$ Arriving ferry passengers

..... Departing airport passengers

..... Arriving airport passengers 


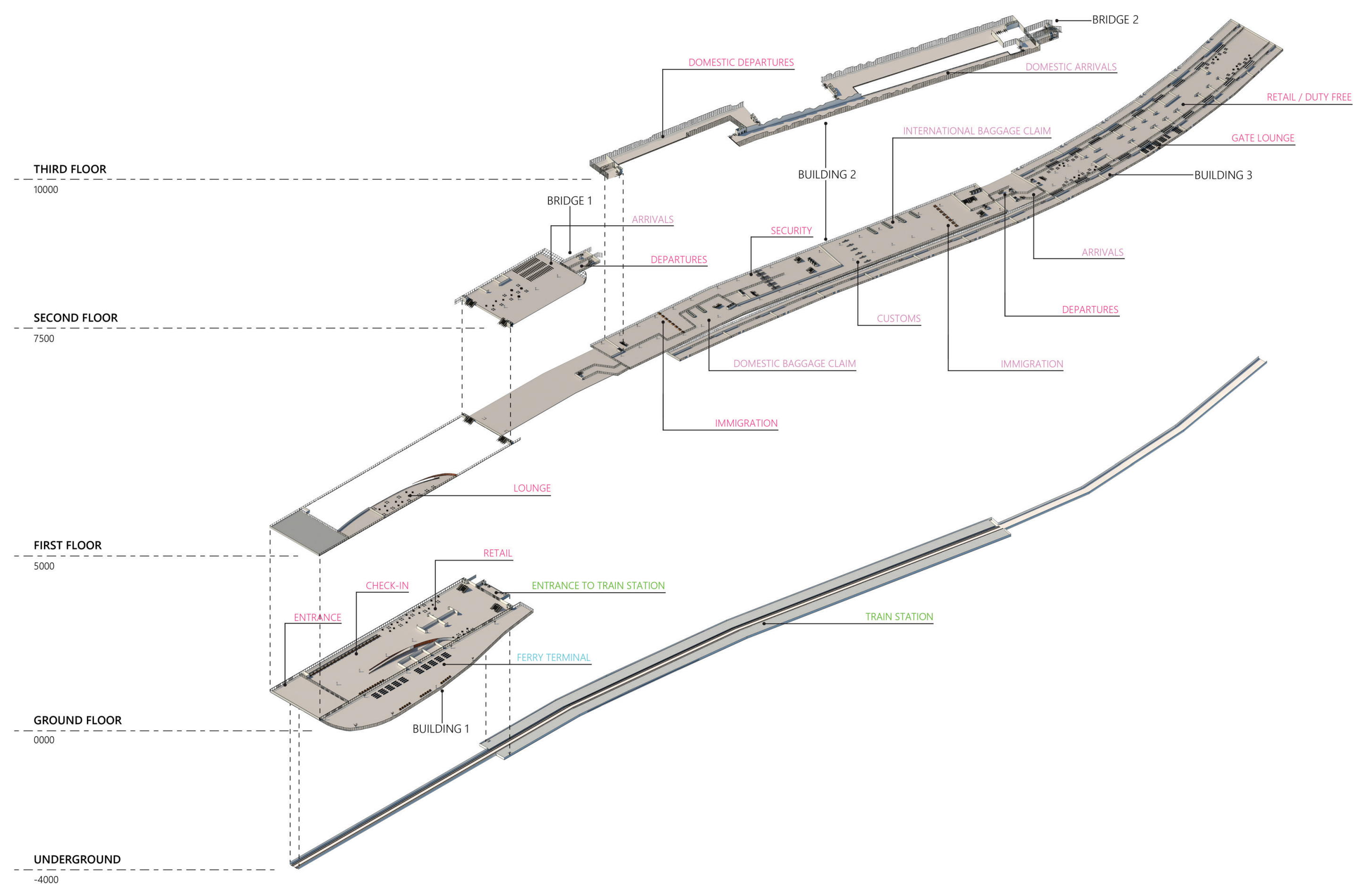


Movement in the interior of the building has been created through the use of different levels which force people to move up and down whilst they travel through the hub. The different levels also allow users to see the movement of other people inside the transport hub (see figure 4.71). Inside the processing building visual links to all the different spaces have been created and these spaces have been interlinked with one another so that passengers can understand the path they must travel (see figure 4.72). The bridges that connect the buildings together have been separated into arriving and departing passengers. The two bridges are overlapped and interconnected with one another so that as people move through the building they are constantly connected to the movement of the people inside the terminal and the transport movement outside.

This transport hub design was effective in creating a sense of movement through the building in some areas. Focusing on the exterior form of the building enabled part of the proposition to be explored. However as not all of the spaces were designed, the spatial experiences within the interior could not be created. The form alone was not enough to allow users to understand the different movement paths within the building.
BUILDING 1

BRIDGE 1

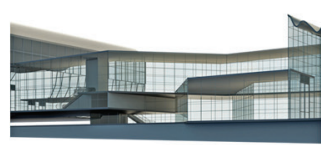

Arrivals and Departures
BUILDING 2

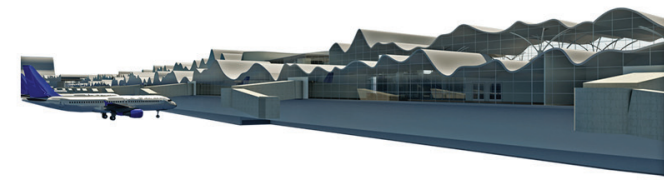

Processing
BRIDGE 2

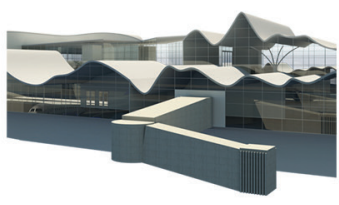

BUILDING 3

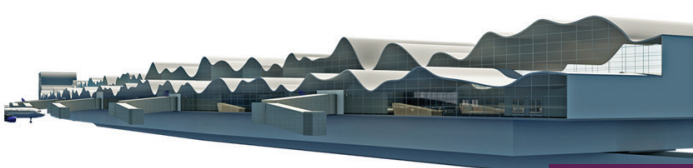

Gate Lounges and Duty Free
119 

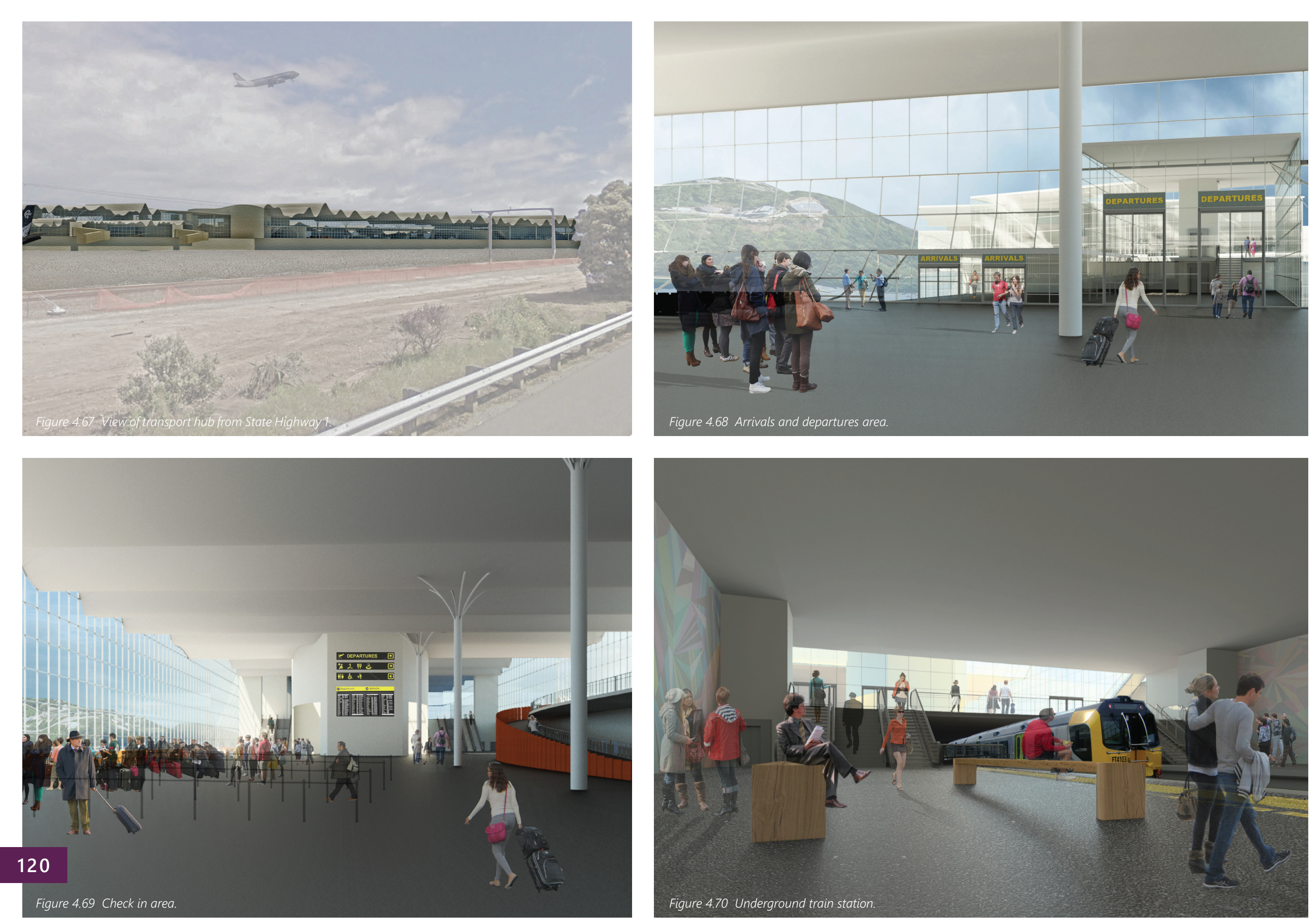


\section{FINAL DESIGN - FOCUS ON KEY AREAS}

The final design for the transport hub focused on the form of the building and three key interior spaces to gain an understanding of how contained movement can be created within the building. This movement between form and interior development meant that the proposition could be more clearly tested to understand how movement can be used overall to engage the body with architecture. The three key areas for interior exploration were the entry foyer, train station and vertical bridge area and gate lounge. As a starting point for the design, diagrammatic models were completed that mapped the different passenger paths along the site. The paths were overlapped and connected at different points along the site. These paths were then extruded up to create a basic form. Once a form had been created, interior spaces were able to be designed which altered the overall exterior form. 

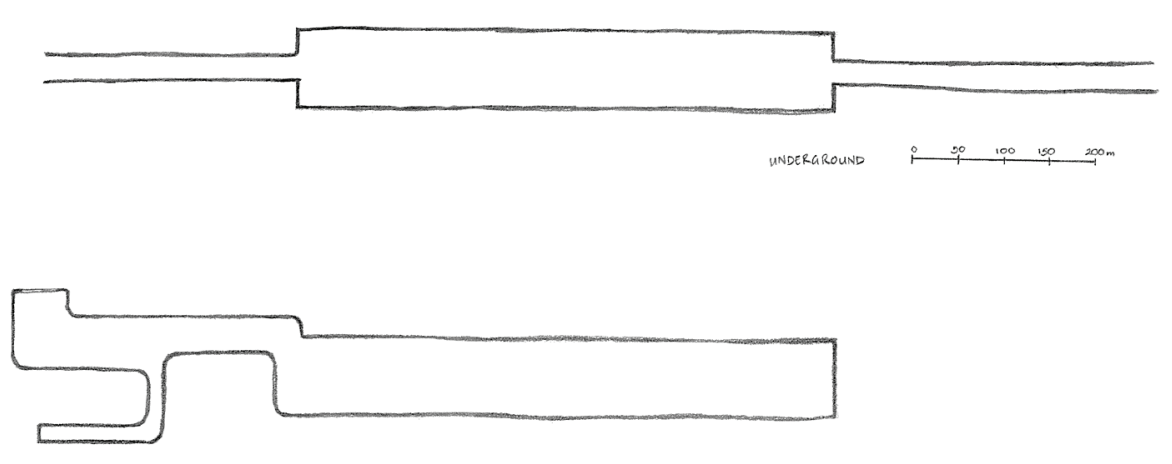

GCound

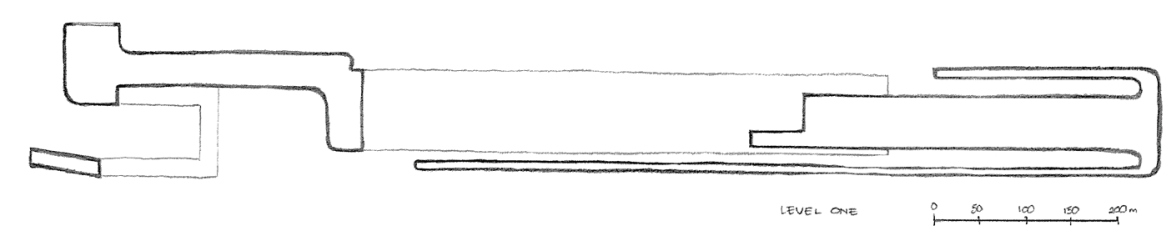

我

$\sqrt{\square}$

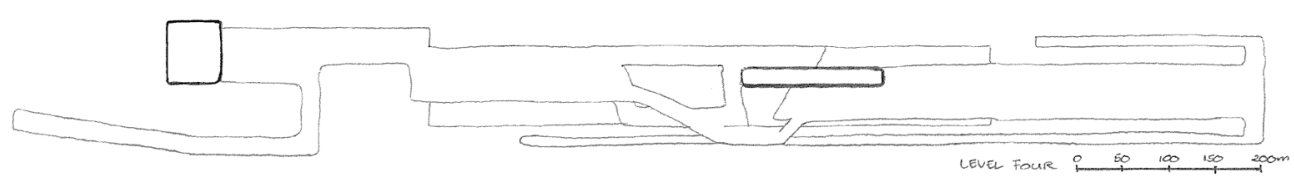

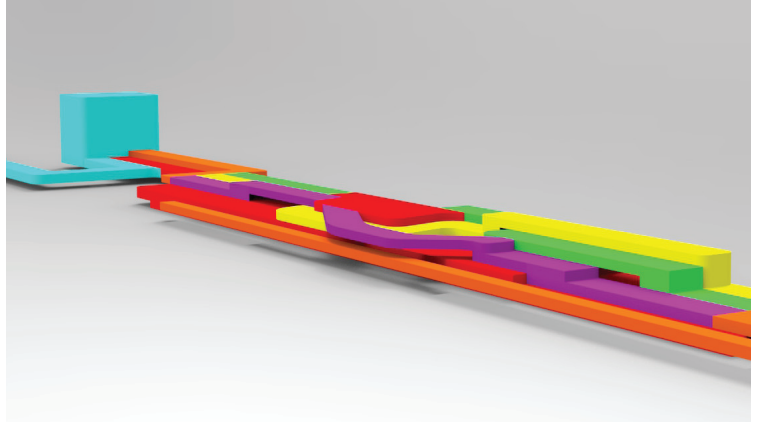
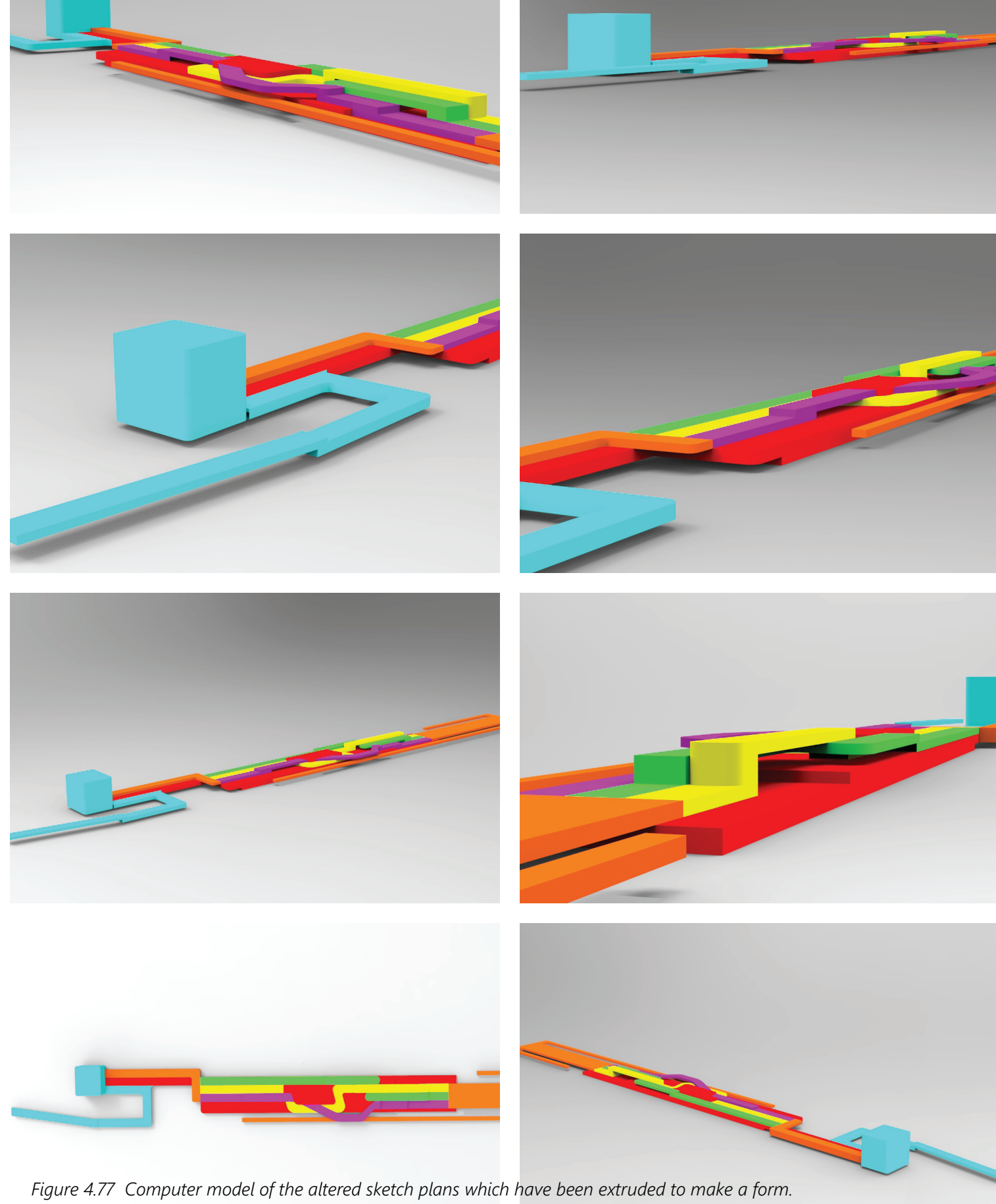



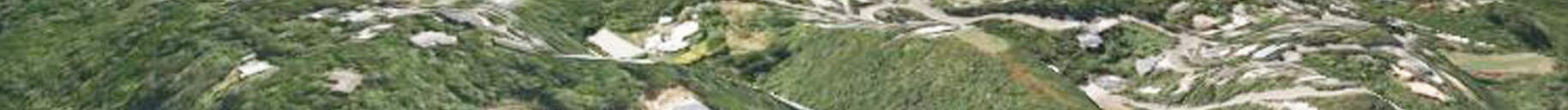

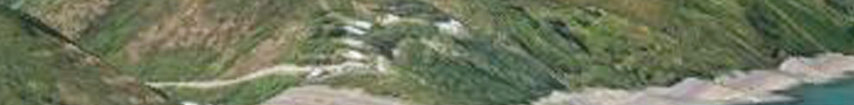

rarar

( 12

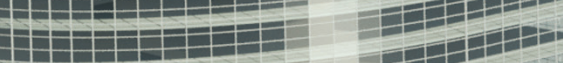

H

H 1 1 1 2 1

H

H

$3+2=$

(1)

\begin{tabular}{lll}
1 & \\
\hline
\end{tabular}

(1) 111)

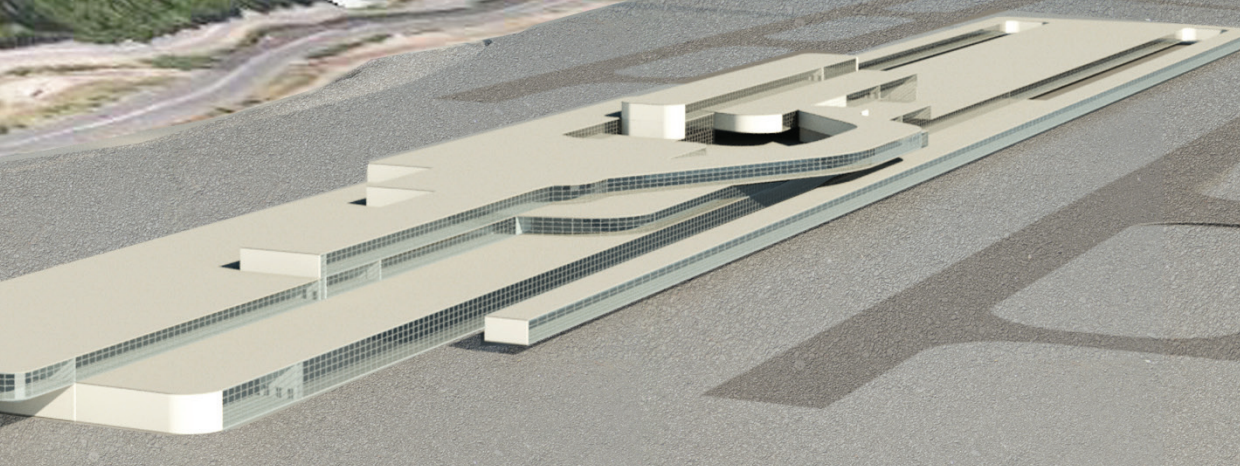

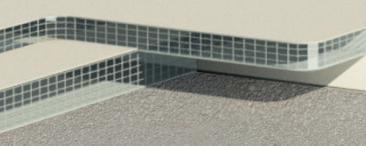
2 -

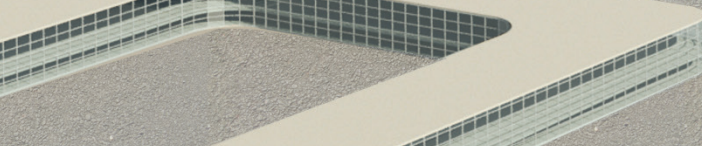




\section{EXTERIOR FORM}

The exterior form of the building highlights the different levels of the building and the areas in which these levels overlap or connect with one another. When a user is approaching the building from the highway or along the runway, they are able to understand the way in which their body may move through the building. They can perceive their bodily movement in the form of the transport hub. ${ }^{74}$ Also with the shifting configurations of the levels the user's eyes are drawn along the varying forms allowing them to read the movement in the building. ${ }^{75}$

The plans on the following page are scaled at 1:2500. They act as diagrammatic plans which depict the arrangement of the different spaces in the transport hub. 


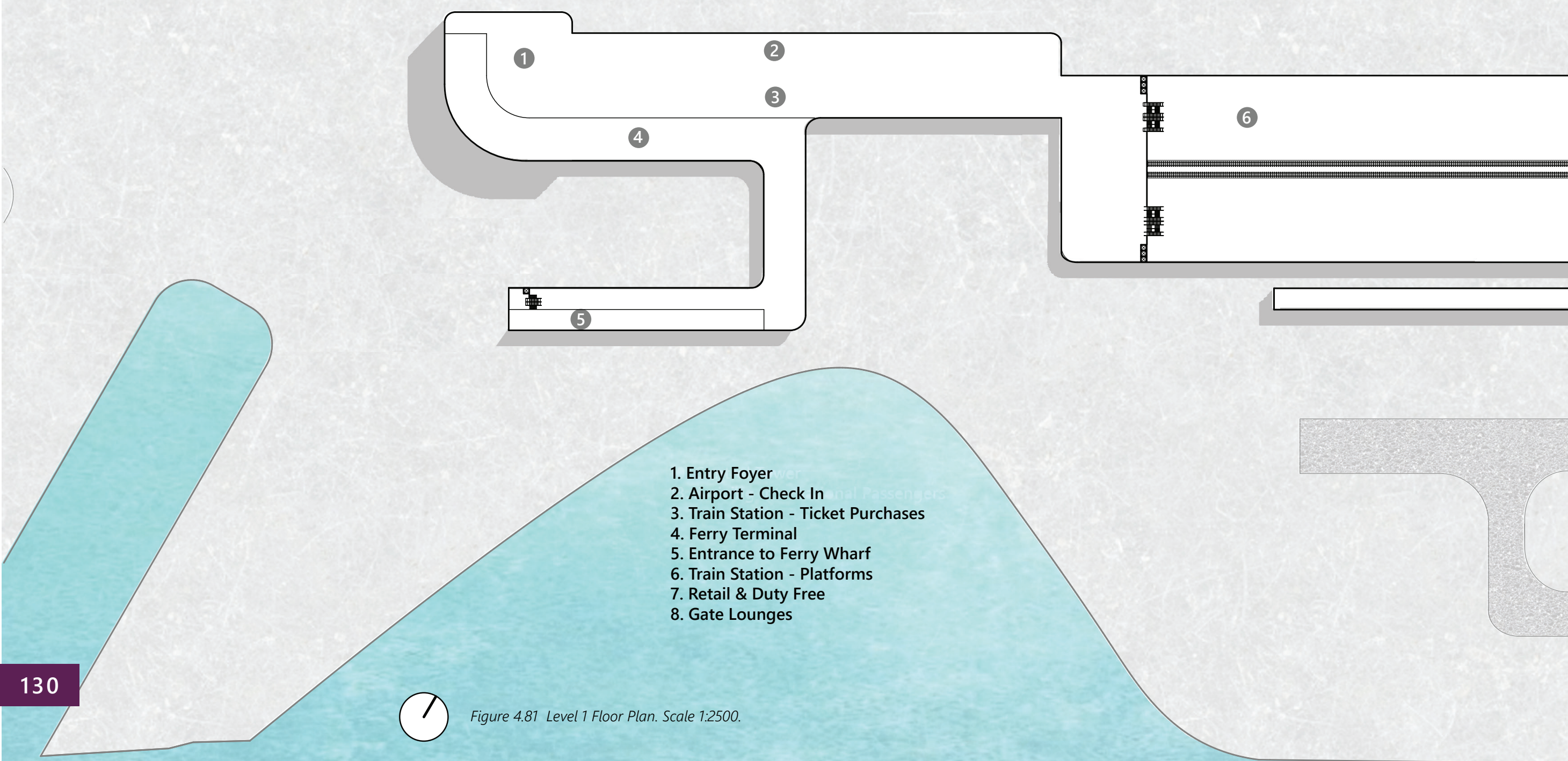

\section{Entry Foyer}

2. Airport - Check In

3. Train Station - Ticket Purchases

4. Ferry Terminal

5. Entrance to Ferry Wharf

6. Train Station - Platforms

7. Retail \& Duty Free

8. Gate Lounges

(1) Figure 4.81 Level 1 Floor Plan. Scale 1:2500. 


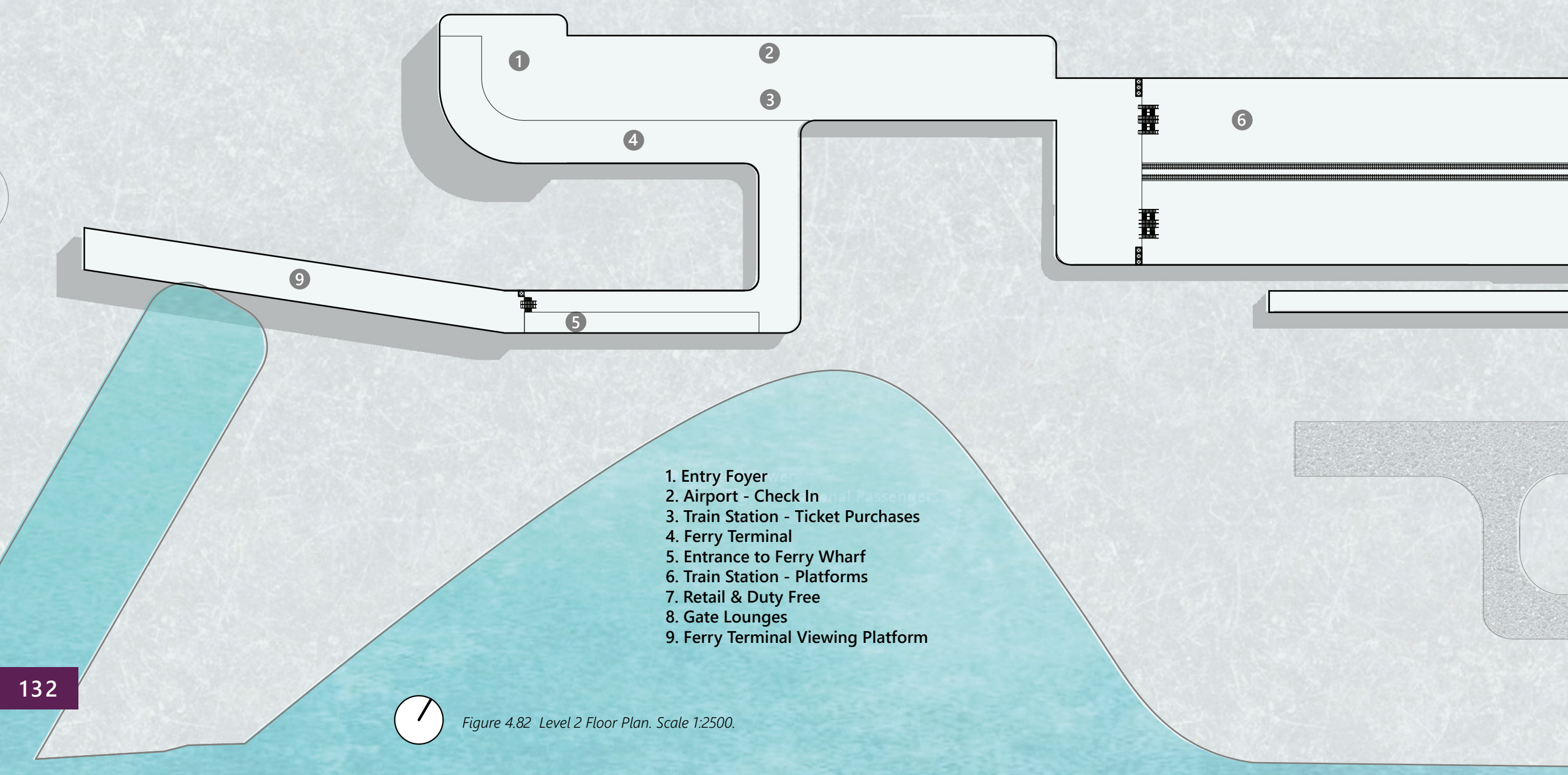




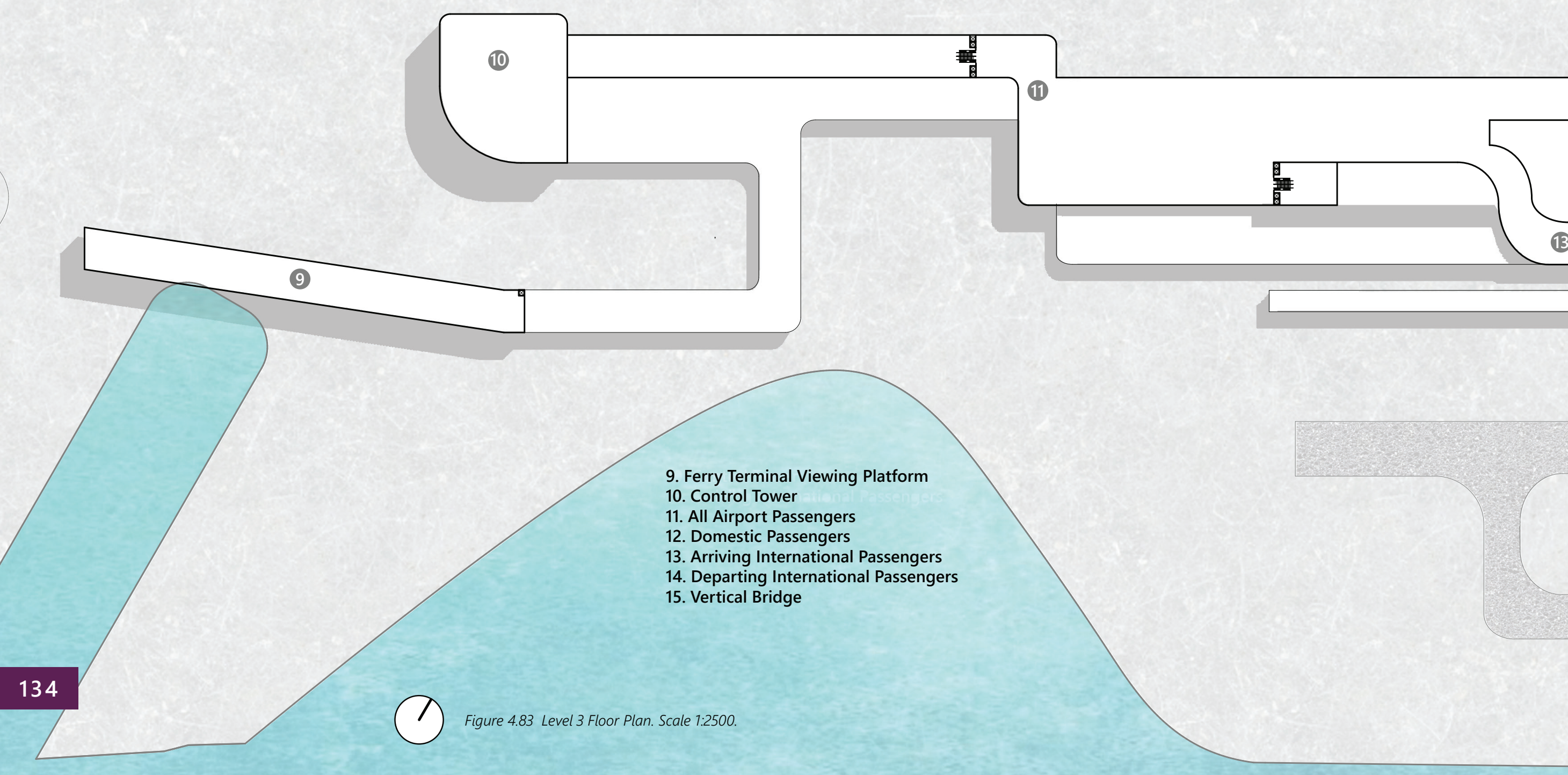




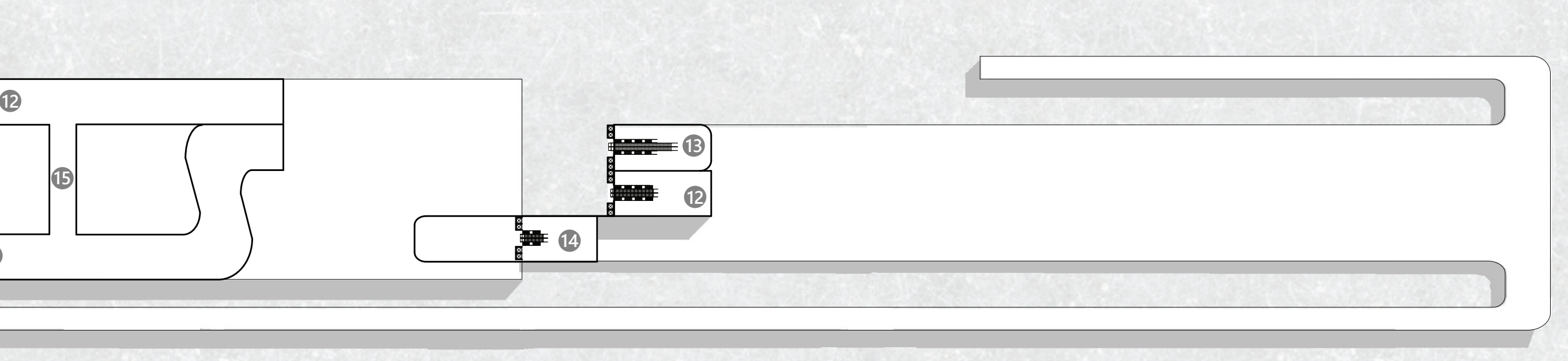






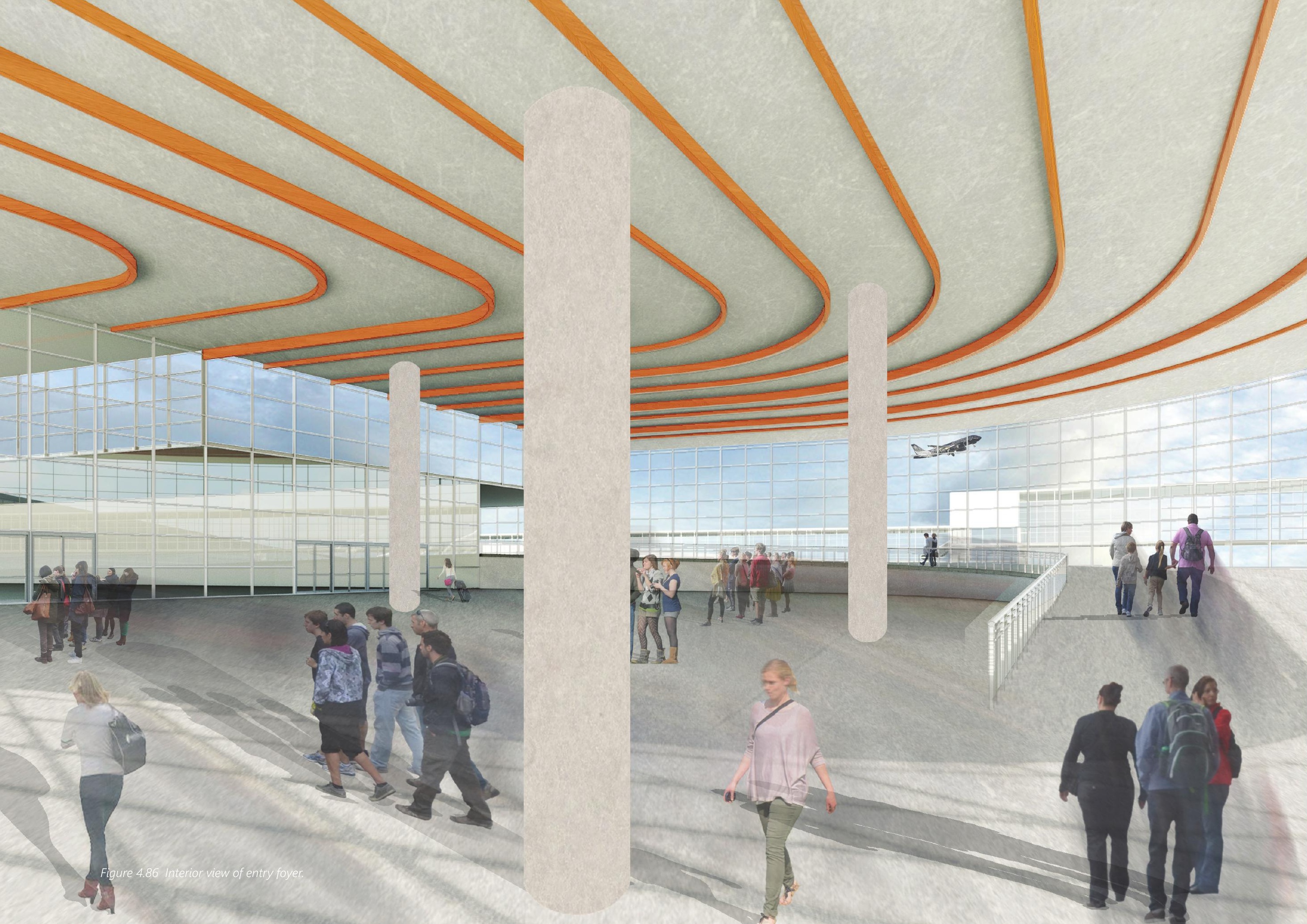




\section{MOVEMENT OF PEOPLE}

Figure 4.87 Plan showing section cut and camera view. Not to scale.
The entry foyer was designed to be an open space in which users of all three transport modes would enter and move to their respective transport areas. The ceiling of the entry foyer contains coloured fins that are curved, which point in the direction that the users must travel to get to the different check in areas. The path for the ferry terminal has been raised along a ramp which helps to direct the user along this path. The windows are curved to reinforce the movement path. Movement inside this area is created through the fins, ramp and windows as they guide the user's eyes and body along the direction in which they should travel. ${ }^{76}$

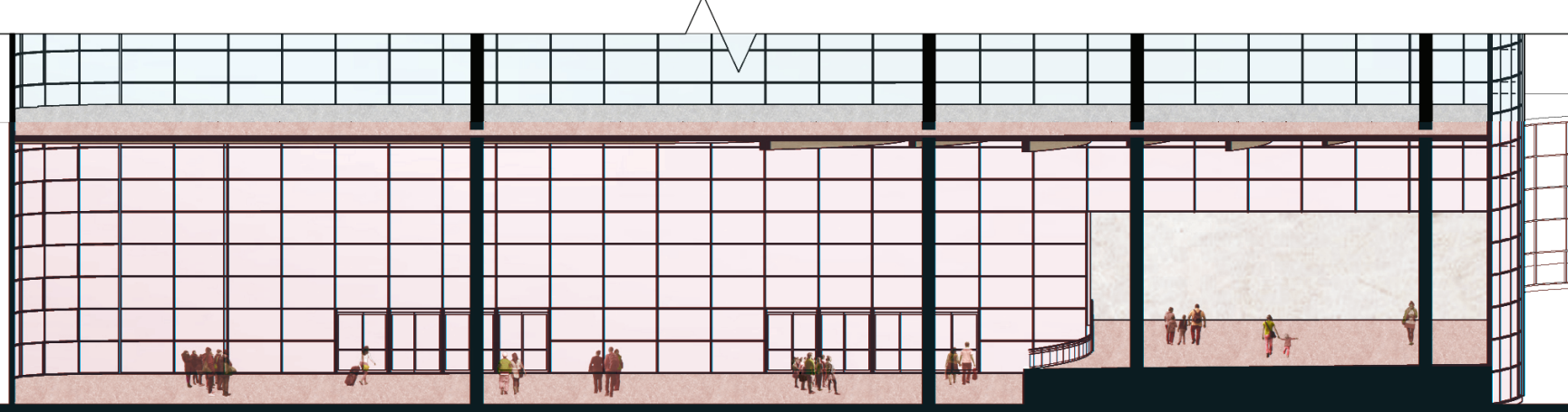




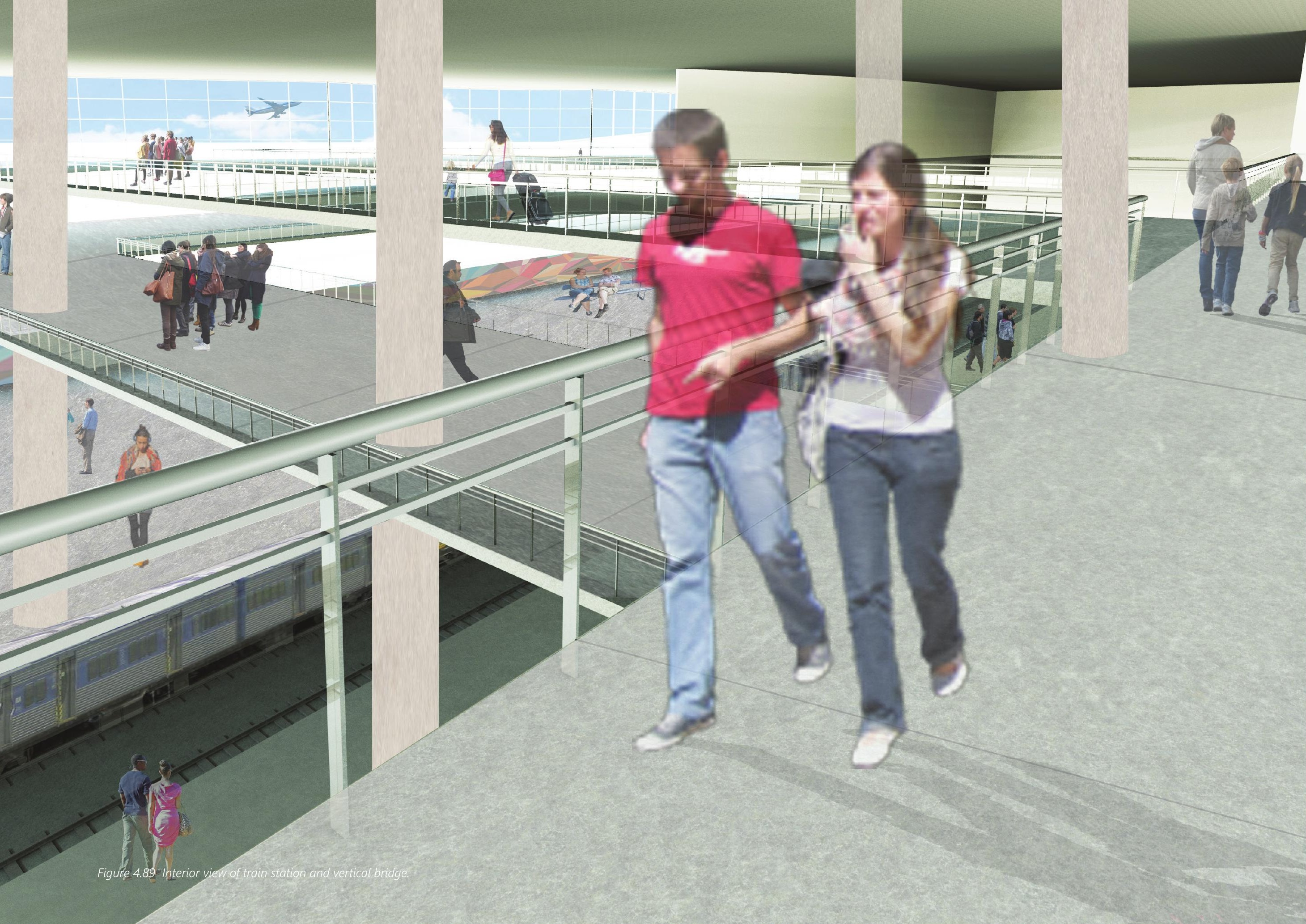




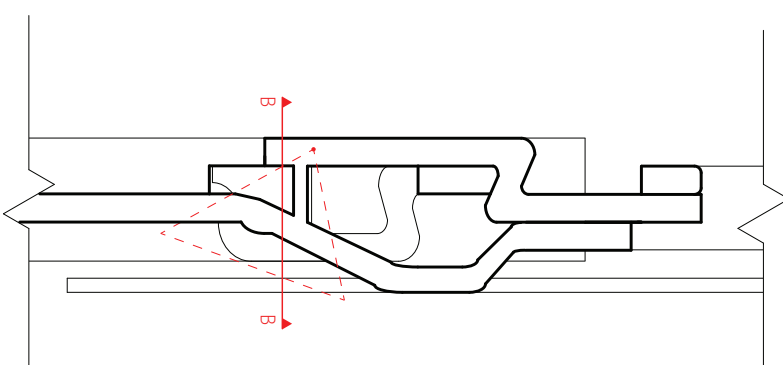

Figure 4.90 Plan showing section cut and camera view. Not to scale.

\section{MOVEMENT OF PEOPLE AND TRANSPORT}

The train station and vertical bridge area uses the opening up of levels to create visual links between the different transport nodes and people using them. This area has been designed to highlight people's movement vertically and along the building as well as the train's movement inside the building. When travelling along this area, the user is able to understand the relationship of the different paths along the transport hub to one another and at which points they connect and separate. It allows users to become immersed and more aware of their movement in relation to the movement of other people in the building and the vehicular movement.

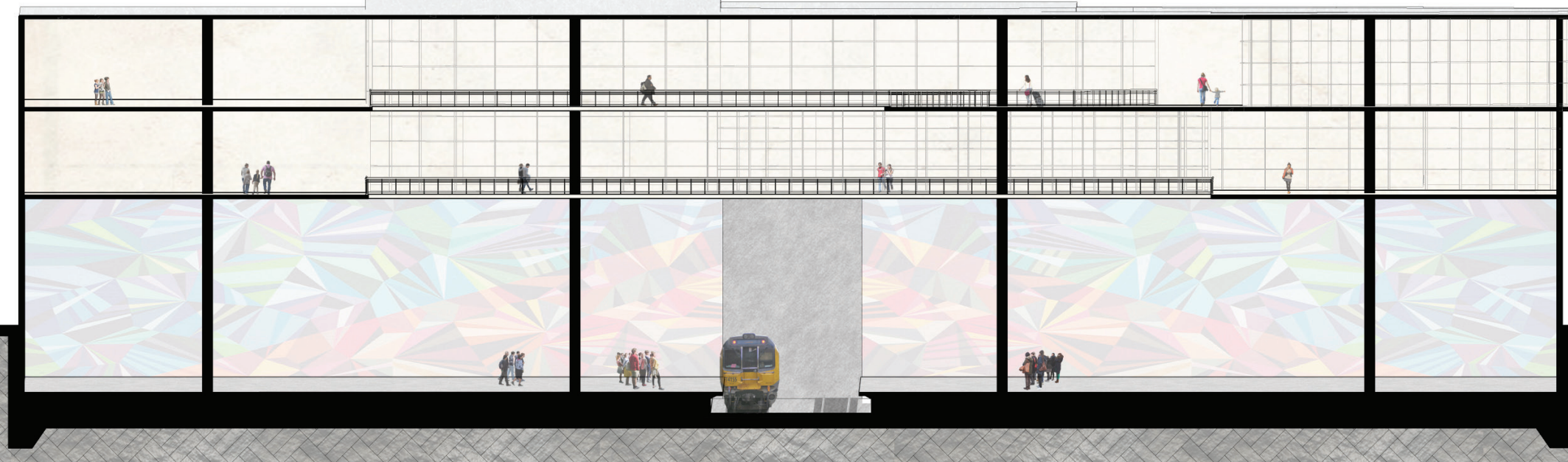




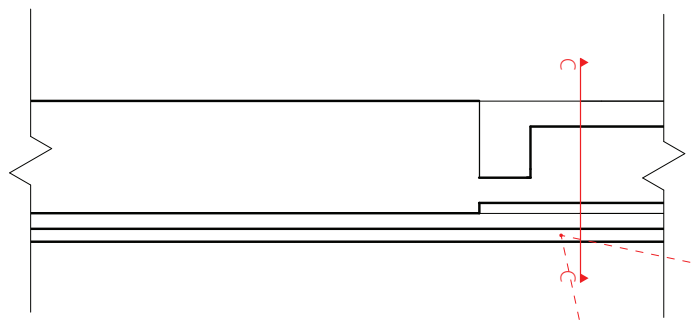

Figure 4.93 Plan showing section cut and camera view. Not to scale.

\section{MOVEMENT OF TRANSPORT}

The gate lounge area was designed to highlight the movement link between people and transport. The gate lounge has a curtain wall which looks out onto the tarmac and the greater site so that users are able to view the different transport movements that are happening on the site. From this space, users can view the interaction between the planes and ferries. This area acts as moment of rest within the building where users can recollect their memories of moving through the transport hub and imagine the final path of movement they will take to get to their plane. This is indicated though the greater spaced transoms and mullions in the window and the spacing of the joints in the floor and roof.

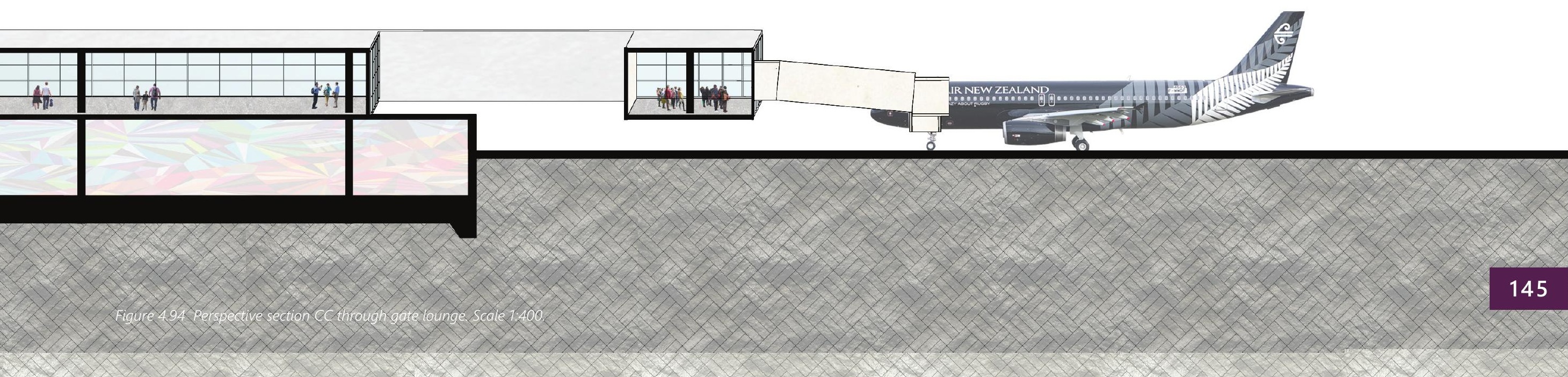




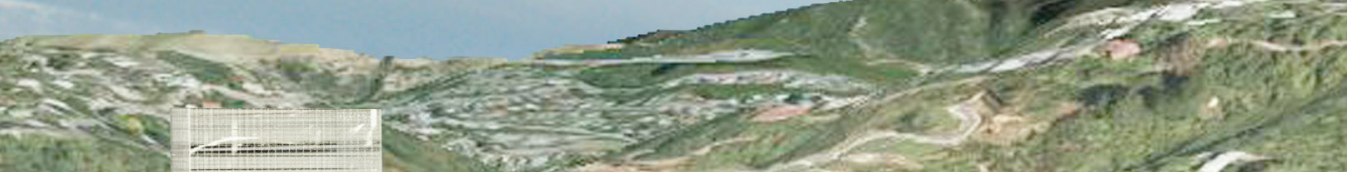

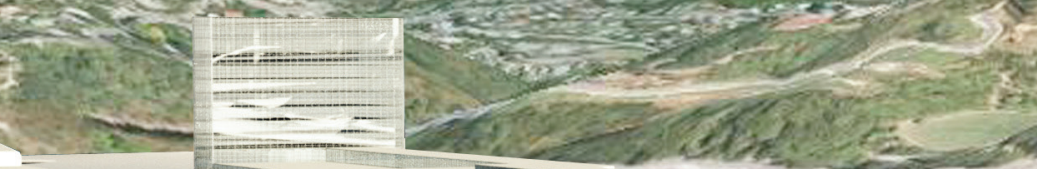

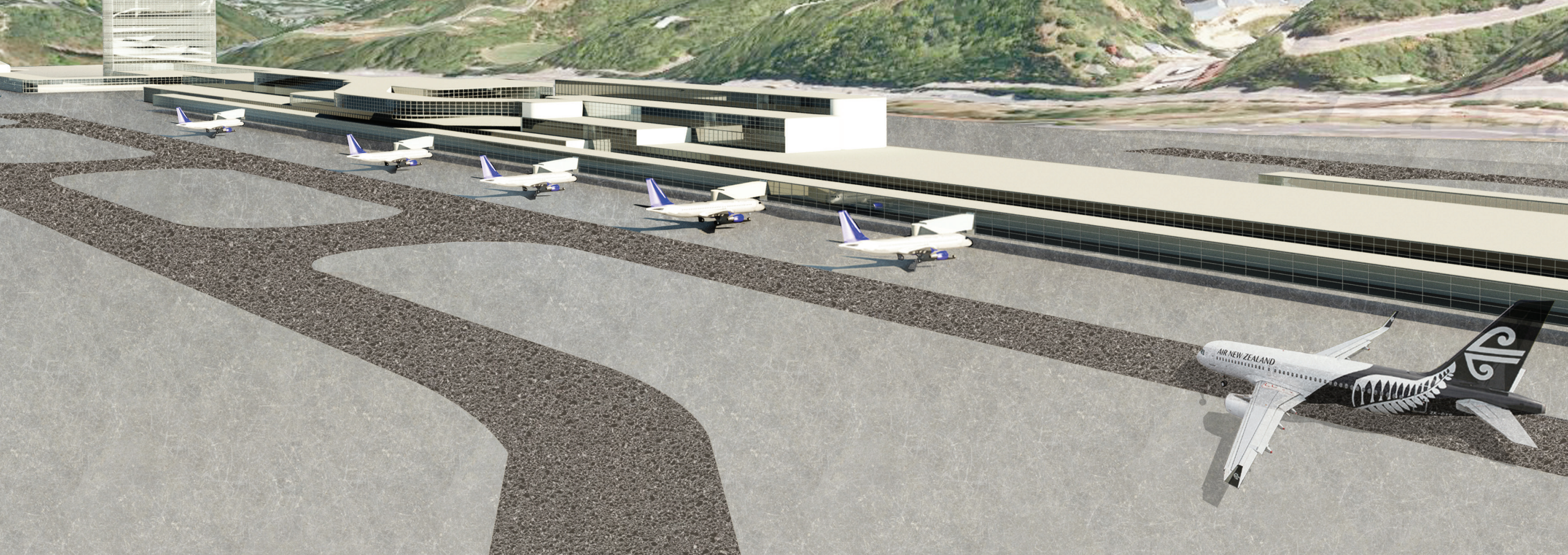




\section{REFLECTION}

Focusing on three key areas and the exterior form of the transport hub meant that the proposition could be tested through contained movement in the form and the experience of movement in the building. The Maxxi Museum precedent was used as a design tool in the final design as it provided strategies for creating movement through different levels which could be visible at all times. By having the movement visible always, the user becomes more aware of the body's movement through the space. Their engagement with the space influences their movement through it. The design is able to highlight the form and how it depicts the different paths and level changes within the transport hub. Also from the form, users are able to understand where each of the different transport nodes are located and which paths they must take to get there. The three key areas were able to focus on the different kinds of movement that were happening inside the transport hub and highlight these effectively so that the architecture activated the body through the building.
With the transport hub being at a macro scale in design, creating contained movement within the building was much more efficient than trying to use physical motions to highlight the movement within the building. The internal spaces of the transport hub enable users to become aware of their own and other people's movement. It allows the user to identify themselves with the space and creates embodied memories of travelling through the building. ${ }^{77}$ The form of the transport hub depicts motion in the architecture through its overlapping surfaces and blurred boundaries. ${ }^{78}$
77 Juhani Pallasmaa, Eyes of the Skin Architecture and the Senses (West Sussex: WileAcademy, 2005), 72.

78 Hardy, "The Expression of Movement in Architecture," 474 


\section{DESIGN DISCUSSION}

This section will cover an overall reflection on the architectural outcomes and the design process in relation to the thesis proposition. Using a design through research methodology meant that a vast body of work was produced with both successful and failed design tests. This design methodology was useful in gaining an understanding of how movement could be used in architecture at a variety of scales to create spatial experiences for the user.

The use of physical movement at the micro scale proved to be successful in engaging the body with architecture. The final installation allowed users to interact with it in a variety of ways to create different forms. Each interaction with the installation created a different form ensuring that the engagement with the installation was never the same. Even though physical movement was successful at a micro scale, it was determined to be less successful at a medium scale. The movement of walls and furniture in the house were unable to change the spatial qualities of the house for the user. The user's engagement with the space was limited to the varying function of the space.

Similarly to the precedents, contained movement was found to be useful at both the medium and macro scales. In the design of the house, contained movement was created through the intertwining paths that allowed the user to imagine their body's movement through the house. The decision to use paths as a form driver was successful as it allowed for the house to have overlapping and interconnected areas. All of these aided in the perception of movement in the architecture. The overlapping of different paths were also used as a form driver for the transport hub. However due to the macro scale of the design, the paths alone were limiting in creating the perception of movement in the building. The interior spaces had to be designed to allow the users eyes to travel through and around the elements of the interior. At a macro scale, contained movement needed to 
be created in both the exterior and interior of the building to allow engagement between the body and architecture to occur.

These three architectural outcomes, highlight the strengths and limitations of using movement in architecture. It can be concluded that physical movement strategies work best when used in the micro scale as it involves a more personal interaction with the architecture. Contained movement strategies are most successful at the medium to macro scale as the interaction with the building happens at a bodily level. A consideration of the body at the macro scale enables an architecture of movement within the interior as well as the external form. The perception of movement in the building at the larger scale creates varying spatial experiences that allows the body to engage with the architecture. 



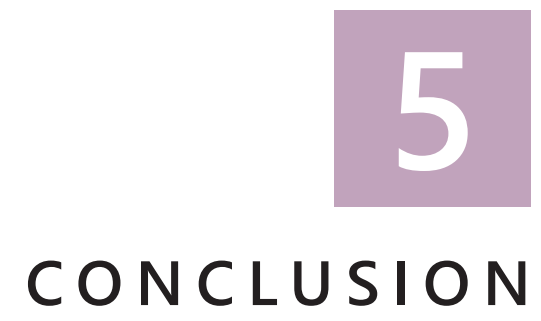


This thesis aimed to answer the proposition how can movement be used to engage the body and architecture. Firstly the theoretical background of movement in architecture was studied to understand the evolution of movement in architecture. From a brief analysis of movement in architecture, the two most common approaches to creating movement was through physical means or expressing it in the form. These two approaches, the physical and the contained movement were used as the foundation to understand how movement was created in six architectural precedents. These precedents outlined strategies that were used in the design of the three architectural outcomes of this thesis.

The three architectural outcomes; installation, house and transport hub were able to test the thesis proposition at the micro, medium and macro scales. A wide range of design tests were completed to test the thesis proposition. The installation engaged the body with architecture through physical movement. Contained movement created spatial experiences in both the house and the transport hub through the perception of movement in the form and internal spaces. However, as the design of the transport hub only focused on three areas, further research into how contained movement could be created in the remaining areas would heighten the understanding of how engagement between the body and architecture occurs at a macro scale.

This thesis was successful in testing physical and contained movement in the creation of architecture. However, if mechanical and responsive kinetic architecture were to be taken further, a study into how a combination of movement strategies could create both a tactile and perceptive engagement of the body and architecture could occur.
In conclusion, the theoretical background and architectural precedents provided a strong foundation on which to test the thesis proposition. This thesis concludes that movement in architecture enables users to become more aware of the architecture they are inhabiting and offers them more choice of how to engage with the architecture. 



\section{LIST OF FIGURES}

All unattributed figures are authors own.

Figure 2.1 Interior of Maison de Verre. Photograph: Rucativava. Source: accessed November 15, 2014. http://www.flickr.com/photos/rucativava/

08

Figure 2.2 Exterior of the Rudolf-MosseHaus. Source: Rudolf-Mosse-Haus, accessed Novemeber 15, 2015. http:modernismus.files. wordpress.com/2010/09/img_4084.jpg

Figure 2.3 Interior showing movable partitions. Source: "Void Space/HingedSPACE Housing," Steven Holl Architects, accessed November 15, 2015. http://www.stevenholl.com/project-detail. php?id $=36 \&$

Figure 2.4 Ramp leading up to the carpenter centre. Source: Kroll, Andrew, "AD Classics: Carpenter Center for the Visual Arts / Le Corbusier" ArchDaily., accessed November 15, 2015. < http:// www.archdaily.com/?p=119384>
Figure 2.5 Movable shutters. Source: Vinnitskaya, Irina, "Kiefer Technic Showroom / Ernst Giselbrecht

+ Partner," ArchDaily, accessed November 15, 2015.<http://www.archdaily.com/?p=89270> 16

Figure 3.1 Storefront for Art and Architecture. Steven Holl. Source: "Storefront for Art and Architecture," Steven Holl Architects, accessed May 10, 2015. http://www.stevenholl.com/projectdetail.php?id=24.

Figure 3.2 Hyposurface. Source: Hyposurface, accessed May 10, 2015. http://www.hyposurface. $\mathrm{com} /$

Figure 3.3 Party wall. nArchitects. Source: "Party Wall," nArchitects, accessed May 10, 2015. http:// www.narchitects.com/frameset-party\%20wall.htm 
Figure 3.4 Movable seating panels. Source: "Erika Mann Primary School," die Baupiloten Architektur, accessed May 10, 2015. http://www.baupiloten. com/en/projekte/erika-mann-primary-school-3/.

26

Figure 3.5 Movable wardrobe panels. Source: "Erika Mann Primary School," die Baupiloten Architektur, accessed May 10, 2015. http:// www.baupiloten.com/en/projekte/erika-mannprimary-school-3/.

\section{6}

Figure 3.6 Students interacting with panels. Source: "Erika Mann Primary School," die Baupiloten Architektur, accessed May 10, 2015. http://www.baupiloten.com/en/projekte/erikamann-primary-school-3/.

Figure 3.7 Sliding house. Source: "Sliding House by dRMM," Dezeen Magazine, accessed May 10, 2015. http://www.dezeen.com/2009/01/19/slidinghouse-by-drmm-2/.
Figure 3.8 Interior of the Mobius House. Source: "Mobius House," UNStudio, accessed May 10, 2015. http://www.unstudio.com/projects/mobiushouse.

Figure 3.9 Interior of the Mobius House. Source: "Mobius House," UNStudio, accessed May 10, 2015. http://www.unstudio.com/projects/mobiushouse.

Figure 3.10 Model of the Bibliotheque Jussieu. Source: "Jussieu - Two Libraries, France, Paris, 1992 ," OMA, accessed May 10, 2015. http://www.oma. eu/projects/1992/jussieu-two-libraries/.

34

Figure 3.11 Overlapping stairs. Source: "MAXXI Museum / Zaha Hadid Architects," ArchDaily, accessed May 10, 2015. <http://www.archdaily. $\mathrm{com} / \mathrm{p}=43822>$ 
Figure 3.12 Interior of Maxxi Museum. Source: "MAXXI Museum / Zaha Hadid Architects," ArchDaily, accessed May 10, 2015. <http://www. archdaily.com/?p=43822>

Figure 3.13 Contrast in colour of gallery and stairs. Source: "MAXXI Museum / Zaha Hadid Architects," ArchDaily, accessed May 10, 2015. <http://www. archdaily.com/?p=43822>

Figure 4.26 Boxetti furniture. Source: "Boxetti," accessed June 02, 2015. http://www.boxetti.com/ en/Collection/\#sofa.

Figure 4.28 The Gucklhupf being transformed. Source: Castle, H. "The Transformable House," accessed June 13, 2015. Architectural Design 70 (2000):86-89.

Figure 4.44 Diagram of movement of passengers through airport terminal. Source: Brian Edwards, The Modern Airport Terminal: New Approaches to Airport Architecture 2nd ed (New York: Spon Press, 2005), 85.
Figure 4.45 Diagram of vertical segregation. Source: Brian Edwards, The Modern Airport Terminal: New Approaches to Airport Architecture 2nd ed (New York: Spon Press, 2005), 125.94

Figure 4.46 Exterior form of Kansai International Airport. Source: "Kansai International Airport," Interesting Engineering, accessed August 27, 2015. http://interestingengineering.com/kansaiinternational-airport/.

Figure 4.47 Interior of Amsterdam Airport Schiphol. Photograph: Laura Agustin. Source: accessed August 27, 2015. http://www.lauraagustin.com/ devious-smuggling-routes-for-undocumentedworkers-or-trafficking-victims.

Figure 4.49.1 Gilbraltar International Airport. Photograph by Hoax Slayer. "Gibraltar Airport Runway Crosses a Main Road," accessed August 27, 2015. Neatorama. http://www.neatorama. com/2012/11/15/Gibraltar-Airport-RunwayCrosses-a-Main-Road/.
Figure 4.49.2 Gisborne Airport. "Strange Airport \#5: Gisborne Airport - Runway With a Railway Crossing," Amusing Planet, accessed August 27, 2015. http://www.amusingplanet.com/2013/08/ gisborne-airport-runway-with-railway.html

Figure 4.49.3 Leipzig Airport. "Driveway Over The Highway at Leipzig/Halle Airport," Much Info, accessed August 27, 2015. http://www.muchinfo.com/2013/02/driveway-over-highway-atleipzighalle.html.

Figure 4.49.4 Madeira Airport. "Madeira Airport - An Award Winning Structure," Interesting Engineering, accessed August 27, 2015. http:// interestingengineering.com/madeira-airport-anaward-winning-structure/.

Figure 4.49.5 Sydney Airport. "Sydney International Airport," Sydney For Everyone, accessed August 27, 2015. http://sydneyforeveryone.com.au/city/ la-perouse/places-of-interest/sydney-airport/. 


\section{B I B L I O G R A P H Y}

Adey, Peter. "Airport, mobility and the calculative architecture of affective control." Geoforum 39 (2008): 438-451. Accessed June 06, 2014. doi: 10.1016/j.geoforum.2007.09.001.

Barley, Nick. Breathing Cities: The Architecture of Movement. Basel: Birkhauser, 2000.

Bechtel, Robert B. "Human Movement and Architecture." Trans-action 4 (1967): 56-56. Accessed August 30, 2014. < http://link.springer. com/article/10.1007\%2FBF03180053>.

Benthem Crouwel Architects. "Schiphol Plaza, Amsterdam Airport Schiphol". Accessed August 212014. http://www.benthemcrouwel.com/portal_ presentation/airports/schiphol-plaza.

Borden, lain. "Stairway: Transforming Architecture in the Golden Lane." Architectural Design 70 (2000): 20-25.
Bloomer, Kent C., and Charles W. Moore. Body, Memory, and Architecture. New Haven: Yale University Press, 1977.

Civil Aviation Authority. "Advisory Circular AC1396: Aerodrome Design Requirements." (2011).

Davidson, Cynthia C. Anybody. Cambridge: The MIT Press, 1997.

Edwards, Brian. The Modern Airport Terminal: New Approaches to Airport Architecture. New York: Spoon press, 2005.

Forty, Adrian. Words and Buildings: A vocabulary of Modern Architecture. London: Thomas and Hudson, 2000.

Foster + Partners. "Thames Hub UK 2011." Accessed August 22 2014. http://www.fosterandpartners. com/projects/thames-hub/.
Fox, Michael and Miles Kemp. Interactive Architecture. New York: Princeton Architectural Press, 2009.

Ganoe, Cathy J. "Design as Narrative: A Theory of Inhabiting Interior Space," Journal of Interior Design 25 (1999): 1-15.

Godwin, Sally. "Van Berkel and Bos: The Mobius House." Architectural Design 70 (2000):76-78.

Hardy, Adam. "The Expression of Movement in Architecture." The Journal of Architecture 16 (2011): 471-497. Accessed April 07, 2014. doi: 10.1080/13602365.2011.598698.

Hill, Jonathan. Immaterial Architecture. Abingdon: Routledge, 2006.

Imrie, Rob. "Architects' Conceptions of the Human Body." Environment and Planning D: Society and Space 21 (2003): 47-65. Accessed August 30, 214. doi: $10.1068 / d 271$ t. 
Jormakka, Kari. Flying Dutchmen: Motion in Architecture. Basel: Birkhauser, 2002.

Kaylo, Janet. "The Body in Phenomenology and Movement Observation." Paper presented at the Action Profilers International in Surrey, England 2001.

Khan, Omar and Dorita Hannah. "Performance/ Architecture: An Interview with Bernard Tschumi," Journal of Architectural Education 61 (2008): 5258. Accessed August 30, 2014. doi: 10.1111/j.1531314X.2008.00187.x.

"MAXXI Museum in Rome", Detail 2 (2010): 164170.

Mills, Criss. Designing with Models: A Studio Guide to Architectural Process Models $3^{\text {rd }}$ ed. New Jersey: John Wiley and Sons, Inc, 2011.
nArchitects. "Party wall." Accessed August 20, 2014, http://www.narchitects.com/frameset-party\%20 wall.htm.

Nesbitt, Kate. Introduction to Theorizing a New Agenda for Architecture: An Anthology of Architectural Theory 1965-1995, edited by Kate Nesbitt, 16-70. New York: Princeton Architectural Press, 1996

Pallasmaa, Juhani. The Eyes of the Skin: Architecture and the Senses. West Sussex: Wile-Academy, 2005.

Pallasmaa, Juhani. "The Geometry of Feeling: A Look at the Phenomenology of Architecture." In Theorizing a New Agenda for Architecture: An Anthology of Architectural Theory 1965-1995, edited by Kate Nesbitt, 447-453. New York: Princeton Architectural Press, 1996. 
Renzo Piano Building Workshop. "Kansai International Airport Terminal." Accessed August 21, 2014. http://www.rpbw.com/project/35/kansaiinternational-airport-terminal/\#

Riley, Terrence. The Un-Private House. New York: Museum of Modern Art, 1999.

Rouillard, Dominique. Building the Slope: Hillside Houses 1920-1960. California: Arts + Architecture Press, 1987.

Schumacher, Michael, Oliver Schaeffer and Michael-Marcus Vogt. Move: Architecture in Motion - Dynamic Components and Elements. Berlin: Birkhäuser, 2010.

Smith, Albert C. Architectural Model as Machine. Oxford: Architectural Press, 2004.

Stickells, Lee. "Conceiving an Architecture of Movement." Architectural Research Quartely 14 (2010): 41-51.
Transformable Design. " "GucklHupf" Mobile Lookout." Accessed December 16, 2014. http:// transformabledesign.com/project/a-2-1gucklhupf-mobile-lookout/.

Wild at Heart, Wellignton Airport. "2030 The Master Plan January 2010." Accessed August 10, 2014, https://www.wellingtonairport.co.nz/ documents/Wellington-Airport-MasterplanJanuary-2010.pdf.

Wolfflin, Heinrich. "Prolegomena to a Psychology of Architecture" in Empathy, Form and Space, edited by Robert Vischer, Harry Francis Mallgrave and Eleftherios Ikonomou, 149-190. Chicago: Getty Center for the History of Art and the Humanities, 1994.

Zuk, William and Roger H. Clark. Kinetic Architecture. New York: Van Nostrand Reinhold, 1970. 
